Supporting Information

\title{
Cellular Uptake Evaluation of Amphiphilic Polymer Assemblies: Importance of Interplay between Pharmacological and Genetic Approaches
}

\author{
Ziwen Jiang ${ }^{\dagger}$ Huan He,$^{\dagger}$ Hongxu Liu ${ }^{\dagger}$ S. Thayumanavan ${ }^{*, \dagger, \neq, \S}$
}

${ }^{\dagger}$ Department of Chemistry, ${ }^{\ddagger}$ Molecular and Cellular Biology Program, ${ }^{\circledR}$ Center for Bioactive Delivery at the Institute for Applied Life Sciences, University of Massachusetts Amherst, Massachusetts 01003, United States

*Email: thai@chem.umass.edu (S.T.) 


\section{Table of Contents}

\section{Supplementary figures and table}

Figure S1. FTIR spectra of PEG, POS, NEG, and MPC.

Figure S2. (a) Relative level of intracellular glutathione (GSH) in HeLa cells after incubating with each amphiphilic polymer. (b) Half maximal inhibitory concentration $\left(\mathrm{IC}_{50}\right)$ of 2-mercaptopyridine in HeLa cells.

Figure S3. A representative purification process for Cy3-labeled amphiphilic polymers by size-exclusion chromatography over SorbaDex 20-LH matrix.

Figure S4. Cellular uptake of amphiphilic polymers in HeLa cells at different time point.

Figure S5. Cellular uptake of varied concentrations of amphiphilic polymers in HeLa cells.

Figure S6. Cellular uptake efficiency of amphiphilic polymers in the presence of pharmacological inhibitors.

Figure S7. Effect of fetal bovine serum on the cellular uptake efficiency of amphiphilic polymers in the presence of pharmacological inhibitors.

Figure S8. Cellular uptake efficiency of amphiphilic polymers in HUVEC in the presence of Dyngo-4a.

Figure S9. Cellular uptake of amphiphilic polymers after treating SK-MEL-2 cells with siDNM2 for 48 hours.

Figure S10. Cellular uptake efficiency of amphiphilic polymers in dynamin triple knockout mouse embryo fibroblasts in the presence of amiloride or in ATP-depleted condition.

Table S1. Resource and tolerated dose of pharmacological inhibitors used in the study.

Figure S11. Structure of the pharmacological inhibitors used in the study.

Table S2. Summary on endocytic pathways of materials with different surface charge.

\section{Supplementary methods}

2.1. Synthesis of chain transfer agent, radical initiator, and monomer(s)

2.2. Reversible addition-fragmentation chain transfer (RAFT) polymerization

2.3. General procedure for end-group labeling via copper-free click chemistry

2.4. Preparation of the amphiphilic polymer stock solution

2.5. General procedure for cell culture and viability assays

2.6. General procedure for the cellular uptake evaluation of amphiphilic polymers

2.7. Cellular uptake evaluation of amphiphilic polymers in the presence of dynasore analog

2.8. Cellular uptake evaluation of amphiphilic polymers in DNM2-GFP SK-MEL-2 cells

2.9. Cellular uptake evaluation of amphiphilic polymers in dynamin triple knockout mouse embryo fibroblasts

2.10. Evaluation of dynasore off-target effects on the cellular uptake of polymers

\section{Spectral data}

\section{References}




\section{Supplementary Figures and Table}

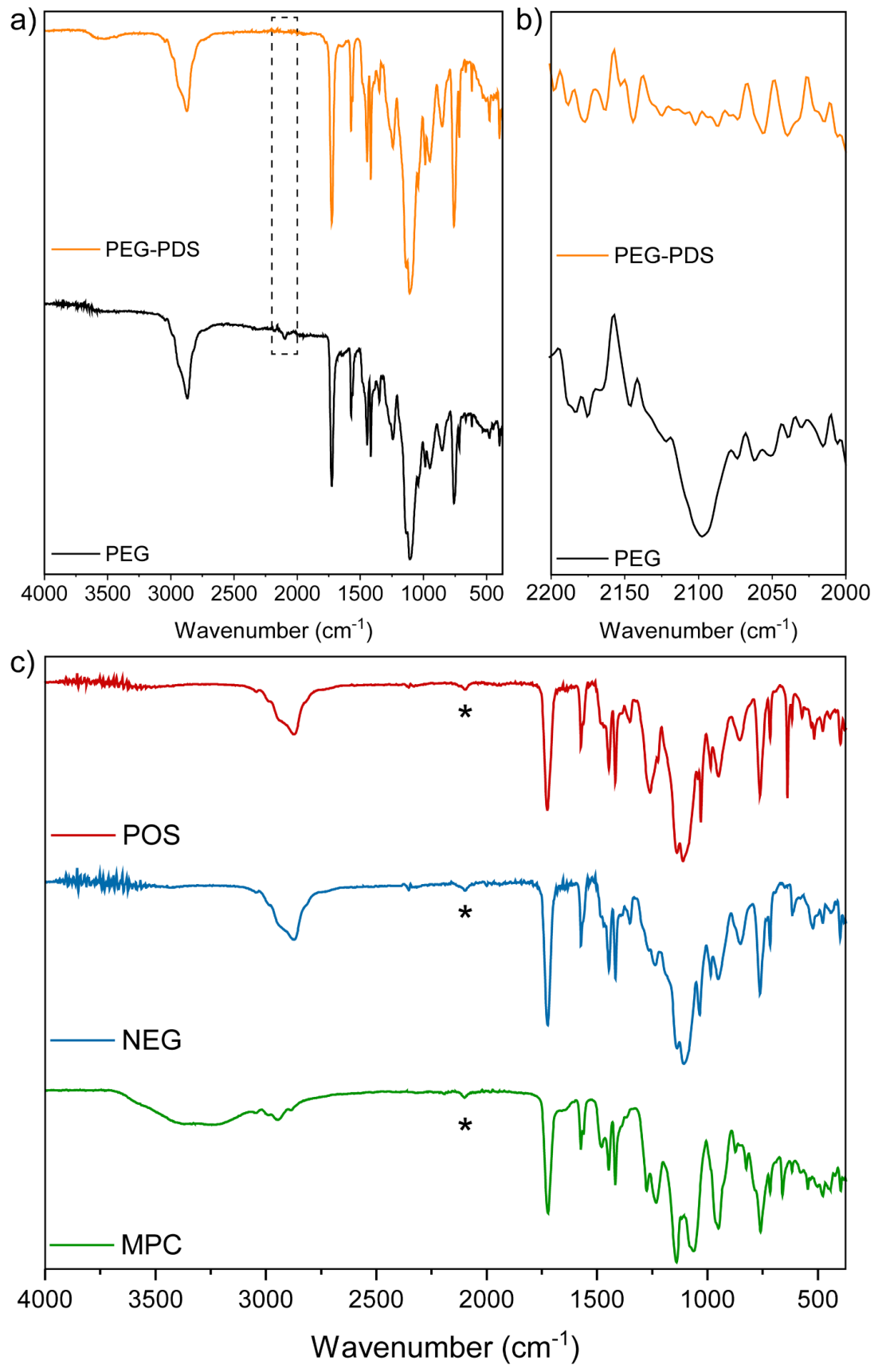

Figure S1. FTIR spectra of (a,b) PEG-PDS and PEG, (c) POS, NEG, and MPC. The comparison between PEG-PDS and PEG demonstrated the appearance of azido group $\left(2100 \mathrm{~cm}^{-1}\right)$ in the polymer. PEG-PDS was synthesized without azido-modifications on the chain transfer agent and radical initiator. The strategy ensures the appearance of azido group on amphiphilic polymers with different surface charge. 

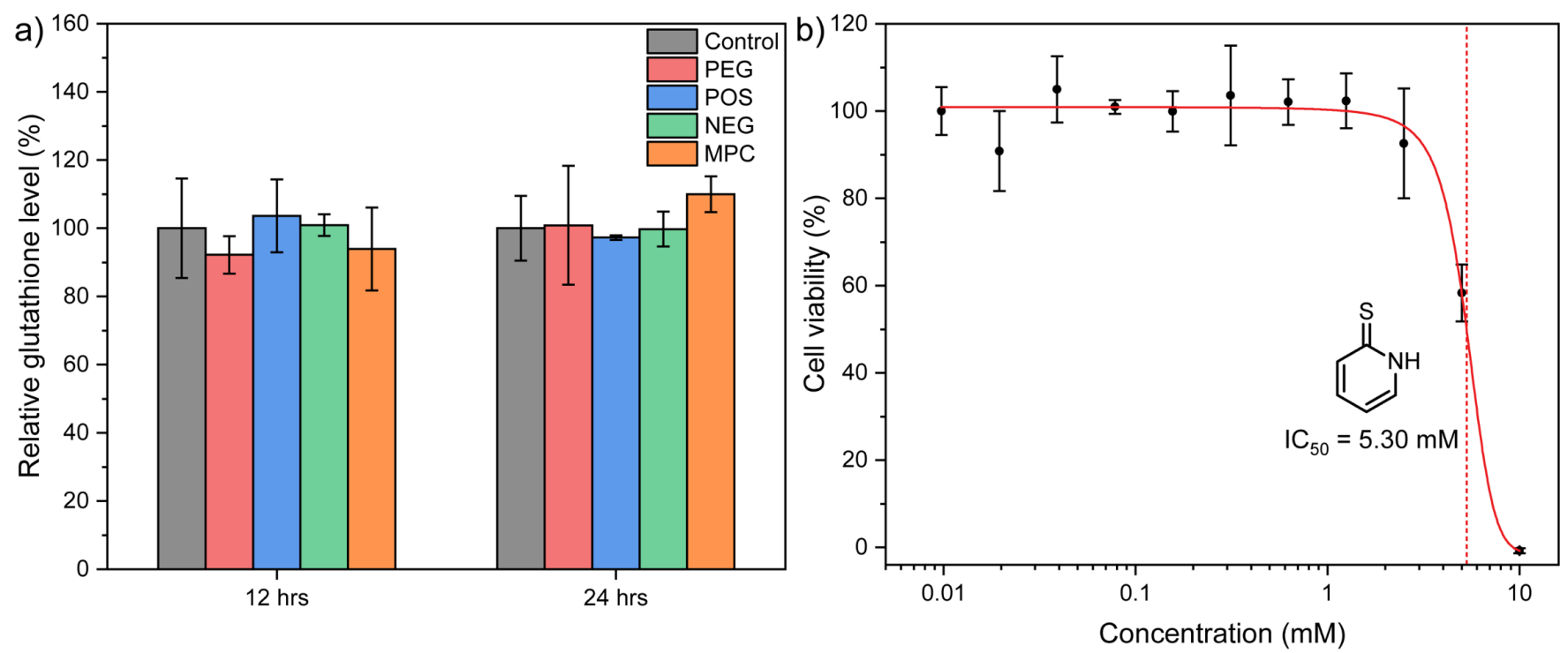

Figure S2. (a) Relative level of intracellular glutathione (GSH) in HeLa cells after incubating with each amphiphilic polymer $\left(0.2 \mathrm{mg} \cdot \mathrm{mL}^{-1}\right)$ at different time points. No significant change in $\mathrm{GSH}$ level was observed after incubating amphiphilic polymers with cells for 24 hours. The GSH level in HeLa cells that treated in complete growth medium without polymer added was normalized as $100 \% . N=3$. (b) Half maximal inhibitory concentration $\left(\mathrm{IC}_{50}\right)$ of 2-mercaptopyridine in HeLa cells at 24-hour time point. From alamarBlue assay, 2-mercaptopyridine has an $\mathrm{IC}_{50}$ value at $(5.30 \pm 0.22) \mathrm{mM}$, which is equal to degrading PDS homopolymers at a concentration of $1.35 \mathrm{mg} \cdot \mathrm{mL}^{-1} \cdot N=4$. In each figure, error bars represent the standard deviation of replicates. 


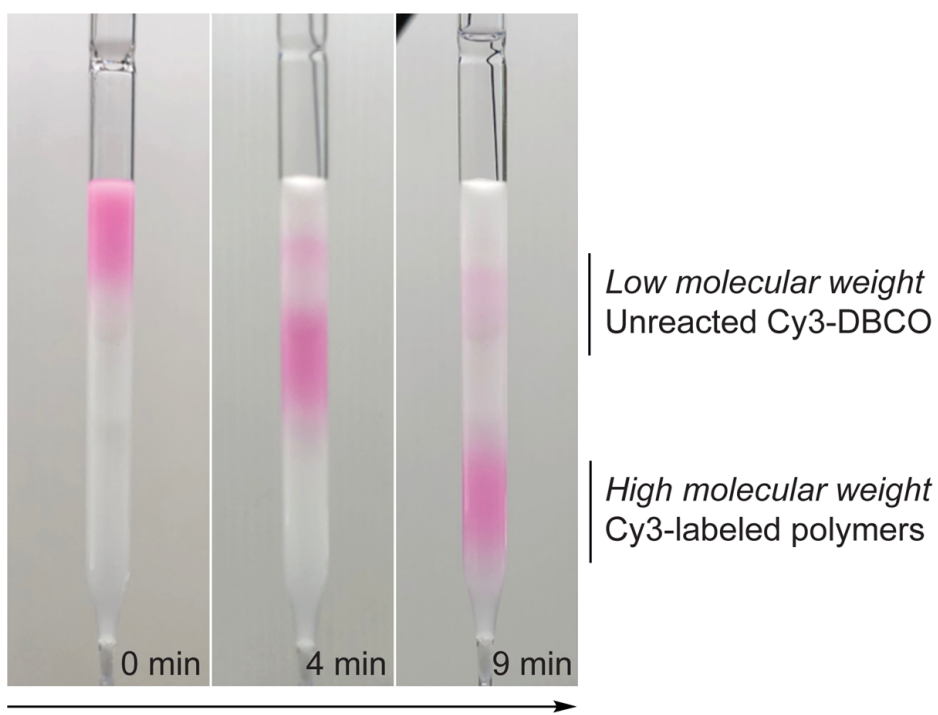

Figure S3. A representative purification process for Cy3-labeled amphiphilic polymers by size-exclusion chromatography over SorbaDex 20-LH matrix.

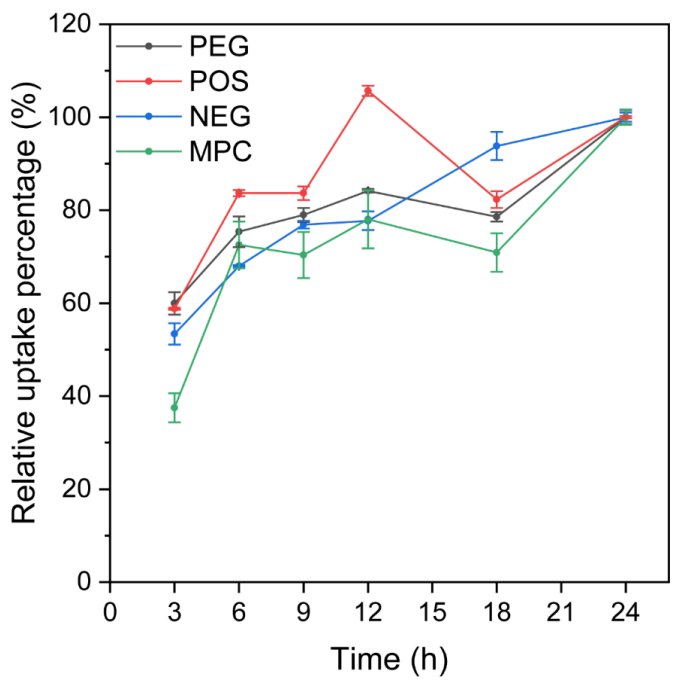

Figure S4. Cellular uptake of amphiphilic polymers at different time point. The median fluorescence Cy3labeled polymer intensity of the HeLa cells is used as the reference and normalized as $100 \%$. The decrease in cellular uptake efficiency from 12-hour to 18-hour is possibly related to cell proliferation. For the experiment, a total number of $30 \mathrm{k} \mathrm{HeLa}$ cells were seeded 24 hours before the experiment. Next, cells were incubated with polymer-containing $\left(0.05 \mathrm{mg} \cdot \mathrm{mL}^{-1}\right.$ for PEG, POS, and MPC, $0.01 \mathrm{mg} \cdot \mathrm{mL}^{-1}$ for NEG) complete DMEM growth medium for different time length and measured with flow cytometry. $N=$ 3. Error bars represent the standard deviation of replicates. 

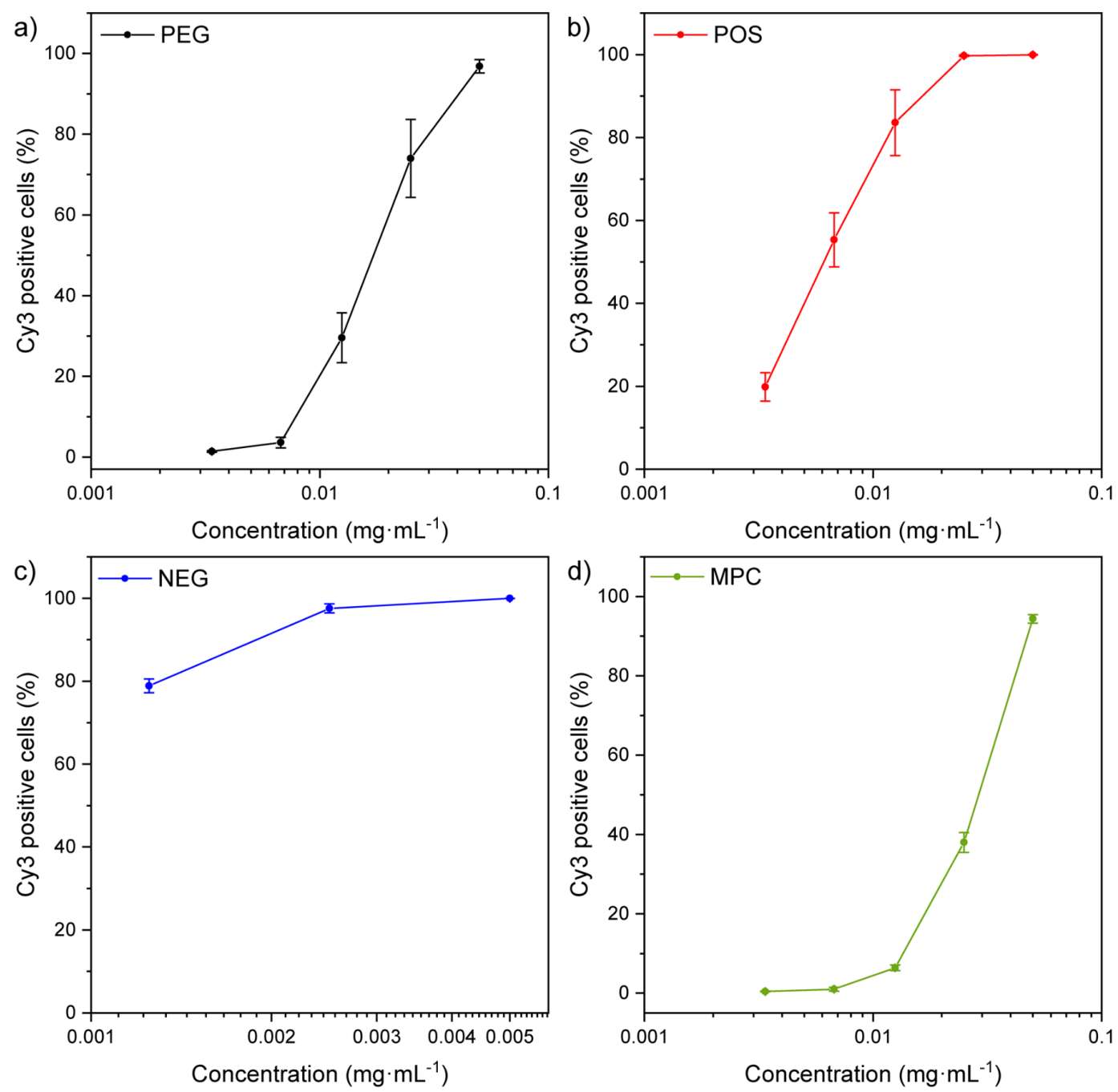

Figure S5. Cellular uptake evaluation of Cy3-labeled polymers at different concentrations in HeLa cells. For the experiment, a total number of $10 \mathrm{k} \mathrm{HeLa}$ cells were seeded 24 hours before the experiment. Next, cells were incubated with polymer-containing DMEM at different concentrations for 3 hours. The percentage of Cy3 positive cells was measured with flow cytometry. The highly efficient cellular uptake of NEG is currently under investigation. $N=4$. Error bars represent the standard deviation of replicates. 

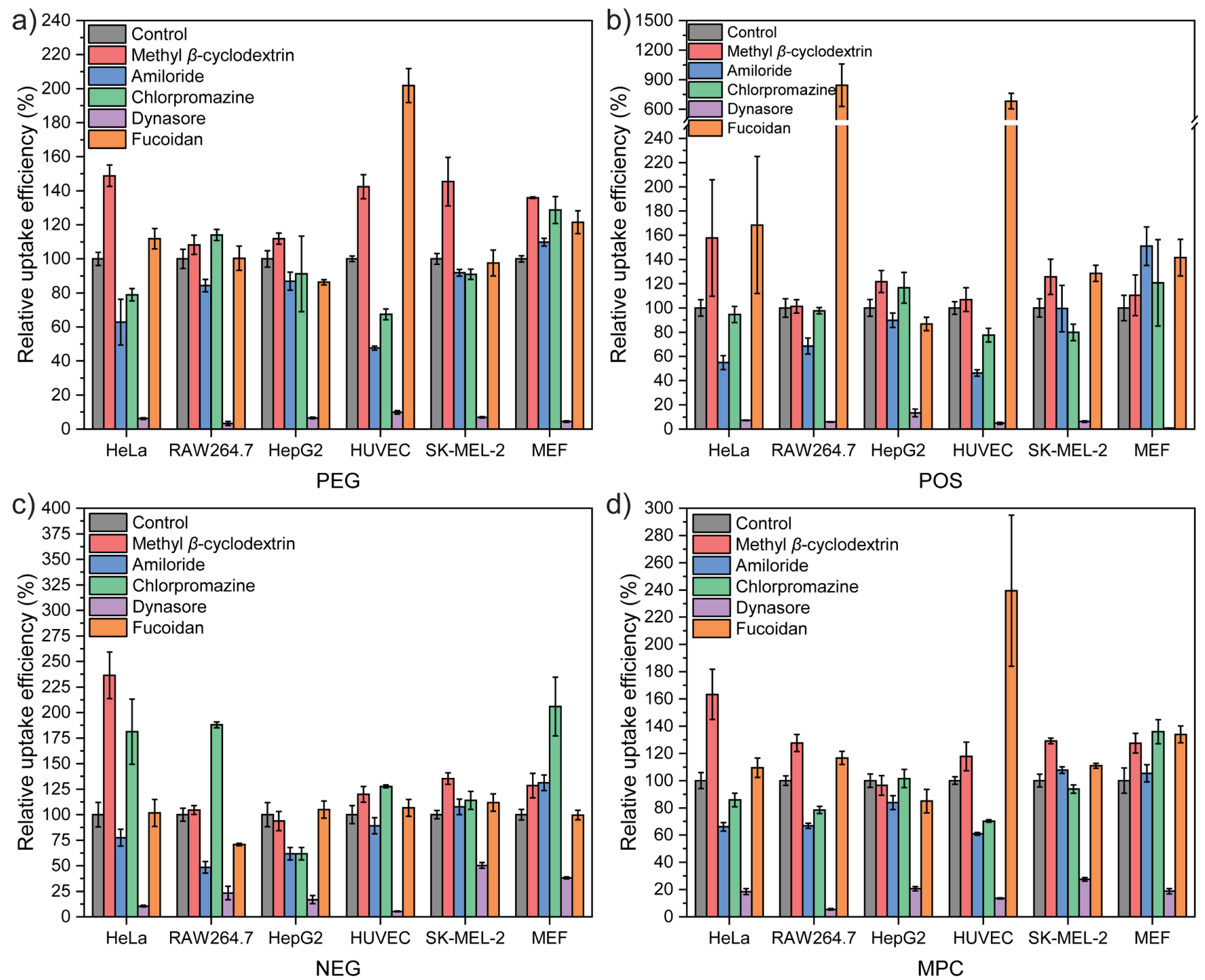

Figure S6. Cellular uptake efficiency of amphiphilic polymers in the presence of pharmacological inhibitors. The evaluation was performed in six different types of cells: HeLa, RAW264.7, HepG2, HUVEC, SK-MEL-2, and MEF. $N=4$. Error bars represent the standard deviation of replicates. AMI, amiloride. $M \beta C D$, methyl- $\beta$-cyclodextrin. CPZ, chlorpromazine. DYN, dynasore. FCD, fucoidan. 

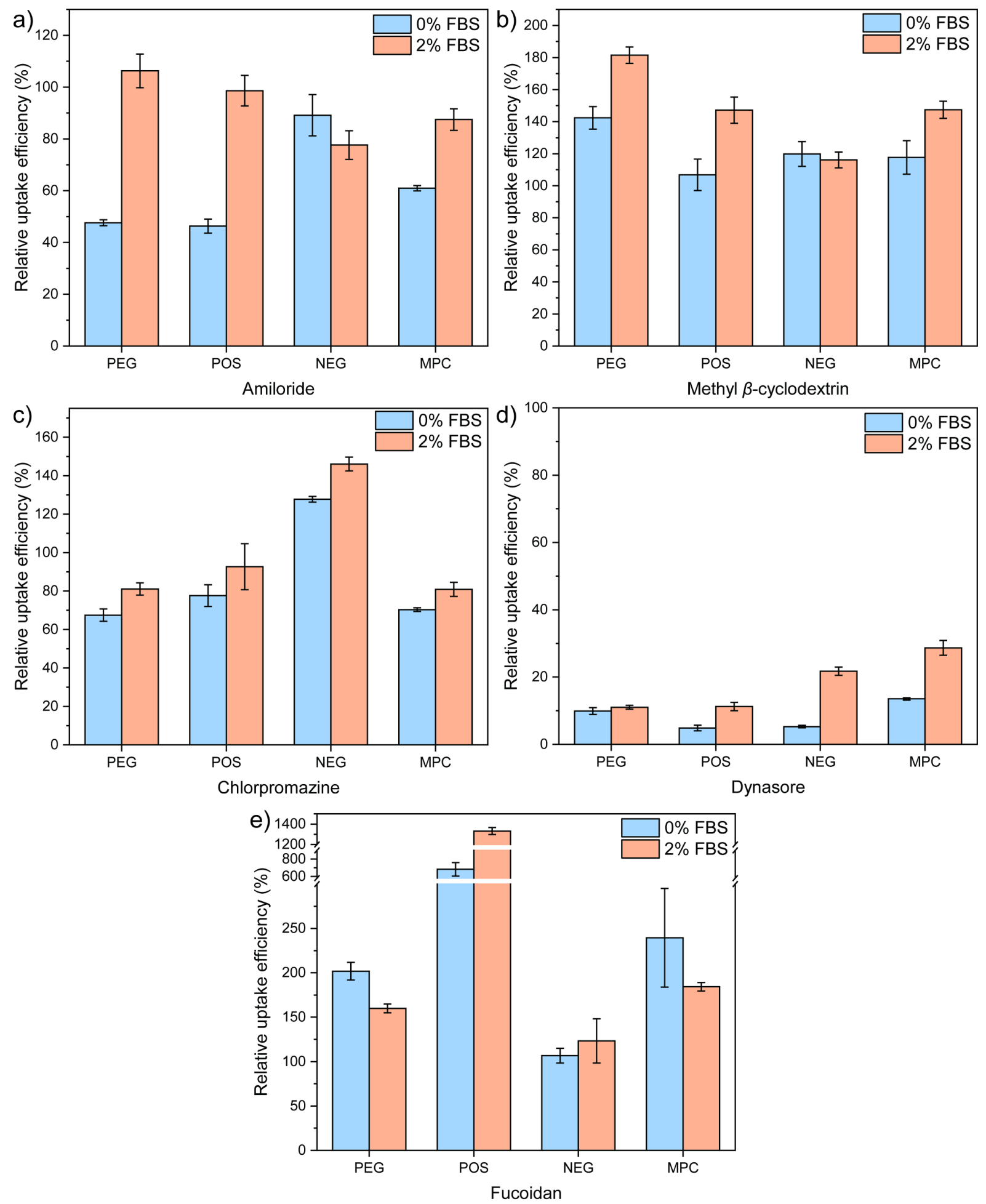

Figure S7. Effect of fetal bovine serum on the cellular uptake efficiency of amphiphilic polymers in the presence of pharmacological inhibitors. The evaluation was conducted in HUVEC. $N=4$. Error bars represent the standard deviation of replicates. 


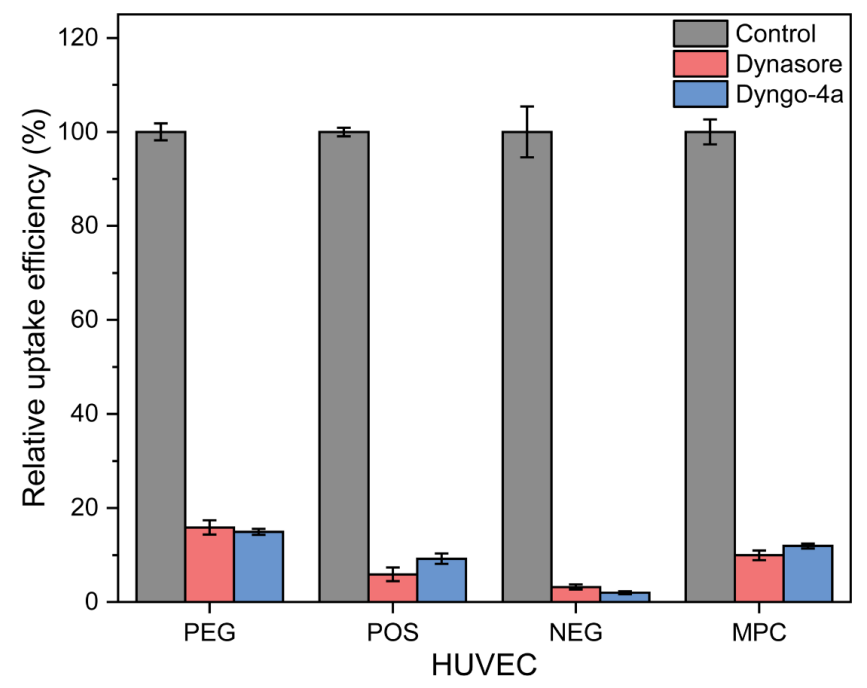

Figure S8. Cellular uptake efficiency of amphiphilic polymers in HUVEC in the presence of Dyngo-4a. $N$ $=4$. Error bars represent the standard deviation of replicates.
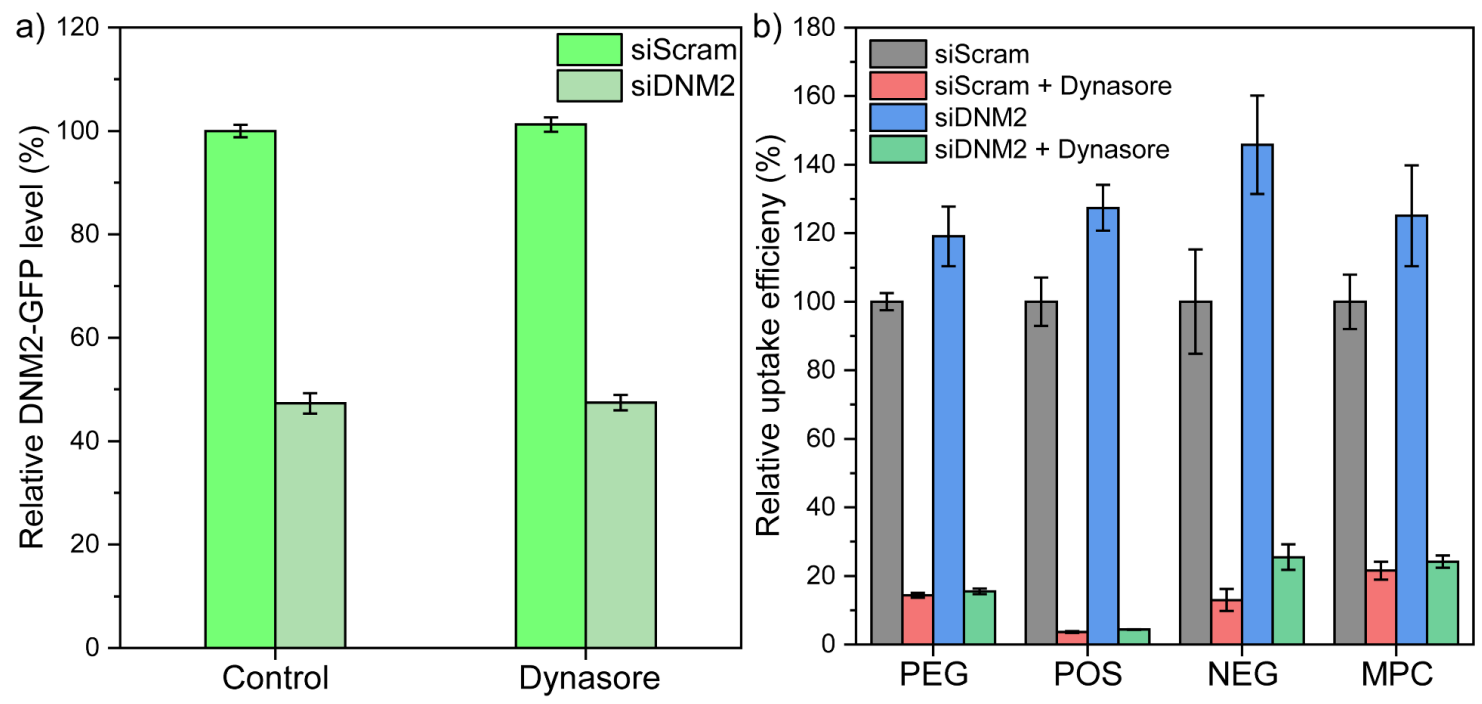

Figure S9. (a) Relative level of DNM2-GFP expression in SK-MEL-2 cells. Cells were treated with either scrambled siRNA or siRNA of dynamin-2 for 48 hours, with or without the subsequent treatment using dynasore. The GFP intensity of scrambled siRNA-treated cells without subsequent dynasore treatment was normalized as $100 \% . N=16$. (b) Cellular uptake efficiency of amphiphilic polymers in SK-MEL-2 cells. The cellular uptake intensity of polymers (Cy3 intensity) in scrambled siRNA-treated cells without subsequent dynasore treatment was normalized as $100 \% . N=4$. In each figure, error bars represent the standard deviation of replicates. 

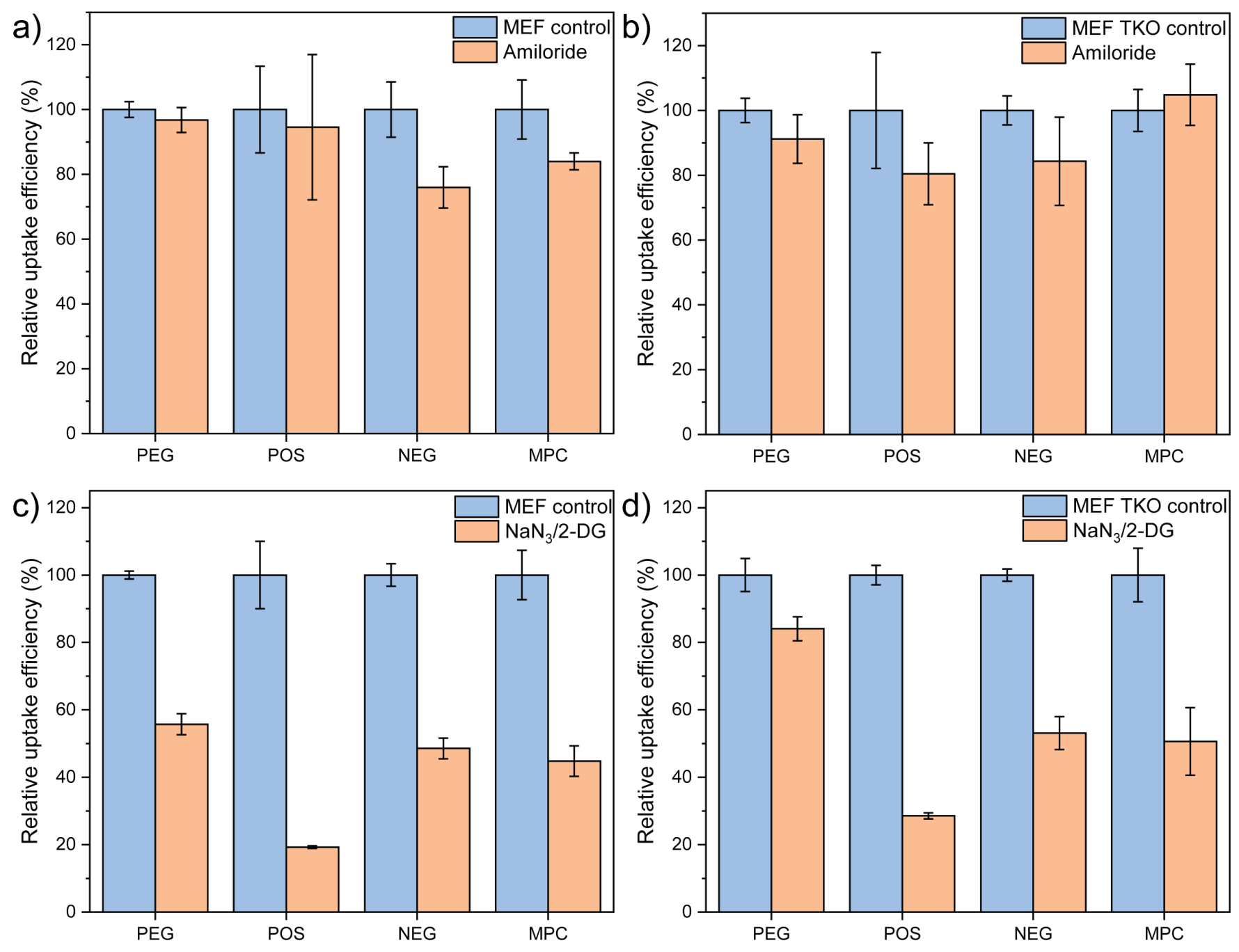

Figure S10. (a b) Cellular uptake efficiency of amphiphilic polymers in (a) dynamin-containing mouse embryo fibroblasts (MEF), (b) dynamin triple knockout mouse embryo fibroblasts (MEF TKO) in the presence of amiloride. $N=4$. (c $\sim$ d) Cellular uptake efficiency of amphiphilic polymers in (c) MEF, (d) MEF TKO in the presence of $\mathrm{NaN}_{3} / 2-\mathrm{DG}$, an ATP-depleted condition. Previous reports have shown that the intracellular ATP can be depleted by treating cells with $\mathrm{NaN}_{3}{ }^{1}$ or 2 -deoxy-D-glucose $(2-\mathrm{DG}) .{ }^{2} \mathrm{~N}=4$. In each figure, error bars represent the standard deviation of replicates. 
Table S1. Resource and tolerated dose of pharmacological inhibitors used in the study.

\begin{tabular}{llll}
\hline Inhibitor & Source & Identifier & Tolerated dose $^{\star}$ \\
\hline Amiloride & Sigma-Aldrich & Cat\# A7410 & $1 \mathrm{mM}^{\dagger, 3}$ \\
Bafilomycin A1 & Santa Cruz Biotechnology & Cat\# sc-201550 & $500 \mathrm{nM}^{\ddagger}$ \\
Chlorpromazine & TCl America & Cat\# C2481 & $10 \mu \mathrm{M}^{\ddagger}$ \\
Cytochalasin B & Abcam & Cat\# ab143482 & $1 \mu \mathrm{M}^{\S}$ \\
Cytochalasin D & Sigma-Aldrich & Cat\# C8273 & $1 \mu \mathrm{M}^{\S}$ \\
2-Deoxy-D-glucose & Santa Cruz Biotechnology & Cat\# sc-202010 & $50 \mathrm{mM}^{\dagger, 4}$ \\
Dynasore & Santa Cruz Biotechnology & Cat\# sc-202592 & $80 \mu \mathrm{M}^{\dagger, 5}$ \\
Dyngo 4a & Abcam & Cat\# ab120689 & $30 \mu \mathrm{M}^{\dagger, 6}$ \\
Dynole 34-2 & Santa Cruz Biotechnology & Cat\# sc-362731 & $6 \mu \mathrm{M}^{\ddagger}$ \\
Fucoidan & Carbosynth & Cat\# YF01606 & $0.1 \mathrm{mg}^{\cdot} \mathrm{mL}^{-1 \dagger, 7}$ \\
Genistein & Santa Cruz Biotechnology & Cat\# sc-3515 & $200 \mu \mathrm{M}^{\ddagger}$ \\
Latrunculin A & Abcam & Cat\# ab144290 & $1 \mu \mathrm{M}^{\S}$ \\
16-epi-Latrunculin B & Abcam & Cat\# ab144292 & $1 \mu \mathrm{M}^{\S}$ \\
Mdivi-1 & Sigma-Aldrich & Cat\# M0199 & $120 \mu \mathrm{M}^{\ddagger}$ \\
Methyl- $\beta$-cyclodextrin & TCl America & Cat\# M1356 & $3.5 \mathrm{mg}^{\ddagger} \mathrm{mL}^{-1 \dagger, 8}$ \\
Nocodazole & Santa Cruz Biotechnology & Cat\# sc-3518 & $20 \mu \mathrm{M}^{\dagger, 9}$ \\
Nystatin & Sigma-Aldrich & Cat\# N4014 & $27 \mu \mathrm{M}^{\dagger, 10}$ \\
OcTMAB & Sigma-Aldrich & Cat\# 359246 & $6 \mu \mathrm{M}^{\ddagger}$ \\
Sodium azide & Sigma-Aldrich & Cat\# 71289 & $10 \mathrm{mM}^{\dagger, 4}$ \\
Pitstop 2 & Sigma-Aldrich & Cat\# SML1169 & $6 \mu \mathrm{M}^{\ddagger}$ \\
\hline
\end{tabular}

* Tolerated dose represents the concentration of the inhibitor that was used to treat HeLa cells. It was chosen either based on literature report or integrating the result from microscopic visualization of cell morphology and alamarBlue assay.

${ }^{\dagger}$ The concentration was chosen based on previous reports.

₹ The concentration was determined by applying the inhibitor to cells for 4 hours and subsequently checking the cell viability.

$\S$ The concentration was determined by applying the inhibitor to cells for 1 hour and subsequently checking the cell viability. 


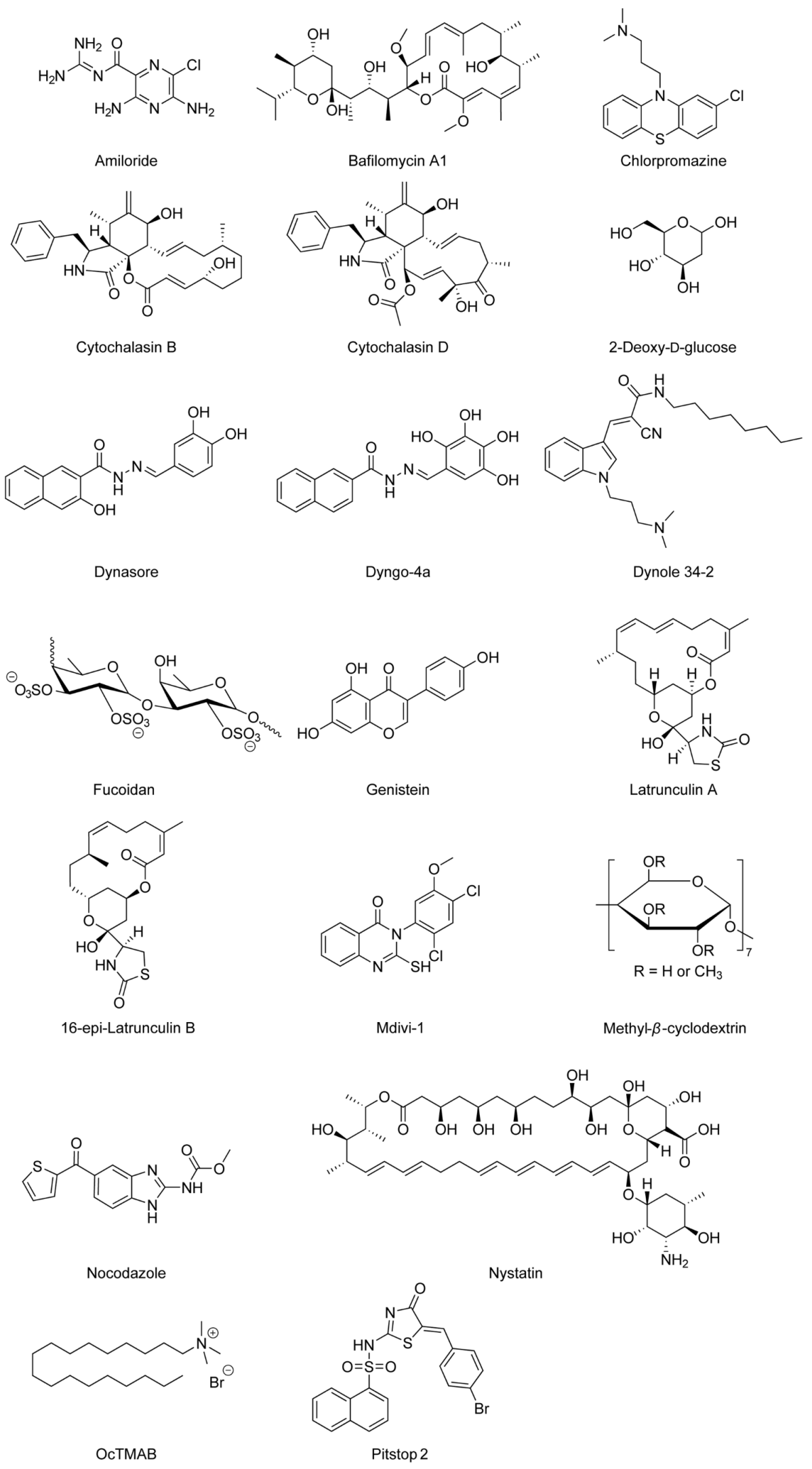

Figure S11. Structure of the pharmacological inhibitors used in the study. 
Table S2. Summary on endocytic pathways of materials with different surface charge. ${ }^{*, \dagger}$

\begin{tabular}{|c|c|c|c|}
\hline Material & Cationic & Anionic & Neutral \\
\hline PEG-PLA ${ }^{11}$ & CME, CaME, MP & MP & $\mathrm{N} / \mathrm{A}$ \\
\hline PEG-PLA ${ }^{12}$ & CME, MP & CME, MP & $\mathrm{N} / \mathrm{A}$ \\
\hline PEG-oligo(cholic acid) $)^{13}$ & CME, CaME, MP & CME, CaME, MP & CME, CaME, MP \\
\hline PAMAM dendrimer ${ }^{14}$ & Non-CME, Non-CaME & CaME & Non-CME, Non-CaME \\
\hline Poly(styrene) $)^{15}$ & CME, MP & CaME, MP & $\mathrm{N} / \mathrm{A}$ \\
\hline Poly(styrene) & $\mathrm{CME}^{16}$ & CME, $\mathrm{MP}^{17}$ & $N / A$ \\
\hline Poly(styrene) $)^{18}$ & CaME, MP & CaME, MP & $\mathrm{N} / \mathrm{A}$ \\
\hline Polymer-DNA complex ${ }^{19}$ & CME & CME & $\mathrm{N} / \mathrm{A}$ \\
\hline Chitosan ${ }^{20}$ & CME, CaME & CME, CaME & $\mathrm{N} / \mathrm{A}$ \\
\hline Chitosan ${ }^{21}$ & CME, MP & CME, MP & $N / A$ \\
\hline Liposome $^{22}$ & CME, CaME, MP & CME, CaME, MP & CME, CaME, MP \\
\hline Graphene $^{23}$ & CME, MP & CME, MP & $N / A$ \\
\hline Quantum Dot ${ }^{24}$ & N/A & CaME & $N / A$ \\
\hline Quantum Dot ${ }^{25}$ & N/A & $N / A$ & $\mathrm{CME}, \mathrm{MP}$ \\
\hline Quantum Dot ${ }^{20,26}$ & CME & CME & $N / A$ \\
\hline Gold nanoparticle ${ }^{4}$ & CME, CaME & CaME & CaME \\
\hline Gold nanoparticle $e^{27}$ & N/A & $N / A$ & MP \\
\hline Upconversion NP21, 28 & CME, CaME & CME, CaME & $N / A$ \\
\hline Upconversion $\mathrm{NP}^{29}$ & CME & $N / A$ & $\mathrm{~N} / \mathrm{A}$ \\
\hline Silica nanoparticle ${ }^{18}$ & CaME & CME, MP & $\mathrm{N} / \mathrm{A}$ \\
\hline Titanium dioxide $\mathrm{NP}^{30}$ & CME, MP & CaME, MP & $N / A$ \\
\hline
\end{tabular}

* MP, macropinocytosis. CME, clathrin-mediated endocytosis. CaME, lipid raft/caveolae-mediated endocytosis. N/A, not available.

${ }^{\dagger}$ The summary is concluded based on either redirecting the conclusion from the reference or estimating from the results of the corresponding reference. 


\section{Experimental Section}

\subsection{Synthesis of chain transfer agent, radical initiator, and monomer(s)}

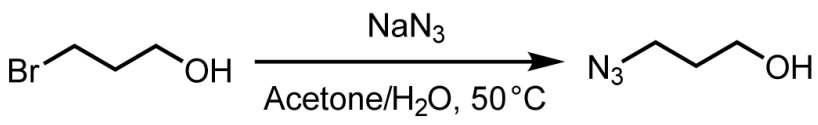

3-Azido-1-propanol

Synthesis of 3-azido-1-propanol. The compound was synthesized based on a previous report. ${ }^{31} 3-$ Bromo-1-propanol $(10 \mathrm{~g}, 71.9 \mathrm{mmol})$ and $\mathrm{NaN}_{3}(10.6 \mathrm{~g}, 163 \mathrm{mmol})$ were dissolved in a mixture of $\mathrm{H}_{2} \mathrm{O}$ /acetone (v:v=3:10,200 mL in total) and stirred at $50^{\circ} \mathrm{C}$ overnight. The mixture was filtered and concentrated in vacuo. Dichloromethane $(\mathrm{DCM}, 200 \mathrm{~mL})$ was added into the concentrated mixture and washed with deionized $\mathrm{H}_{2} \mathrm{O}$ for three times. The organic layer was dried over $\mathrm{MgSO}_{4}$ and concentrated in vacuo. The product was obtained as pale-yellow oil $(6.5 \mathrm{~g}, 64.2 \mathrm{mmol}, 89 \%) .{ }^{1} \mathrm{H} \mathrm{NMR}\left(400 \mathrm{MHz}, \mathrm{CDCl}_{3}\right)$ $\delta 3.81-3.71(\mathrm{~m}, 2 \mathrm{H}), 3.46(\mathrm{t}, J=6.6 \mathrm{~Hz}, 2 \mathrm{H}), 1.97(\mathrm{~s}, 1 \mathrm{H}), 1.84(\mathrm{p}, J=6.3 \mathrm{~Hz}, 2 \mathrm{H})$ (Figure SP1). ${ }^{13} \mathrm{C}$ NMR (100 MHz, $\left.\mathrm{CDCl}_{3}\right) \delta 59.98,48.61,31.57$ (Figure SP2).

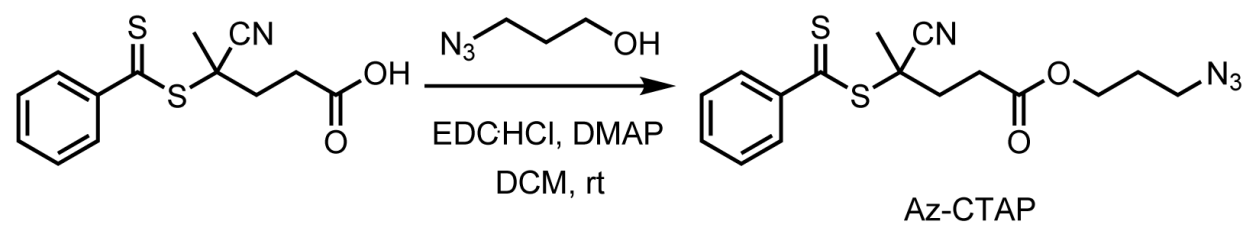

Synthesis of chain transfer agent (Az-CTAP). The compound was synthesized according to a previous report. $^{32}$ 4-Cyano-4-(phenylcarbonothioylthio)pentanoic acid (0.96 g, 3.42 mmol), 3-azido-1-propanol (1.73 g, $17 \mathrm{mmol}$ ), and 4-dimethylaminopyridine (DMAP, $20 \mathrm{mg}, 0.17 \mathrm{mmol}$ ) were dissolved in $60 \mathrm{~mL}$ DCM. While the solution was cooling in an ice bath, $N$-(3-dimethylaminopropyl)- $N$ '-ethylcarbodiimide hydrochloride $(E D C \cdot \mathrm{HCl}, 1.96 \mathrm{~g}, 10 \mathrm{mmol})$ was added. Then the reaction mixture was stirred in an ice bath for 2 hours and warmed up to room temperature to continuously stir overnight. Subsequently, the reaction mixture was washed with saturated $\mathrm{NaCl}$ solution three times, dried with anhydrous $\mathrm{Na}_{2} \mathrm{SO}_{4}$ and 
concentrated in vacuo. Finally, the concentrated mixture was purified by column chromatography over silica gel with $n$-hexanes-EtOAc $(v: v=5: 1)$. The product was obtained as dark-red oil $(0.87 \mathrm{~g}, 70 \%) .{ }^{1} \mathrm{H}$ $\operatorname{NMR}\left(400 \mathrm{MHz}, \mathrm{CDCl}_{3}\right) \delta 7.93-7.88(\mathrm{~m}, 2 \mathrm{H}), 7.60-7.54(\mathrm{~m}, 1 \mathrm{H}), 7.43-7.37(\mathrm{~m}, 2 \mathrm{H}), 4.21(\mathrm{t}, J=6.2$ $\mathrm{Hz}, 2 \mathrm{H}), 3.41(\mathrm{t}, J=6.6 \mathrm{~Hz}, 2 \mathrm{H}), 2.74-2.58(\mathrm{~m}, 3 \mathrm{H}), 2.49-2.38(\mathrm{~m}, 1 \mathrm{H}), 1.97-1.88(\mathrm{~m}, 5 \mathrm{H})$ (Figure SP3).

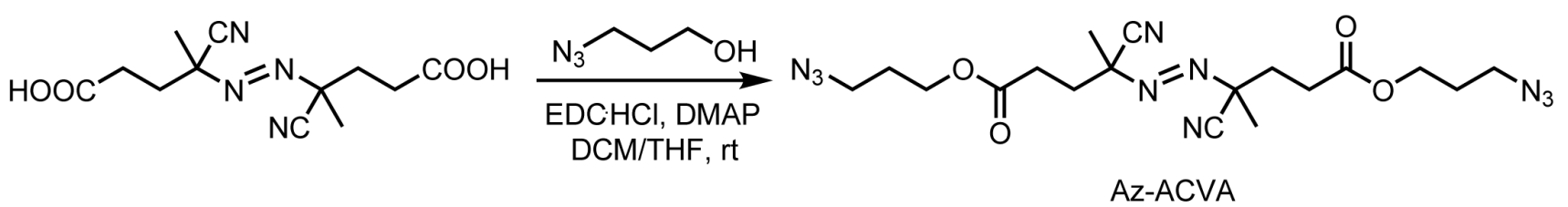

Synthesis of radical initiator (Az-ACVA). 4,4'-Azobis(4-cyanovaleric acid) (2 g, $7.1 \mathrm{mmol}), 3$-azido-1propanol $(2.16 \mathrm{~g}, 21.4 \mathrm{mmol})$, and DMAP $(695 \mathrm{mg}, 5.7 \mathrm{mmol})$ were dissolved in a mixture of DCM/THF $(v: v=1: 1,100 \mathrm{~mL}$ in total) and cooled in an ice bath. Subsequently, EDC $\mathrm{HCl}(3.29 \mathrm{~g}, 17.1 \mathrm{mmol})$ was suspended in $10 \mathrm{~mL}$ DCM and added into the reaction mixture dropwise. The reaction mixture was stirred in the ice bath for another 3 hours and warmed up to room temperature to stir for 1 hour. Next, the reaction was quenched by washing with saturated $\mathrm{NaCl}$ solution for three times. The organic layer was dried over $\mathrm{MgSO}_{4}$ and concentrated in vacuo. The mixture was then purified by column chromatography over silica gel with $\mathrm{CHCl}_{3}-\mathrm{EtOAc}(v: v=94: 6)$. The product was obtained as transparent oil $(2.27 \mathrm{~g}, 5.1 \mathrm{mmol}, 72 \%)$. ${ }^{1} \mathrm{H}$ NMR $\left(400 \mathrm{MHz}, \mathrm{CDCl}_{3}\right) \delta 4.21$ (tdd, $\left.J=6.1,3.8,1.8 \mathrm{~Hz}, 4 \mathrm{H}\right), 3.40(\mathrm{td}, J=6.6,2.9 \mathrm{~Hz}, 4 \mathrm{H}), 2.60-$ $2.30(\mathrm{~m}, 8 \mathrm{H}), 1.93(\mathrm{pd}, J=6.4,2.7 \mathrm{~Hz}, 4 \mathrm{H}), 1.73(\mathrm{~s}, 3 \mathrm{H}), 1.68(\mathrm{~s}, 3 \mathrm{H})$ (Figure SP4). ${ }^{13} \mathrm{C}$ NMR $(100 \mathrm{MHz}$, $\left.\mathrm{CDCl}_{3}\right) \delta 171.35,117.62,72.07,62.26,48.34,33.30,29.18,28.20,24.13$ (Figure SP5). ESI-MS m/z calculated for $\mathrm{C}_{18} \mathrm{H}_{26} \mathrm{~N}_{10} \mathrm{NaO}_{4}[\mathrm{M}+\mathrm{Na}]^{+} 469.20$, found 469.20 . 


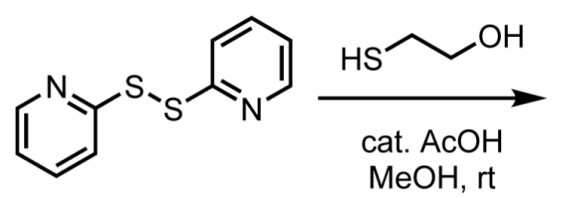

2-(Pyridin-2-yldisulfanyl)ethanol

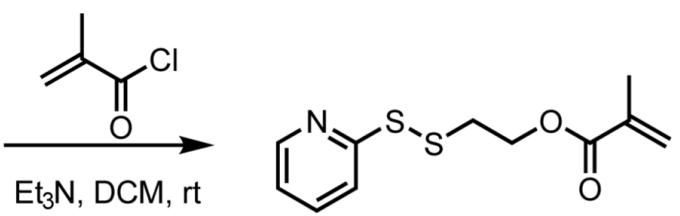

Pyridyl disulfide ethyl methacrylate

Synthesis of pyridyl disulfide ethyl methacrylate. The compound was synthesized based on a previous report with modifications ${ }^{33}$ 2,2'-Dipyridyl disulfide (15 g, $\left.68 \mathrm{mmol}\right), 2$-mercaptoethanol $(4.4 \mathrm{~g}$, $56.7 \mathrm{mmol})$, and acetic acid $(1 \mathrm{~mL})$ were dissolved in $100 \mathrm{~mL} \mathrm{MeOH}$ and stirred at room temperature for 3 hours. The solvent was evaporated in vacuo and the yellow oil mixture was dissolved in $50 \mathrm{~mL}$ ethyl acetate. Next, $n$-hexanes was added into the ethyl acetate solution until small amount of yellow solid recrystallized from the solution. The mixture was placed in $-20{ }^{\circ} \mathrm{C}$ overnight until the majority of $2-$ pyridinthione byproduct recrystallized. The yellow crystal was filtered and the filtrate was collected. After evaporating the solvent of the filtrate, the mixture was purified by flash chromatography over silica gel with $n$-hexanes-EtOAc (4:1 to 3:2). The product, 2-(pyridin-2-yldisulfanyl)ethanol was obtained as paleyellow oil $(7.7 \mathrm{~g}, 41 \mathrm{mmol}, 72 \%) .{ }^{1} \mathrm{H}$ NMR $\left(500 \mathrm{MHz}, \mathrm{CDCl}_{3}\right) \delta 8.51$ (ddd, $\left.J=5.0,1.8,0.9 \mathrm{~Hz}, 1 \mathrm{H}\right), 7.61$ - $7.54(\mathrm{~m}, 1 \mathrm{H}), 7.40(\mathrm{dt}, J=8.1,1.0 \mathrm{~Hz}, 1 \mathrm{H}), 7.15(\mathrm{ddd}, J=7.4,5.0,1.1 \mathrm{~Hz}, 1 \mathrm{H}), 5.80-5.65(\mathrm{~s}, 1 \mathrm{H})$, $3.80(\mathrm{t}, J=5.0 \mathrm{~Hz}, 2 \mathrm{H}), 2.98-2.92(\mathrm{~m}, 2 \mathrm{H})$ (Figure SP6).

In the second step, 2-(pyridin-2-yldisulfanyl)ethanol $(7.54 \mathrm{~g}, 40.3 \mathrm{mmol}$ ) and triethylamine $(4.9 \mathrm{~g}, 6.7 \mathrm{~mL}$, $48.3 \mathrm{mmol}$ ) were dissolved in $30 \mathrm{~mL}$ anhydrous DCM and stirred in an ice bath. The mixture was purged with argon for 5 mins. Methacryloyl chloride $(5.5 \mathrm{~g}, 5.1 \mathrm{~mL}, 52.3 \mathrm{mmol}$ ) was dissolved in $5 \mathrm{~mL}$ DCM and added into the reaction mixture dropwise. The mixture was then stirred at $4{ }^{\circ} \mathrm{C}$ for 2 hours under an argon atmosphere and then warmed up to room temperature to stir for 1 hour. Next, the mixture was washed with $10 \% \mathrm{NaCl}$ solution for five times. The organic layer was dried over $\mathrm{MgSO}_{4}$ and concentrated in vacuo. The concentrated mixture was purified by column chromatography over silica gel with $n$-hexanesEtOAc (9:1 to 7:3). The product, pyridyl disulfide ethyl methacrylate was obtained as pale-yellow oil (6.95 g, $27.2 \mathrm{mmol}, 67 \%) .{ }^{1} \mathrm{H}$ NMR $\left(500 \mathrm{MHz}, \mathrm{CDCl}_{3}\right) \delta 8.47$ (ddd, $\left.J=4.8,1.8,0.9 \mathrm{~Hz}, 1 \mathrm{H}\right), 7.69(\mathrm{dt}, J=8.3$, 
$1.1 \mathrm{~Hz}, 1 \mathrm{H}), 7.62(\mathrm{ddd}, J=8.1,7.3,1.8 \mathrm{~Hz}, 1 \mathrm{H}), 7.09(\mathrm{ddd}, J=7.4,4.8,1.1 \mathrm{~Hz}, 1 \mathrm{H}), 6.12(\mathrm{dt}, J=1.8,1.0$ $\mathrm{Hz}, 1 \mathrm{H}), 5.58(\mathrm{p}, J=1.6 \mathrm{~Hz}, 1 \mathrm{H}), 4.40(\mathrm{t}, J=6.4 \mathrm{~Hz}, 2 \mathrm{H}), 3.09(\mathrm{t}, J=6.4 \mathrm{~Hz}, 2 \mathrm{H}), 1.94(\mathrm{~s}, 3 \mathrm{H})$ (Figure SP7). ${ }^{13} \mathrm{C}$ NMR $\left(100 \mathrm{MHz}, \mathrm{CDCl}_{3}\right) \delta 167.23,159.94,149.92,137.20,136.14,126.20,121.01,119.94$, 62.58, 37.62, 18.45 (Figure SP8).

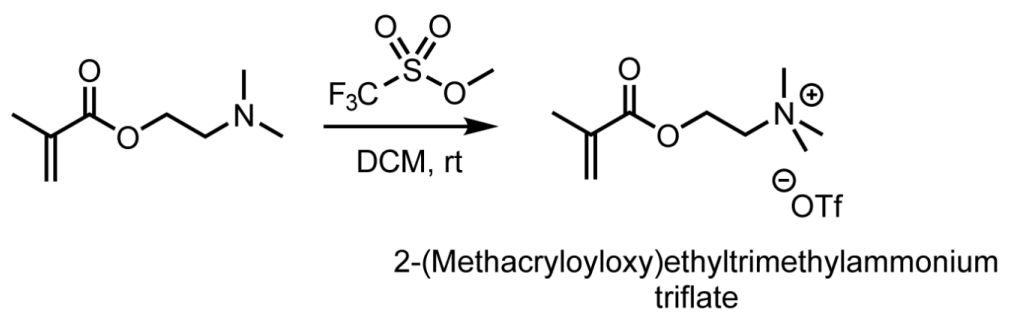

Synthesis of 2-(methacryloyloxy)ethyltrimethylammonium triflate. 2-(Dimethylamino)ethyl methacrylate $(4.35 \mathrm{~g}, 4.66 \mathrm{~mL}, 27.7 \mathrm{mmol})$ was dissolved in $12 \mathrm{~mL}$ DCM and purged with argon for 5 mins. The solution was cooled in an ice bath. Methyl trifluoromethanesulfonate $(5 \mathrm{~g}, 3.45 \mathrm{~mL}, 30.5 \mathrm{mmol})$ was added into the reaction mixture dropwise. The reaction mixture was warmed up to room temperature and stirred for 3 hours under an argon atmosphere. Next, the reaction mixture was added into cold diethyl ether dropwise. The white precipitate was collected and dried under vacuum. The product was obtained as white powder (8.66 g, $27 \mathrm{mmol}, 97 \%) .{ }^{1} \mathrm{H}$ NMR (400 MHz, $\left.\mathrm{D}_{2} \mathrm{O}\right) \delta 6.19(\mathrm{~d}, J=1.4 \mathrm{~Hz}, 1 \mathrm{H}), 5.80(\mathrm{p}, J$ $=1.6 \mathrm{~Hz}, 1 \mathrm{H}), 4.69-4.63(\mathrm{~m}, 2 \mathrm{H}), 3.84-3.79(\mathrm{~m}, 2 \mathrm{H}), 3.26(\mathrm{~s}, 9 \mathrm{H}), 1.96(\mathrm{~s}, 3 \mathrm{H})$ (Figure SP9). ${ }^{13} \mathrm{C}$ NMR (125 MHz, $\left.\mathrm{D}_{2} \mathrm{O}\right) \delta 168.42,135.15,127.63,119.62$ (q, $\left.J=317.1 \mathrm{~Hz}\right), 64.61,58.56,53.73,17.20$ (Figure SP10). ${ }^{19} \mathrm{~F}$ NMR (376 MHz, $\left.\mathrm{D}_{2} \mathrm{O}\right) \delta-78.82$ (Figure SP11).

\subsection{Reversible addition-fragmentation chain transfer (RAFT) polymerization}




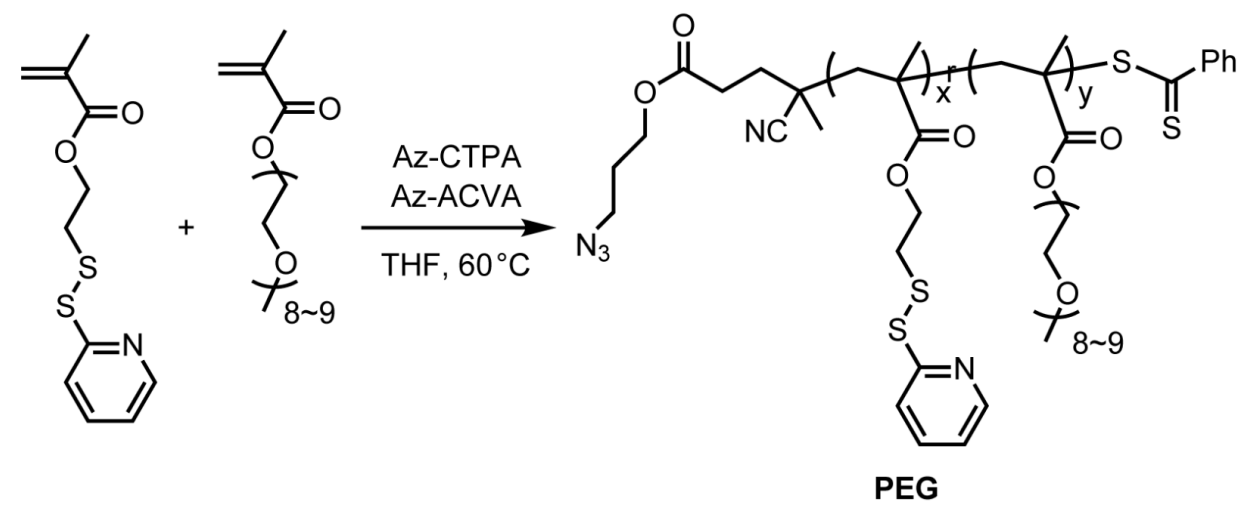

Synthesis of PEG, charge-neutral amphiphilic random copolymer. Pyridyl disulfide ethyl methacrylate (822 mg, $3.22 \mathrm{mmol}, 31.9$ equiv.), poly(ethylene glycol) methyl ether methacrylate (690 mg, $1.38 \mathrm{mmol}$, 13.7 equiv., $M_{\mathrm{n}}$ 500), Az-CTAP (36.6 mg, $0.1 \mathrm{mmol}, 1.0$ equiv.), and Az-ACVA (9 mg, $0.02 \mathrm{mmol}, 0.2$ equiv.) were dissolved in $3 \mathrm{~mL}$ anhydrous tetrahydrofuran (THF) and transferred to a 10-mL Schlenk flask. The flask was sealed and the reaction mixture was degassed with four freeze-pump-thaw cycles. After refilling the flask with an argon atmosphere, the reaction was dipped into a prewarmed oil bath at $60{ }^{\circ} \mathrm{C}$ and stirred for 20 hours. Next, the polymerization was quenched by freezing the mixture with liquid nitrogen and exposing to air. The polymer was purified by dissolving in $\mathrm{CHCl}_{3}$ and subsequently precipitating in cold diethyl ether for three times. The product was dried under vacuum and obtained as viscous pink oil (1.45 g). GPC (THF), $M_{\mathrm{n}}: 10.3 \mathrm{~K}, \oslash: 1.10 .{ }^{1} \mathrm{H} \mathrm{NMR}\left(500 \mathrm{MHz}, \mathrm{CDCl}_{3}\right) \delta 8.45$ (s), 7.66 (s), $7.09(\mathrm{~s}), 4.21(\mathrm{~s}), 4.06(\mathrm{~s}), 3.71-3.56(\mathrm{~m}), 3.54(\mathrm{dd}), 3.36(\mathrm{~s}), 3.02(\mathrm{~s}), 1.91(\mathrm{~s}), 1.83(\mathrm{~s}), 1.04(\mathrm{~s}), 0.89$ (s) (Figure SP12). The molar ratio between three repeating units was determined by integrating the aromatic proton in the pyridine and the methoxy proton $(\delta 3.3)$ in the polyethylene glycol side chain (x:y $=0.63: 0.37) \cdot{ }^{13} \mathrm{C} \mathrm{NMR}\left(100 \mathrm{MHz}, \mathrm{CDCl}_{3}\right)($ Figure SP13). 


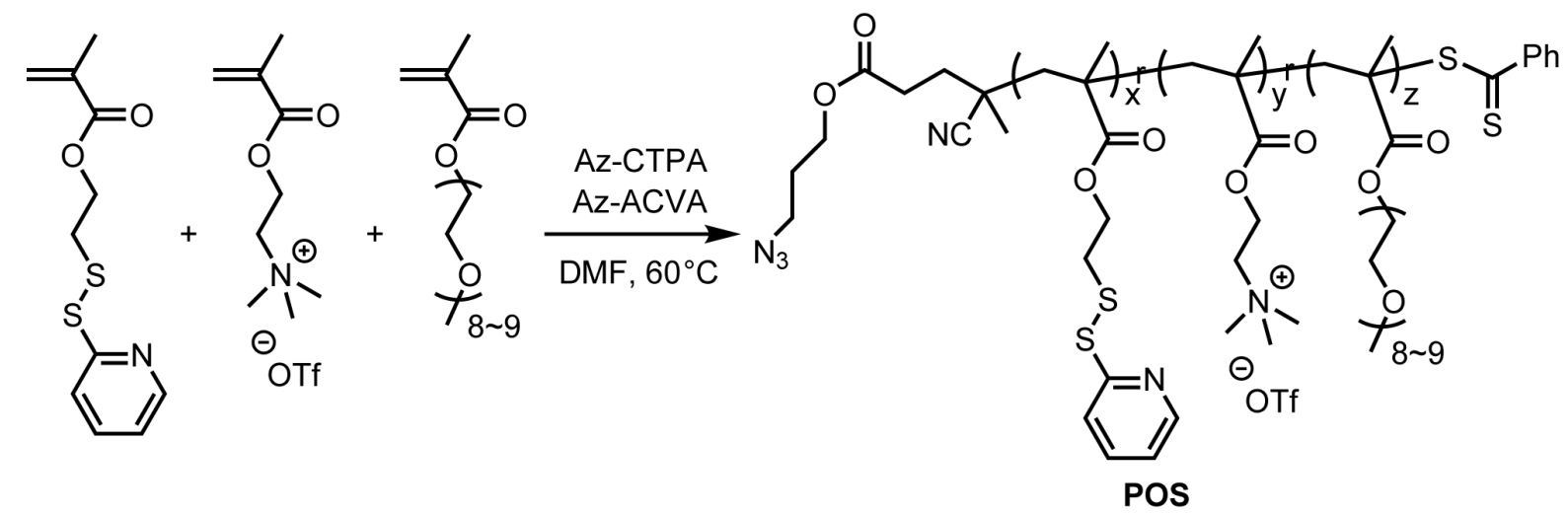

Synthesis of POS, cationic amphiphilic random copolymer. Pyridyl disulfide ethyl methacrylate $(500 \mathrm{mg}$, $1.96 \mathrm{mmol}, 33.8$ equiv.), 2-(methacryloyloxy)ethyltrimethylammonium triflate $(90 \mathrm{mg}, 0.28 \mathrm{mmol}, 4.8$ equiv.), poly(ethylene glycol) methyl ether methacrylate (280 mg, $0.56 \mathrm{mmol}, 9.7$ equiv., $\left.M_{\mathrm{n}} 500\right)$, AzCTAP (21.0 mg, $0.058 \mathrm{mmol}, 1.0$ equiv.), and Az-ACVA (5.2 mg, $0.012 \mathrm{mmol}, 0.2$ equiv.) were dissolved in $1.8 \mathrm{~mL}$ anhydrous dimethylformamide (DMF) and transferred to a 10-mL Schlenk flask. The flask was sealed and the reaction mixture was degassed with four freeze-pump-thaw cycles. After refilling the flask with an argon atmosphere, the reaction was dipped into a prewarmed oil bath at $60{ }^{\circ} \mathrm{C}$ and stirred for 20 hours. Next, the polymerization was quenched by freezing the mixture with liquid nitrogen and exposing to air. The polymer was purified by dialyzing against acetone using $1 \mathrm{kD} \mathrm{MWCO}$ dialysis tubing for 24 hours. The product was dried under vacuum and obtained as viscous pink oil (731 mg). GPC (TFE), $M_{\mathrm{n}}$ : $28.6 \mathrm{k}$, : $1.12 .{ }^{1} \mathrm{H}$ NMR $\left(400 \mathrm{MHz},\left(\mathrm{CD}_{3}\right)_{2} \mathrm{CO}\right) \delta 8.49$ (s), 7.81 (s), 7.23 (s), 4.59 (s), 4.29 (s), 4.11 (s), $4.00(\mathrm{~s}), 3.72(\mathrm{~d}), 3.65-3.53(\mathrm{~m}), 3.47(\mathrm{t}), 3.29(\mathrm{~s}), 3.17(\mathrm{~s}), 2.78(\mathrm{~d}), 2.08(\mathrm{~s}), 1.98-1.83(\mathrm{~m}), 1.16(\mathrm{~d})$, 0.97 (s) (Figure SP14). The molar ratio of three repeating units was determined by integrating the aromatic proton in the pyridine, the methylene proton $(\delta 4.0)$ next to the quaternary amine, and the methoxy proton (ס 3.3$)$ in the polyethylene glycol side chain $(x: y: z=0.65: 0.11: 0.24) .{ }^{13} \mathrm{C} \mathrm{NMR}(100 \mathrm{MHz}$, $\left.\left(\mathrm{CD}_{3}\right)_{2} \mathrm{CO}\right)$ (Figure SP15). 


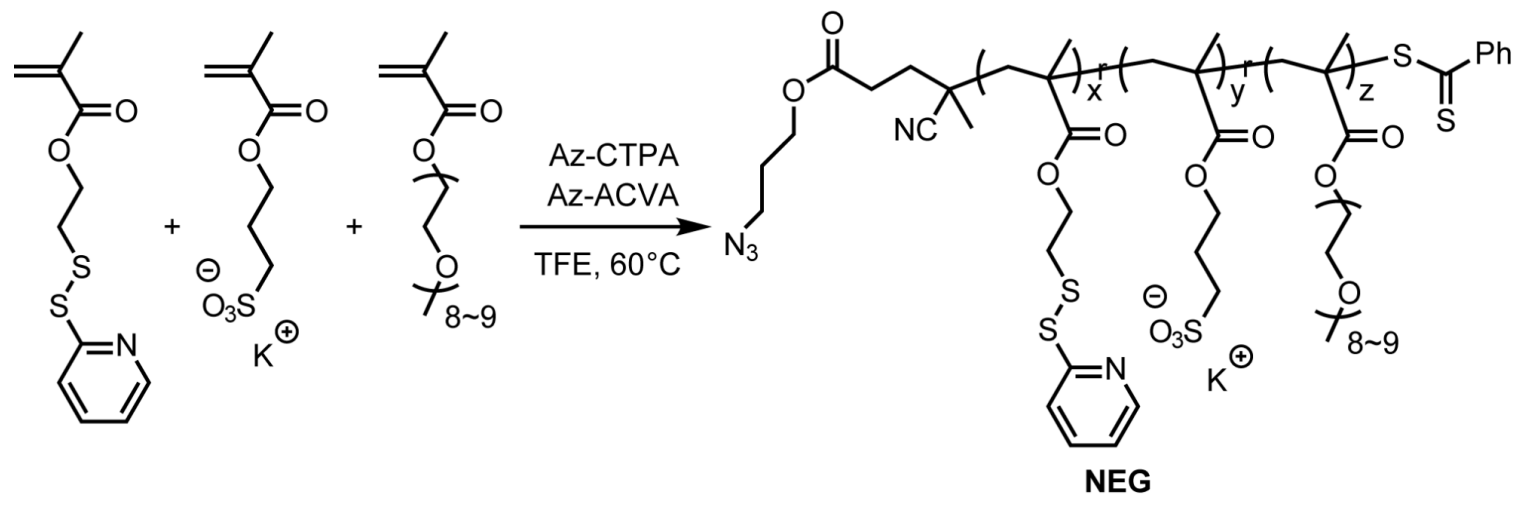

Synthesis of NEG, anionic amphiphilic random copolymer. Pyridyl disulfide ethyl methacrylate (531 mg, $1.96 \mathrm{mmol}, 34.6$ equiv.), 3-sulfopropyl methacrylate potassium salt (73 mg, $0.30 \mathrm{mmol}, 4.9$ equiv.), poly(ethylene glycol) methyl ether methacrylate (297 mg, 0.59 mmol, 9.9 equiv., $M_{\mathrm{n}}$ 500), Az-CTAP (21.8 mg, 0.060 mmol, 1.0 equiv.), and Az-ACVA (5.4 mg, 0.012 mmol, 0.2 equiv.) were dissolved in $1.8 \mathrm{~mL}$ trifluoroethanol (TFE) and transferred to a 10-mL Schlenk flask. The flask was sealed and the reaction mixture was degassed with four freeze-pump-thaw cycles. After refilling the flask with an argon atmosphere, the reaction was dipped into a prewarmed oil bath at $60{ }^{\circ} \mathrm{C}$ and stirred for 20 hours. Next, the polymerization was quenched by freezing the mixture with liquid nitrogen and exposing to air. The polymer was purified by dialyzing against a mixture of acetone/MeOH $(v \cdot v=1: 1)$ using $1 \mathrm{kD}$ MWCO dialysis tubing for 24 hours. The product was dried under vacuum and obtained as viscous pink oil (485 mg). GPC (TFE), $M_{\mathrm{n}}: 27.6 \mathrm{k}$, Ð: 1.18. ${ }^{1} \mathrm{H}$ NMR (400 MHz, $\left.\mathrm{CDCl}_{3}\right) \delta 8.45$ (s), 7.67 (s), 7.10 (s), 4.22 (s), $4.08(\mathrm{~s}), 3.95(\mathrm{q}), 3.74-3.57(\mathrm{~m}), 3.57-3.51(\mathrm{~m}), 3.38(\mathrm{~s}), 3.02(\mathrm{~s}), 1.92(\mathrm{~s}), 1.83(\mathrm{~s}), 1.05(\mathrm{~s}), 0.89(\mathrm{~s})$ (Figure SP16). The molar ratio of three repeating units was determined by integrating the aromatic proton in the pyridine, the methylene proton ( $\delta 2.9)$ next to the sulfonate group, and the methoxy proton $(\delta 3.3)$ in the polyethylene glycol side chain (x:y:z $=0.59: 0.16: 0.25) .{ }^{13} \mathrm{C} \mathrm{NMR}\left(125 \mathrm{MHz}, \mathrm{CDCl}_{3}\right)($ Figure SP17). 


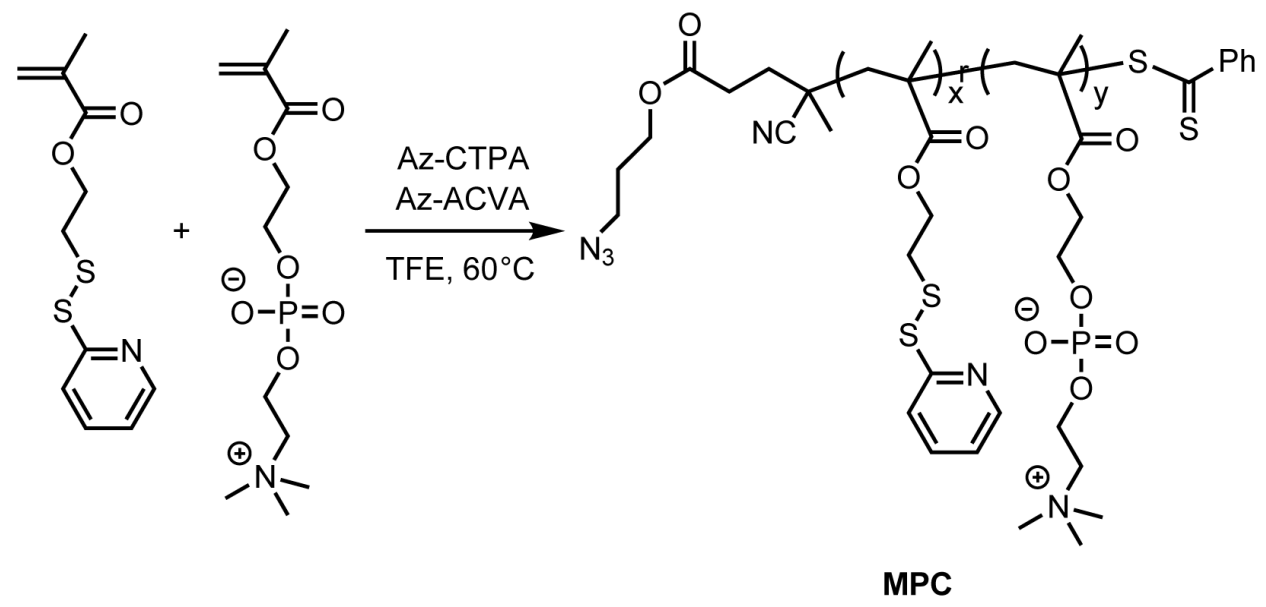

Synthesis of MPC, zwitterionic amphiphilic random copolymer. Pyridyl disulfide ethyl methacrylate (514 mg, $2.01 \mathrm{mmol}, 39.3$ equiv.), 2-methacryloyloxyethyl phosphorylcholine (255 mg, $0.86 \mathrm{mmol}, 16.8$ equiv.), Az-CTAP (18.6 mg, $0.051 \mathrm{mmol}, 1.0$ equiv.), and Az-ACVA (4.5 mg, $0.010 \mathrm{mmol}, 0.2$ equiv.) were dissolved in $1.6 \mathrm{~mL}$ trifluoroethanol (TFE) and transferred to a 10-mL Schlenk flask. The flask was sealed and the reaction mixture was degassed with four freeze-pump-thaw cycles. After refilling the flask with an argon atmosphere, the reaction was dipped into a prewarmed oil bath at $60^{\circ} \mathrm{C}$ and stirred for 20 hours. Next, the polymerization was quenched by freezing the mixture with liquid nitrogen and exposing to air. The polymer was purified by dialyzing against a mixture of acetone $/ \mathrm{MeOH} / \mathrm{H}_{2} \mathrm{O}(v: v: v=1: 1: 1)$ using $1 \mathrm{kD}$ MWCO dialysis tubing for 24 hours. The product was dried under vacuum and obtained as palepink powder (746 mg). GPC (TFE), $M_{\mathrm{n}}: 25.0 \mathrm{k}$, Ð: 1.30. ${ }^{1} \mathrm{H} \mathrm{NMR}\left(400 \mathrm{MHz}, \mathrm{CF}_{3} \mathrm{CD}_{2} \mathrm{OD}\right.$ ) $\delta 8.11$ (s), 7.80 $-7.49(\mathrm{~m}), 7.03(\mathrm{~s}), 4.25-3.84(\mathrm{~m}), 3.44(\mathrm{~s}), 3.02(\mathrm{~s}), 2.94-2.78(\mathrm{~m}), 1.82(\mathrm{br}), 0.99(\mathrm{~s}), 0.84(\mathrm{~s})$ (Figure SP18). The molar ratio of two repeating units was determined by integrating the aromatic proton in the pyridine and the methylene proton $(\delta 2.9)$ next to the quaternary amine $(x: y: z=0.65: 0.35) .{ }^{13} \mathrm{C} N M R(100$ $\mathrm{MHz}, \mathrm{CF}_{3} \mathrm{CD}_{2} \mathrm{OD}$ ) (Figure SP19). ${ }^{31} \mathrm{P} \mathrm{NMR}\left(162 \mathrm{MHz}, \mathrm{CF}_{3} \mathrm{CD}_{2} \mathrm{OD}\right.$ ) (Figure SP20). 


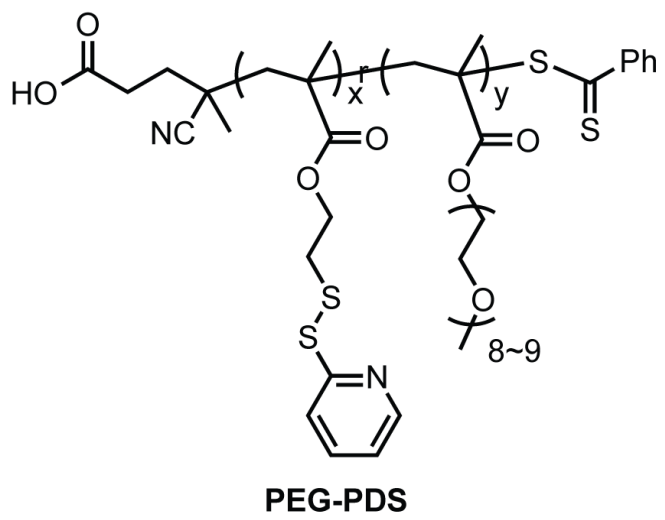

Synthesis of PEG-PDS, charge-neutral amphiphilic random copolymer without azido-tag. The random copolymer was synthesized following a previous report, ${ }^{34}$ using pyridyl disulfide ethyl methacrylate and poly(ethylene glycol) methyl ether methacrylate $\left(\begin{array}{lll}M_{\mathrm{n}} & 500\end{array}\right)$ as co-monomers. 4-Cyano-4(phenylcarbonothioylthio)pentanoic acid was used as the chain transfer agent. 2,2'-Azobis(2methylpropionitrile) was used as the radical initiator. The polymer was utilized to compare with the FTIR spectrum of the azido-tagged polymer (PEG) (Figure S1).

\subsection{General procedure for end-group labeling via copper-free click chemistry} Amphiphilic polymers and DBCO-Cy3 (Lumiprobe, Cat\# E10F0, 1.05 equiv. vs. the azido-end-group on the polymer) were dissolved in $2 \mathrm{~mL}$ trifluoroethanol and stirred at room temperature for 24 hours (Figure S3). The solvent was evaporated and the mixture was purified by gel permeation chromatography over SorbaDex 20-LH gel filtration matrix (Cat\# 801009). The SorbaDex 20-LH matrix is compatible with organic eluent and was dispersed in the eluent for at least 1 hour before packing the column. A mixture of $\mathrm{CHCl}_{3} / \mathrm{MeOH}(v: v=3: 1)$ was used as the eluent for PEG, POS, and NEG. A mixture of $\mathrm{CHCl}_{3} / \mathrm{TFE}(v: v$ = 3:1) was used as the eluent for MPC. The fraction that runs faster represents the molecules with higher molecular weight (Figure S4). The high-molecular-weight fraction was respectively collected and dried under vacuum. The yield of the dye-conjugation is quantitative.

\subsection{Preparation of the amphiphilic polymer stock solution}


Amphiphilic polymer (1 mg) was first dissolved in $40 \mu \mathrm{L}$ organic solvent (acetone for PEG and POS; trifluoroethanol for NEG and MPC). Deionized water ( $1 \mathrm{~mL}$, pre-filtered with $0.22 \mu \mathrm{m}$ syringe filter unit) was added dropwise into the organic solution of amphiphilic polymers while stirring. The mixture was continuously stirred at room temperature for 2 hours. Subsequently, a calculated amount of dithiothreitol ( 0.1 equiv. vs. the pyridine disulfide unit in polymer) stock solution was added into the mixture to crosslink $\sim 20 \%$ pyridine disulfide unit. The mixture was then stirred overnight. Next, the mixture was purified and concentrated with deionized water using Amicon centrifugal filters with $3 \mathrm{k}$ MWCO. The volume of the concentrated polymer solution was adjusted to afford the polymer stock solution at a concentration of 10 $\mathrm{mg} \cdot \mathrm{mL}^{-1}$. The stock solution would be directly spiked into cell culture medium for future studies.

\subsection{General procedure for cell culture and viability assays}

Cell culture. All cells used in the study were cultured in a humidified atmosphere $\left(5 \% \mathrm{CO}_{2}\right)$ at $37^{\circ} \mathrm{C}$. HeLa (Cat\# CCL-2) and SK-MEL-2 (Cat\# HTB-68) cell lines were purchased from ATCC. Human umbilical vein endothelial cell (HUVEC) was purchased from Lonza (Cat\# C2519A). RAW264.7 and HepG2 cell lines were a gift from Dr. Vincent M. Rotello (University of Massachusetts Amherst). Primary mouse embryo fibroblasts (MEF) were a gift from Dr. Jesse Mager (University of Massachusetts Amherst). The DNM2-GFP SK-MEL-2 cell line was provided by Dr. David G. Drubin (University of California, Berkeley). Conditional dynamin triple knockout mouse embryo fibroblasts were a gift from Dr. Pietro De Camilli (Yale University). Except HUVEC, all cells were grown and passaged in Dulbecco's modified eagle medium: Nutrient mixture F-12 + 1× GlutaMAX (DMEM, ThermoFisher, Cat\# 10565018) supplemented with $10 \%$ fetal bovine serum (FBS) and $1 \%$ antibiotics (100 $\mathrm{U} \cdot \mathrm{mL}^{-1}$ penicillin-streptomycin). HUVEC was grown and passaged in EGM-2 endothelial cell growth medium-2 BulletKit (Lonza, Cat\# CC-

3162). Cell viability assays were conducted with unlabeled amphiphilic polymers. Cellular uptake evaluation was performed with amphiphilic polymers respectively labeled with Cy3. 
AlamarBlue assay to determine the biocompatible range of polymers. A total of $10 \mathrm{k}$ HeLa cells were cultured in a 96-well plate for $24 \mathrm{~h}$ prior to the experiment. To evaluate the cytotoxicity of amphiphilic polymers, a stock solution of the unlabeled amphiphilic polymers was made before the experiment. The stock solution was serially 2-fold diluted into full DMEM growth medium. Next, the complete growth medium for HeLa cells was replaced by the polymer-containing medium and incubated for 24 hours. After washing with phosphate buffer saline (PBS), the cells were incubated with $220 \mu \mathrm{L}$ full DMEM/F12 growth medium containing $10 \%$ alamarBlue reagent for $60 \mathrm{~min}$. Cell viability was calculated by measuring the fluorescence intensity of alamarBlue at $590 \mathrm{~nm}$, with an excitation wavelength at $535 \mathrm{~nm}$.

Glutathione fluorometric assay. The intracellular glutathione level of HeLa cells was evaluated using glutathione fluorometric assay kit (BioVision, Cat\# K264). A total of 100k HeLa cells were cultured in a 6well plate for $72 \mathrm{~h}$ prior to the experiment. The stock solution of unlabeled amphiphilic polymers was added into fresh complete growth medium to result in a concentration of $0.2 \mathrm{mg} \cdot \mathrm{mL}^{-1}$. The cells were respectively incubated for 12 hours and 24 hours. After washing with phosphate buffer saline, the cells were dissociated from the plate and processed according to the manual of the kit. The fluorescence readout from each group was normalized based on the value of the control group in which no polymer was presented (Figure S2a).

Half maximal inhibitory concentration $\left(\mathrm{IC}_{50}\right)$ of 2-mercaptopyridine. The reaction byproduct between glutathione and the pyridine disulfide units in polymers is 2-mercaptopyridine. To evaluate the $\mathrm{IC}_{50}$ of 2mercaptopyridine, a total of 10k HeLa cells were cultured in a 96-well plate for 24 hours prior to the experiment. The yellow solid (Sigma-Aldrich, Cat\# M5852) was dissolved in complete DMEM/F12 growth medium and incubated with cells for 24 hours. After washing with phosphate buffer saline, the cells were incubated with $220 \mu \mathrm{L}$ full DMEM growth medium containing $10 \%$ alamarBlue reagent for 60 min. Cell viability was calculated by measuring the fluorescence intensity of alamarBlue at $590 \mathrm{~nm}$, with an 
excitation wavelength at $535 \mathrm{~nm}$. The $\mathrm{IC}_{50}$ value was obtained after fitting the dose-dependent cell viability data with DoseResp function in OriginPro 2018.

\subsection{General procedure for the cellular uptake evaluation of amphiphilic polymers}

Tolerated dose of pharmacological inhibitors. The tolerated dose for each inhibitor was chosen based on integrating the result from microscopic visualization of cell morphology and alamarBlue assay. A total of $10 \mathrm{k}$ HeLa cells were cultured in a 96 -well plate for 24 hours prior to the experiment. To evaluate the cytotoxicity of pharmacological inhibitors, a stock solution of the inhibitor in DMSO was made before the experiment. Note that the water-soluble compounds ( $\mathrm{M} \beta \mathrm{CD}$ and fucoidan) were directly dissolved in DMEM. The stock solution was diluted into DMEM medium by 1,000 times, resulting in $0.1 \%$ DMSO residue in the medium. Next, the complete growth medium for HeLa cells was replaced by the inhibitorcontaining DMEM and incubated for the time of interest (Table S1). After washing with phosphate buffer saline, the cells were incubated with $220 \mu \mathrm{L}$ full DMEM growth medium containing $10 \%$ alamarBlue reagent for $60 \mathrm{~min}$. Cell viability was calculated by measuring the fluorescence intensity of alamarBlue at $590 \mathrm{~nm}$, with an excitation wavelength at $535 \mathrm{~nm}$. The tolerated dose for each inhibitor was chosen based on integrating the result from alamarBlue assay and microscopic visualization of cell morphology.

Cellular uptake of amphiphilic polymers in ATP-depleted condition. A total of 20k HeLa cells were cultured in a 48-well plate for 24 hours prior to the experiment. For ATP depletion, cells were cultured for 1 hour in DMEM containing $10 \mathrm{mM} \mathrm{NaN}_{3}$ and $50 \mathrm{mM}$ 2-deoxy-D-glucose (2-DG). For temperature control, the $37^{\circ} \mathrm{C}$ condition was maintained in the incubator and the $4{ }^{\circ} \mathrm{C}$ condition was maintained in the fridge. Subsequently, in the presence of inhibitors, the cells were incubated with Cy3-labelled amphiphilic polymers that spiked into the medium for additional 3 hours. The final concentration of each amphiphilic polymer was maintained at $10 \mu \mathrm{g} \cdot \mathrm{mL}^{-1}$. After washing the cells with cold PBS, the fluorescence intensity of Cy3 within the cells was measured using flow cytometry with an excitation wavelength of $561 \mathrm{~nm}$. For the positive control, HeLa cells were cultured in DMEM for 1 hour and incubated with Cy3-labelled 
polymers for another 3 hours. For the blank group, HeLa cells were cultured in DMEM for 4 hours. After subtracting the fluorescence signal from the blank group, Сy3 fluorescence of the positive control group was normalized as $100 \%$.

Cellular uptake of amphiphilic polymers in the presence of pharmacological inhibitors. HeLa cells. A total of $10 \mathrm{k}$ HeLa cells were cultured in a 96 -well plate for 24 hours prior to the experiment. For inhibiting different endocytic pathways, cells were cultured for 1 hour in DMEM containing amiloride (1 mM), methyl$\beta$-cyclodextrin $\left(3.4 \mathrm{mg} \cdot \mathrm{mL}^{-1}\right)$, chlorpromazine $(10 \mu \mathrm{M})$, dynasore $(80 \mu \mathrm{M})$, and fucoidan $\left(0.1 \mathrm{mg} \cdot \mathrm{mL}^{-1}\right)$, respectively. Subsequently, in the presence of inhibitors, the cells were incubated with Cy3-labelled amphiphilic polymers that spiked into the medium for additional 3 hours. The final concentration of amphiphilic polymers was maintained at $20 \mu \mathrm{g} \cdot \mathrm{mL}^{-1}$ for PEG, $10 \mu \mathrm{g} \cdot \mathrm{mL}^{-1}$ for POS, $2 \mu \mathrm{g} \cdot \mathrm{mL}^{-1}$ for NEG, and $50 \mu \mathrm{g} \cdot \mathrm{mL}^{-1}$ for MPC. After washing the cells with cold PBS, the fluorescence intensity of Cy3 within the cells was measured using flow cytometry with an excitation wavelength of $561 \mathrm{~nm}$. For the positive control, HeLa cells were cultured in DMEM for 1 hour and incubated with Cy3-labelled polymers for another 3 hours. For the blank group, HeLa cells were cultured in DMEM for 4 hours. After subtracting the fluorescence signal from the blank group, Cy3 fluorescence of the positive control group was normalized as $100 \%$.

RAW264.7 cells. A total of 20k RAW264.7 cells (less than 6 passages) were cultured in a 96-well plate for 24 hours prior to the experiment. For inhibiting different endocytic pathways, cells were cultured for 1 hour in DMEM containing amiloride $(1 \mathrm{mM})$, methyl- $\beta$-cyclodextrin $\left(1 \mathrm{mg} \cdot \mathrm{mL}^{-1}\right)$, chlorpromazine $(10 \mu \mathrm{M})$, dynasore $(80 \mu \mathrm{M})$, and fucoidan $\left(0.1 \mathrm{mg} \cdot \mathrm{mL}^{-1}\right)$, respectively. Subsequently, in the presence of inhibitors, the cells were incubated with Cy3-labelled amphiphilic polymers that spiked into the medium for additional 3 hours. The final concentration of amphiphilic polymers was maintained at $20 \mu \mathrm{g} \cdot \mathrm{mL}^{-1}$ for PEG, 10 $\mu \mathrm{g} \cdot \mathrm{mL}^{-1}$ for POS, $2 \mu \mathrm{g} \cdot \mathrm{mL}^{-1}$ for NEG, and $50 \mu \mathrm{g} \cdot \mathrm{mL}^{-1}$ for MPC. After washing the cells with cold PBS, the fluorescence intensity of Cy3 within the cells was measured using flow cytometry with an excitation 
wavelength of $561 \mathrm{~nm}$. For the positive control, RAW264.7 cells were cultured in DMEM for 1 hour and incubated with Cy3-labelled polymers for another 3 hours. For the blank group, RAW264.7 cells were cultured in DMEM for 4 hours. After subtracting the fluorescence signal from the blank group, Cy3 fluorescence of the positive control group was normalized as $100 \%$.

HepG2 cells. A total of $20 \mathrm{k}$ HepG2 cells were cultured in a 96 -well plate for 24 hours prior to the experiment. For inhibiting different endocytic pathways, cells were cultured for 1 hour in DMEM containing amiloride $(1 \mathrm{mM})$, methyl- $\beta$-cyclodextrin $\left(2 \mathrm{mg} \cdot \mathrm{mL}^{-1}\right)$, chlorpromazine $(10 \mu \mathrm{M})$, dynasore $(80 \mu \mathrm{M})$, and fucoidan $\left(0.1 \mathrm{mg} \cdot \mathrm{mL}^{-1}\right)$, respectively. Subsequently, in the presence of inhibitors, the cells were incubated with Cy3-labelled amphiphilic polymers that spiked into the medium for additional 3 hours. The final concentration of amphiphilic polymers was maintained at $20 \mu \mathrm{g} \cdot \mathrm{mL}^{-1}$ for PEG, $10 \mu \mathrm{g} \cdot \mathrm{mL}^{-1}$ for POS, 2 $\mu \mathrm{g} \cdot \mathrm{mL}^{-1}$ for NEG, and $50 \mu \mathrm{g} \cdot \mathrm{mL}^{-1}$ for MPC. After washing the cells with cold PBS, the fluorescence intensity of Cy3 within the cells was measured using flow cytometry with an excitation wavelength of 561 nm. For the positive control, HepG2 cells were cultured in DMEM for 1 hour and incubated with Cy3labelled polymers for another 3 hours. For the blank group, HepG2 cells were cultured in DMEM for 4 hours. After subtracting the fluorescence signal from the blank group, Cy3 fluorescence of the positive control group was normalized as $100 \%$.

HUVEC cells. A total of 25k HUVEC (less than 3 passages) were cultured in a 96-well plate for 24 hours prior to the experiment. For inhibiting different endocytic pathways, cells were cultured for 1 hour in FBSfree EGM-2 medium containing amiloride $(1 \mathrm{mM})$, methyl- $\beta$-cyclodextrin $\left(1 \mathrm{mg} \cdot \mathrm{mL}^{-1}\right)$, chlorpromazine $(10$ $\mu \mathrm{M})$, dynasore $(80 \mu \mathrm{M})$, and fucoidan $\left(0.1 \mathrm{mg} \cdot \mathrm{mL}^{-1}\right)$, respectively. Subsequently, in the presence of inhibitors, the cells were incubated with Cy3-labelled amphiphilic polymers that spiked into the medium for additional 3 hours. The final concentration of amphiphilic polymers was maintained at $20 \mu \mathrm{g} \cdot \mathrm{mL}^{-1}$ for PEG, $10 \mu \mathrm{g} \cdot \mathrm{mL}^{-1}$ for POS, $2 \mu \mathrm{g} \cdot \mathrm{mL}^{-1}$ for NEG, and $50 \mu \mathrm{g} \cdot \mathrm{mL}^{-1}$ for MPC. After washing the cells with cold PBS, the fluorescence intensity of Cy3 within the cells was measured using flow cytometry with an 
excitation wavelength of $561 \mathrm{~nm}$. For the positive control, HUVEC cells were cultured in FBS-free EGM2 medium for 1 hour and incubated with Cy3-labelled polymers for another 3 hours. For the blank group, HUVEC cells were cultured in FBS-free EGM-2 medium for 4 hours. After subtracting the fluorescence signal from the blank group, Cy3 fluorescence of the positive control group was normalized as $100 \%$. To evaluate the effect of serum on the cellular uptake of polymers in HUVEC cells, the FBS-free EGM-2 medium was replaced with full EGM-2 growth medium in the above procedures.

SK-MEL-2 cells. A total of 20k SK-MEL-2 cells were cultured in a 96 -well plate for 24 hours prior to the experiment. For inhibiting different endocytic pathways, cells were cultured for 1 hour in DMEM containing amiloride $(1 \mathrm{mM})$, methyl- $\beta$-cyclodextrin $\left(1 \mathrm{mg} \cdot \mathrm{mL}^{-1}\right)$, chlorpromazine $(10 \mu \mathrm{M})$, dynasore $(80 \mu \mathrm{M})$, and fucoidan $\left(0.1 \mathrm{mg} \cdot \mathrm{mL}^{-1}\right)$, respectively. Subsequently, in the presence of inhibitors, the cells were incubated with Cy3-labelled amphiphilic polymers that spiked into the medium for additional 3 hours. The final concentration of amphiphilic polymers was maintained at $20 \mu \mathrm{g} \cdot \mathrm{mL}^{-1}$ for PEG, $10 \mu \mathrm{g} \cdot \mathrm{mL}^{-1}$ for POS, 2 $\mu \mathrm{g} \cdot \mathrm{mL}^{-1}$ for NEG, and $50 \mu \mathrm{g} \cdot \mathrm{mL}^{-1}$ for MPC. After washing the cells with cold PBS, the fluorescence intensity of Cy3 within the cells was measured using flow cytometry with an excitation wavelength of 561 nm. For the positive control, SK-MEL-2 cells were cultured in DMEM for 1 hour and incubated with Cy3labelled polymers for another 3 hours. For the blank group, SK-MEL-2 cells were cultured in DMEM for 4 hours. After subtracting the fluorescence signal from the blank group, Cy3 fluorescence of the positive control group was normalized as $100 \%$.

Primary mouse embryo fibroblasts. A total of 10k MEF cells (less than 3 passages) were cultured in a 96-well plate for 24 hours prior to the experiment. Note that the cells were collected from mouse embryos by Dr. Jesse Mager (UMass Amherst). For inhibiting different endocytic pathways, cells were cultured for 1 hour in DMEM containing amiloride $(1 \mathrm{mM})$, methyl- $\beta$-cyclodextrin $\left(1 \mathrm{mg} \cdot \mathrm{mL}^{-1}\right)$, chlorpromazine $(10 \mu \mathrm{M})$, dynasore $(80 \mu \mathrm{M})$, and fucoidan $\left(0.1 \mathrm{mg} \cdot \mathrm{mL}^{-1}\right)$, respectively. Subsequently, in the presence of inhibitors, the cells were incubated with Cy3-labelled amphiphilic polymers that spiked into the medium for additional 
3 hours. The final concentration of amphiphilic polymers was maintained at $20 \mu \mathrm{g} \cdot \mathrm{mL}^{-1}$ for PEG, 10 $\mu \mathrm{g} \cdot \mathrm{mL}^{-1}$ for POS, $2 \mu \mathrm{g} \cdot \mathrm{mL}^{-1}$ for NEG, and $50 \mu \mathrm{g} \cdot \mathrm{mL}^{-1}$ for MPC. After washing the cells with cold PBS, the fluorescence intensity of Cy3 within the cells was measured using flow cytometry with an excitation wavelength of $561 \mathrm{~nm}$. For the positive control, MEF cells were cultured in DMEM for 1 hour and incubated with Cy3-labelled polymers for another 3 hours. For the blank group, MEF cells were cultured in DMEM for 4 hours. After subtracting the fluorescence signal from the blank group, Cy3 fluorescence of the positive control group was normalized as $100 \%$.

\subsection{Cellular uptake evaluation of amphiphilic polymers in the presence of dynasore analog}

Flow cytometry. HeLa cells. A total of 10k HeLa cells were cultured in a 96-well plate for 24 hours prior to the experiment. For inhibiting different endocytic pathways, cells were cultured for 1 hour in DMEM containing dynasore $(80 \mu \mathrm{M})$ and Dyngo-4a $(30 \mu \mathrm{M})$, respectively. Subsequently, in the presence of inhibitors, the cells were incubated with Cy3-labelled amphiphilic polymers that spiked into the medium for additional 3 hours. The final concentration of amphiphilic polymers was maintained at $20 \mu \mathrm{g} \cdot \mathrm{mL}^{-1}$ for PEG, $10 \mu \mathrm{g} \cdot \mathrm{mL}^{-1}$ for POS, $2 \mu \mathrm{g} \cdot \mathrm{mL}^{-1}$ for NEG, and $50 \mu \mathrm{g} \cdot \mathrm{mL}^{-1}$ for MPC. After washing the cells with cold PBS, the fluorescence intensity of Cy3 within the cells was measured using flow cytometry with an excitation wavelength of $561 \mathrm{~nm}$. For the positive control, HeLa cells were cultured in DMEM for 1 hour and incubated with Cy3-labelled polymers for another 3 hours. For the blank group, HeLa cells were cultured in DMEM for 4 hours. After subtracting the fluorescence signal from the blank group, Cy3 fluorescence of the positive control group was normalized as $100 \%$.

HUVEC cells. A total of 25k HUVEC (less than 3 passages) were cultured in a 96-well plate for 24 hours prior to the experiment. For inhibiting different endocytic pathways, cells were cultured for 1 hour in FBSfree EGM-2 medium containing DMEM containing dynasore $(80 \mu \mathrm{M})$ and Dyngo-4a $(30 \mu \mathrm{M})$, respectively. Subsequently, in the presence of inhibitors, the cells were incubated with Cy3-labelled amphiphilic polymers that spiked into the medium for additional 3 hours. The final concentration of amphiphilic 
polymers was maintained at $20 \mu \mathrm{g} \cdot \mathrm{mL}^{-1}$ for PEG, $10 \mu \mathrm{g} \cdot \mathrm{mL}^{-1}$ for POS, $2 \mu \mathrm{g} \cdot \mathrm{mL}^{-1}$ for NEG, and $50 \mu \mathrm{g} \cdot \mathrm{mL}^{-}$

${ }^{1}$ for MPC. After washing the cells with cold PBS, the fluorescence intensity of Cy3 within the cells was measured using flow cytometry with an excitation wavelength of $561 \mathrm{~nm}$. For the positive control, HUVEC cells were cultured in FBS-free EGM-2 medium for 1 hour and incubated with Cy3-labelled polymers for another 3 hours. For the blank group, HUVEC cells were cultured in FBS-free EGM-2 medium for 4 hours. After subtracting the fluorescence signal from the blank group, Cy3 fluorescence of the positive control group was normalized as $100 \%$.

Confocal microscopy. A total of 80k RAW264.7 cells (less than 6 passages) were seeded into a glass bottom dish (Cellvis, \#D35C4-20-0-N) for 24 hours prior to the experiment. To evaluate the effect of dynasore, cells were cultured for 1 hour in DMEM containing dynasore $(80 \mu \mathrm{M})$. Subsequently, in the presence of inhibitors, the cells were incubated with Cy3-labelled amphiphilic polymers that spiked into the medium for additional 3 hours. The final concentration of amphiphilic polymers was maintained at $100 \mu \mathrm{g} \cdot \mathrm{mL}^{-1}$ for PEG, $80 \mu \mathrm{g} \cdot \mathrm{mL}^{-1}$ for POS, $25 \mu \mathrm{g} \cdot \mathrm{mL}^{-1}$ for NEG, and $100 \mu \mathrm{g} \cdot \mathrm{mL}^{-1}$ for MPC. After washing with phosphate buffer saline, the cells were incubated with NucBlue (Hoechst 33342, 1 drop in $500 \mu \mathrm{L}$ medium) for 5 min in FluoroBrite DMEM at $37^{\circ} \mathrm{C}$ to stain the nucleus. The intracellular distribution was measured by confocal microscopy with excitation wavelengths of $405 \mathrm{~nm}$ (Hoechst 33342) and $561 \mathrm{~nm}$ (Cy3-labeled polymers).

\subsection{Cellular uptake evaluation of amphiphilic polymers in DNM2-GFP SK-MEL-2 cells}

Dynamin-2 knockdown in DNM2-GFP SK-MEL-2 cells. A total of 10k DNM2-GFP SK-MEL-2 cells were cultured in a 96-well plate in complete DMEM growth medium for 24 hours prior to the experiment. Note that these SK-MEL-2 cells with GFP tagged on one endogenous DNM2 allele ${ }^{35}$ were provided by Dr. David G. Drubin (University of California, Berkeley). Lipofectamine RNAiMAX (ThermoFisher, Cat\# 13778030) was used to transfect either scrambled siRNA (siScram, Sigma-Aldrich, Cat \#SIC001) or 
siRNA of dynamin-2 (siDNM2, ThermoFisher, Cat\# S4212) into SK-MEL-2 cells. The sequence of siDNM2 is 5'-ACAUCAACACGAACCAUGA-3'. Lipofectamine RNAiMAX and siDNM2 (or siScram) were complexed for transfection based on the ThermoFisher manual. Briefly, each siRNA was diluted with nuclease-free water to afford $10 \mu \mathrm{M}$ stock solution. The stock solution of siRNA (2 $\mu \mathrm{L})$ was added into $100 \mu \mathrm{L}$ Opti-MEM reduced serum medium (Opti-MEM, ThermoFisher, Cat\# 51985034). Meanwhile, $6 \mu \mathrm{L}$ of Lipofectamine was separately added into another $100 \mu \mathrm{L}$ fresh Opti-MEM. Afterwards, $25 \mu \mathrm{L}$ of lipid and siRNA was separately taken out from their Opti-MEM solution and mixed for 5 minutes at room temperature. DMEM was removed from cells and $100 \mu \mathrm{L}$ fresh Opti-MEM was added to each well. The lipid-RNA complex containing Opti-MEM $(10 \mu \mathrm{L})$ was added into each well and incubated for 48 hours or 72 hours. After washing with phosphate buffer saline, the siScram- or siDNM2-treated SK-MEL-2 cells are ready to be further evaluated.

Cellular uptake evaluation of amphiphilic polymers. The medium for siScram- or siDNM2-treated (48hour or 72-hour) cells was replaced with DMEM. Cy3-labelled amphiphilic polymers were spiked into the medium to incubate for 3 hours. In parallel, to evaluate the effect of dynasore, the siScram- or siDNM2treated cells were cultured for 1 hour in DMEM containing dynasore (80 $\mu \mathrm{M})$. Subsequently, in the presence of dynasore, the cells were incubated with Cy3-labelled amphiphilic polymers that spiked into the medium for additional 3 hours. The final concentration of amphiphilic polymers was maintained at 20 $\mu \mathrm{g} \cdot \mathrm{mL}^{-1}$ for PEG, $10 \mu \mathrm{g} \cdot \mathrm{mL}^{-1}$ for POS, $2 \mu \mathrm{g} \cdot \mathrm{mL}^{-1}$ for NEG, and $50 \mu \mathrm{g} \cdot \mathrm{mL}^{-1}$ for MPC. After washing the cells with cold PBS, the fluorescence intensity of GFP and Cy3 within the cells was measured using flow cytometry with excitation wavelengths of $488 \mathrm{~nm}$ and $561 \mathrm{~nm}$. For the positive control, the fluorescence signal in siScram-treated SK-MEL-2 cells without dynasore treatment was normalized as $100 \%$. For the blank group, SK-MEL-2 cells were cultured in DMEM for 3 hours. After subtracting the fluorescence signal from the blank group, GFP or Cy3 fluorescence of the positive control group was normalized as $100 \%$. 


\subsection{Cellular uptake evaluation of amphiphilic polymers in dynamin triple knockout mouse embryo}

\section{fibroblasts}

Generation of dynamin triple knockout fibroblasts. The conditional dynamin triple-knockout mouse embryo fibroblasts (MEF TKO) were provided by Dr. Pietro De Camilli (Yale University). The deletion of dynamin in these cells is mediated by a tamoxifen-inducible knockout strategy. These cells express a Cre-estrogen receptor mutant knock-in transgene from the ROSA26 locus. Only in response to tamoxifen exposure, Cre is shuttled into the nucleus. The conditional MEF TKO cells were seeded in T75 cell culture flask and cultured in full DMEM growth medium containing $3 \mu \mathrm{M}$ 4-hydroxytamoxifen (4-OHT, SigmaAldrich, Cat\# H6278) for 2 days. Next, these cells were split into a 48-well plate. A total of 5k cells were seeded into each well and cultured in full DMEM growth medium containing $300 \mathrm{nM} 4-\mathrm{OHT}$. The medium was replaced every two days with fresh full DMEM growth medium containing $300 \mathrm{nM} 4-\mathrm{OHT}$. The TKO cells used for the experiment were between 6-8 days since the initial $3 \mu \mathrm{M} 4-\mathrm{OHT}$ treatment. The simultaneous loss of dynamin 1,2,3 was confirmed by Western blot. ${ }^{36}$ These dynamin triple knockout cells were denoted as MEF TKO cells.

Cellular uptake evaluation of amphiphilic polymers. A total of $10 \mathrm{k}$ conditional MEF TKO without 4OHT treatment were seeded in a 48-well plate and cultured in complete DMEM growth medium for 48 hours prior to the experiment. These dynamin-containing cells were denoted as MEF. Note that these MEF cells were immortalized by the $3 T 3$ method of serial passaging, different from the primary MEF cells provided by Dr. Jesse Mager. The medium for MEF and MEF TKO cells was replaced with DMEM. Cy3labelled amphiphilic polymers were spiked into the medium to incubate for additional 3 hours. The final concentration of amphiphilic polymers was maintained at $20 \mu \mathrm{g} \cdot \mathrm{mL}^{-1}$ for PEG, $10 \mu \mathrm{g} \cdot \mathrm{mL}^{-1}$ for POS, 2 $\mu \mathrm{g} \cdot \mathrm{mL}^{-1}$ for NEG, and $50 \mu \mathrm{g} \cdot \mathrm{mL}^{-1}$ for MPC. In parallel, to evaluate the effect of pharmacological inhibitors, the MEF or MEF TKO cells were cultured for 1 hour in DMEM containing dynasore $(80 \mu \mathrm{M})$, amiloride (1 $\mathrm{mM}$ ), and $\mathrm{NaN}_{3} / 2-\mathrm{DG}(10 \mathrm{mM} / 50 \mathrm{mM}$ ), respectively. Subsequently, in the presence of inhibitors, the cells were incubated with Cy3-labelled amphiphilic polymers that spiked into the medium for additional 3 
hours. After washing the cells with cold PBS, the fluorescence intensity of Cy3 within the cells was measured using flow cytometry with an excitation wavelength of $561 \mathrm{~nm}$. For the comparison between MEF and MEF TKO cells, the fluorescence signal of Cy3-labelled polymers in MEF cells were normalized as $100 \%$. In the experiments with inhibitors, For the positive control, the fluorescence signal in cells without dynasore treatment was normalized as $100 \%$. For the blank group, MEF or MEF TKO cells were cultured in DMEM for 3 hours. After subtracting the fluorescence signal from the blank group, Cy3 fluorescence of the positive control group was normalized as $100 \%$.

\subsection{Evaluation of dynasore off-target effects}

Flow cytometry. A total of $10 \mathrm{k}$ HeLa cells were cultured in a 96 -well plate for 24 hours prior to the experiment. For inhibiting different endocytic pathways, cells were cultured for 1 hour in DMEM containing OctTAB (6 $\mu \mathrm{M})$, Dynole 34-2 (6 $\mu \mathrm{M})$, Mdivi-1 (30 $\mu \mathrm{M})$, bafilomycin A1 (400 nM, $200 \mathrm{nM}$, or $100 \mathrm{nM})$, nystatin $(27 \mu \mathrm{M})$, nocodazole $(20 \mu \mathrm{M})$, genistein $(100 \mu \mathrm{M}$ or $50 \mu \mathrm{M})$, and Pitstop $2(6 \mu \mathrm{M})$, respectively. Subsequently, in the presence of inhibitors, the cells were incubated with Cy3-labelled amphiphilic polymers that spiked into the medium for additional 3 hours. Note that the actin inhibitors were conducted with a different time scale. For actin inhibitors, cells were cultured for 30 minutes in DMEM containing cytochalasin B $(20 \mu \mathrm{M}, 2 \mu \mathrm{M}$, or $0.2 \mu \mathrm{M})$, cytochalasin $\mathrm{D}(20 \mu \mathrm{M}, 2 \mu \mathrm{M}$, or $0.2 \mu \mathrm{M})$, latrunculin $\mathrm{A}(1 \mu \mathrm{M}$, $0.5 \mu \mathrm{M}$, or $0.1 \mu \mathrm{M})$, and 16-epi-latrunculin $\mathrm{B}(1 \mu \mathrm{M}, 0.5 \mu \mathrm{M}$, or $0.1 \mu \mathrm{M})$, respectively. Subsequently, in the presence of inhibitors, the cells were incubated with Cy3-labelled amphiphilic polymers that spiked into the medium for additional 30 minutes. The final concentration of amphiphilic polymers was maintained at $20 \mu \mathrm{g} \cdot \mathrm{mL}^{-1}$ for PEG, $10 \mu \mathrm{g} \cdot \mathrm{mL}^{-1}$ for POS, $2 \mu \mathrm{g} \cdot \mathrm{mL}^{-1}$ for NEG, and $50 \mu \mathrm{g} \cdot \mathrm{mL}^{-1}$ for MPC. After washing the cells with cold PBS, the fluorescence intensity of Cy3 within the cells was measured using flow cytometry with an excitation wavelength of $561 \mathrm{~nm}$. For the positive control, HeLa cells were cultured in DMEM for 1 hour and incubated with Cy3-labelled polymers for another 3 hours. For the blank group, HeLa cells were cultured in DMEM for 4 hours. The time scale for control groups of actin inhibitors 
were correspondingly adjusted. After subtracting the fluorescence signal from the blank group, Cy3 fluorescence of the positive control group was normalized as $100 \%$.

Confocal microscopy. A total of 80k RAW264.7 cells (less than 6 passages) were seeded into a glass bottom dish (Cellvis, \#D35C4-20-0-N) for 24 hours prior to the experiment. (a) To evaluate the effect of latrunculin A, cells were cultured for 30 minutes in DMEM containing latrunculin $A(1 \mu M)$. Subsequently, in the presence of inhibitors, the cells were incubated with Cy3-labelled amphiphilic polymers that spiked into the medium for additional 30 minutes. (b) To evaluate the effect of genistein, cells were cultured for 1 hour in DMEM containing genistein $(100 \mu \mathrm{M})$. Subsequently, in the presence of inhibitors, the cells were incubated with Cy3-labelled amphiphilic polymers that spiked into the medium for additional 3 hours. The final concentration of amphiphilic polymers was maintained at $100 \mu \mathrm{g} \cdot \mathrm{mL}^{-1}$ for PEG, $80 \mu \mathrm{g} \cdot \mathrm{mL}^{-1}$ for POS, $25 \mu \mathrm{g} \cdot \mathrm{mL}^{-1}$ for NEG, and $100 \mu \mathrm{g} \cdot \mathrm{mL}^{-1}$ for MPC. After washing with phosphate buffer saline, the cells were incubated with NucBlue (Hoechst 33342, 1 drop in $500 \mu \mathrm{L}$ medium) for 5 min in FluoroBrite DMEM at $37^{\circ} \mathrm{C}$ to stain the nucleus. The intracellular distribution measured by confocal microscopy with excitation wavelengths of $405 \mathrm{~nm}$ (Hoechst 33342) and $561 \mathrm{~nm}$ (Cy3-labelled polymers).

Actin filament staining. A total of 80k RAW264.7 cells (less than 6 passages) were seeded into a glass bottom dish (Cellvis, \#D35C4-20-0-N) for 24 hours prior to the experiment. To evaluate the effect of latrunculin A, cells were cultured for 60 minutes in DMEM containing latrunculin $A(1 \mu M)$. After washing with PBS, the cells were fixed with fixation/permeabilization solution (BD Biosciences, Cat\# 554714) at room temperature for 15 minutes. The cells were washed with PBS and stained with phalloidin-iFluor 488 working solution (diluted from 1000x into $1 \times$ with PBS that contains 1\% FBS, Abcam, Cat\# ab176753) at room temperature for 90 minutes. The cells were washed with PBS and incubated with NucBlue (Hoechst 33342, 1 drop in $500 \mu \mathrm{L}$ medium) for $5 \mathrm{~min}$ in FluoroBrite DMEM at $37^{\circ} \mathrm{C}$ to stain the nucleus. The 
intracellular distribution of nucleus and actin filaments was measured by confocal microscopy with excitation wavelengths of $405 \mathrm{~nm}$ (Hoechst 33342) and $488 \mathrm{~nm}$ (phalloidin-iFluor 488). 


\section{Spectral data}

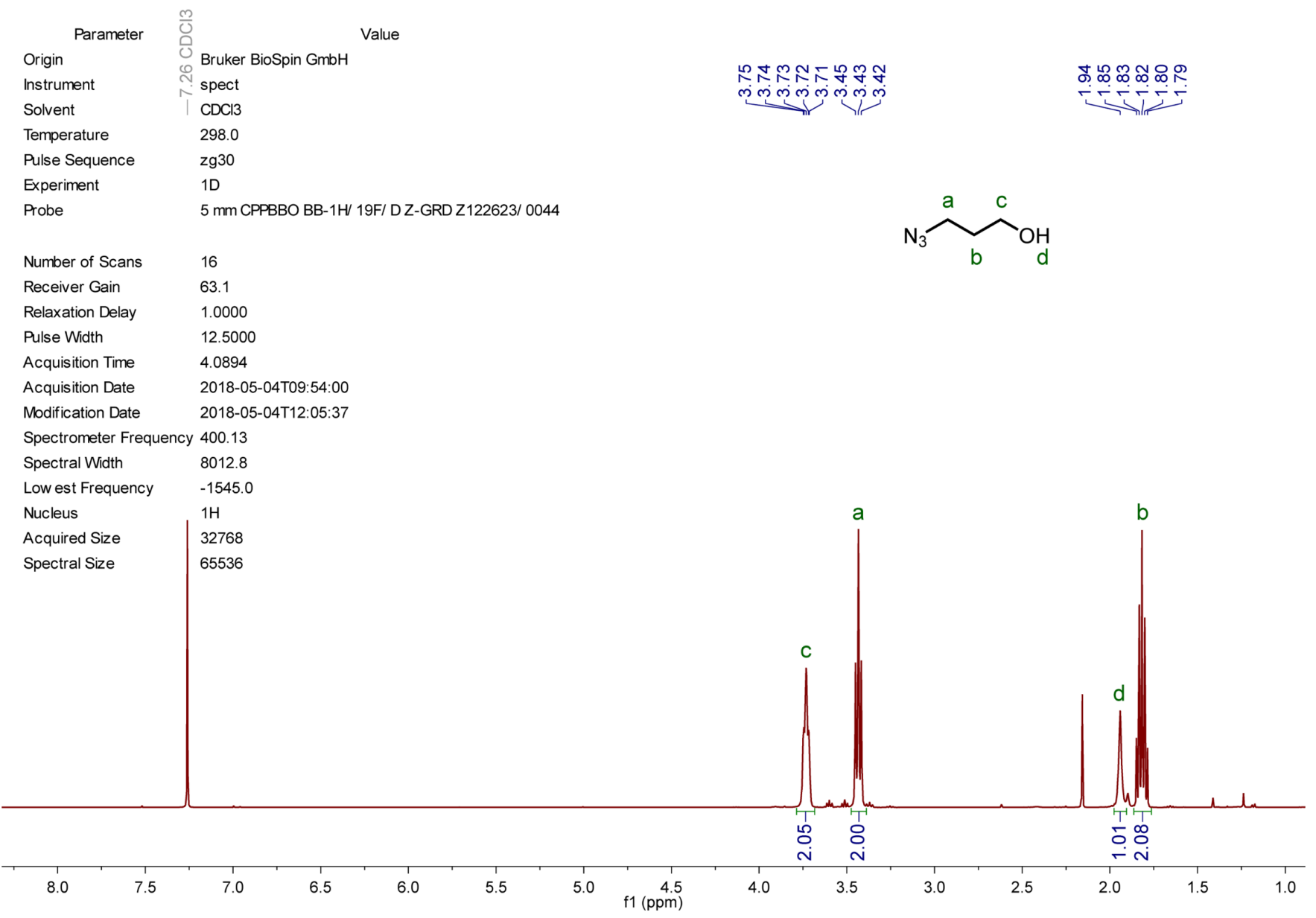

Figure SP1. ${ }^{1} \mathrm{H}$ NMR spectrum (400 MHz) of 3-azido-1-propanol in $\mathrm{CDCl}_{3}$. 


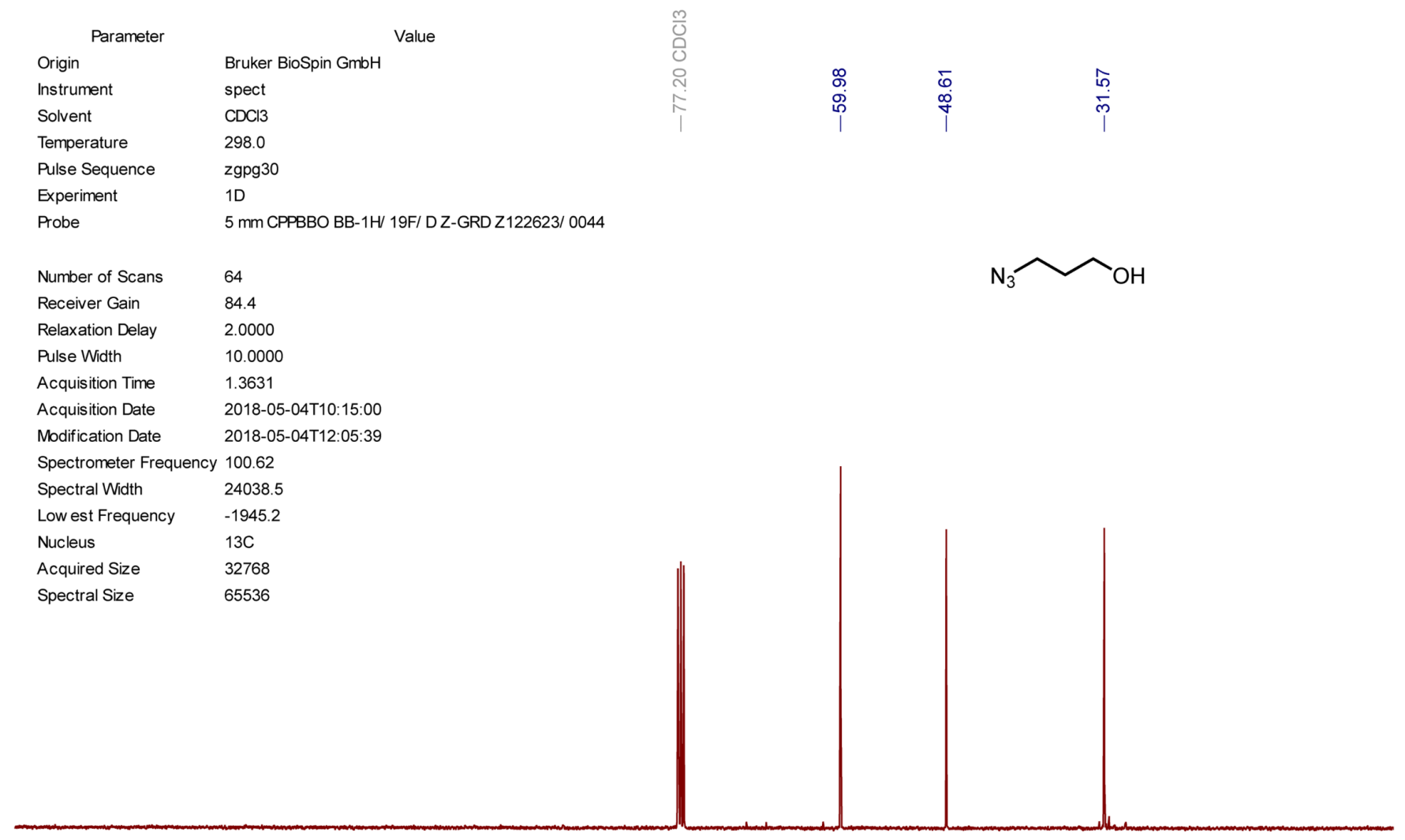

$\begin{array}{lllllllllllllllllllllllllllllllll}145 & 140 & 135 & 130 & 125 & 120 & 115 & 110 & 105 & 100 & 95 & 90 & 85 & 80 & 75 & 70 & 65 & 60 & 55 & 50 & 45 & 40 & 35 & 30 & 25 & 20 & 15 & 10 & 5 & \end{array}$

Figure SP2. ${ }^{13} \mathrm{C}$ NMR spectrum (100 MHz) of 3-azido-1-propanol in $\mathrm{CDCl}_{3}$. 


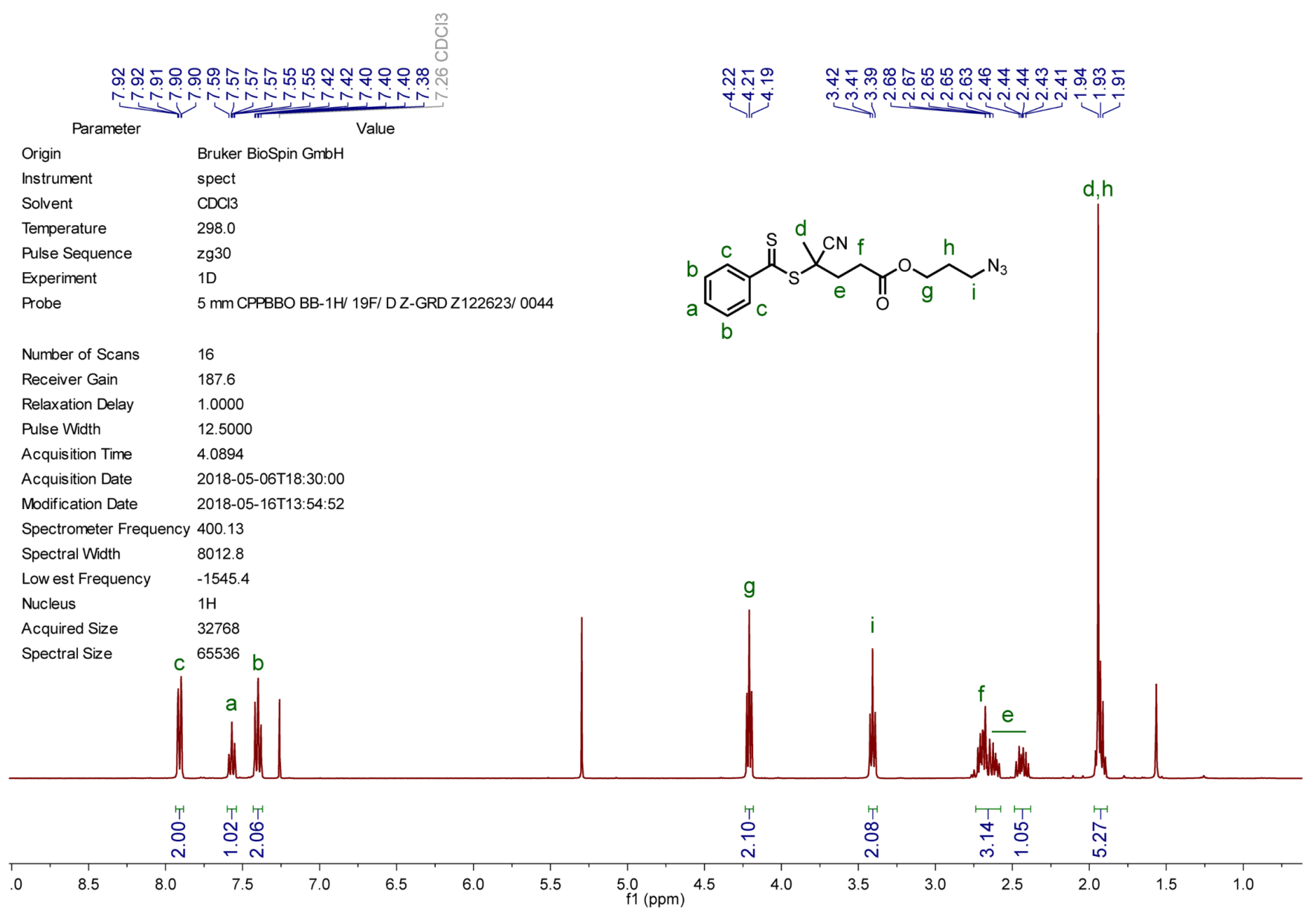

Figure SP3. ${ }^{1} \mathrm{H}$ NMR spectrum (400 MHz) of Az-CTAP in $\mathrm{CDCl}_{3}$. 


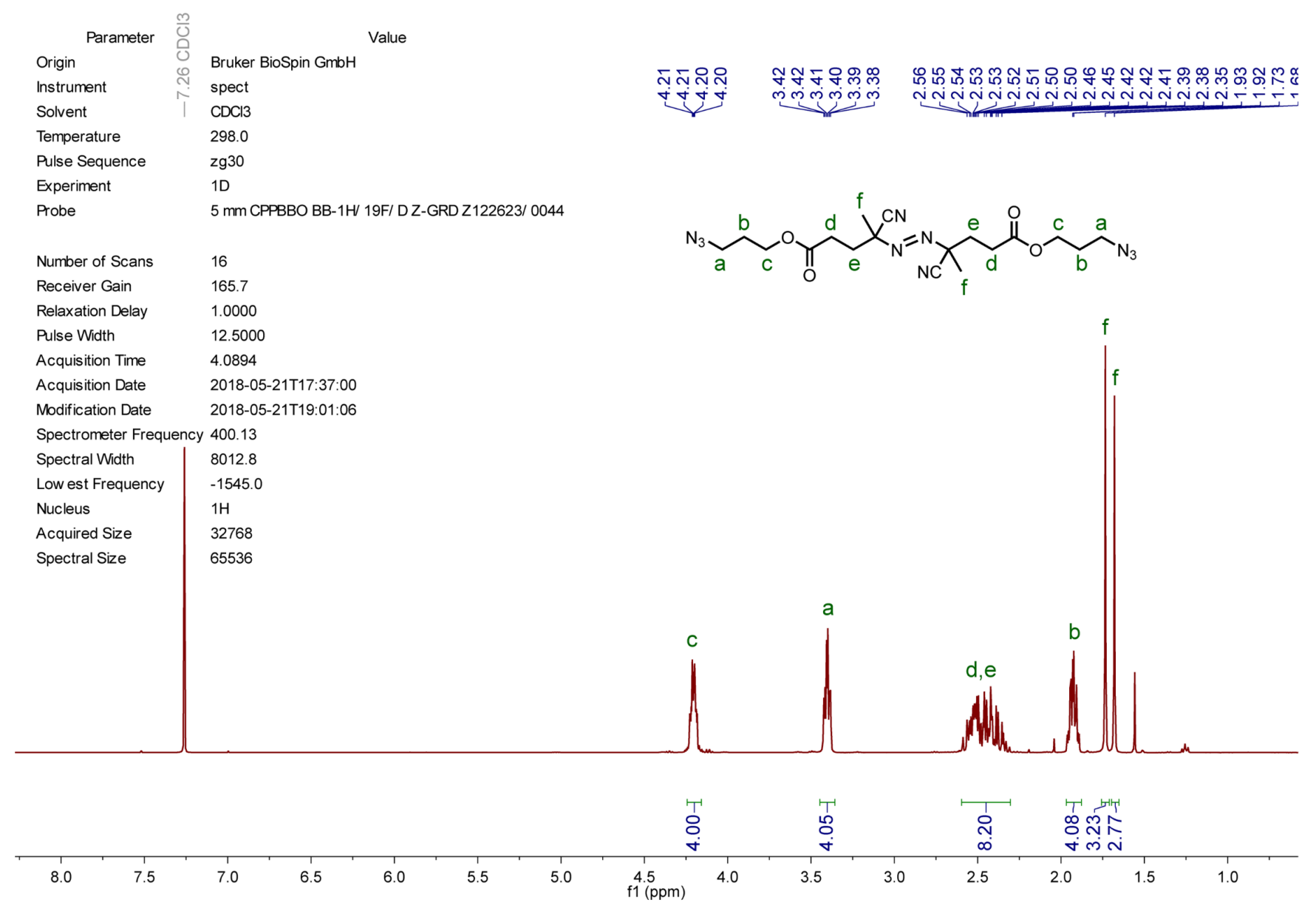

Figure SP4. ${ }^{1} \mathrm{H}$ NMR spectrum (400 MHz) of Az-ACVA in $\mathrm{CDCl}_{3}$. 


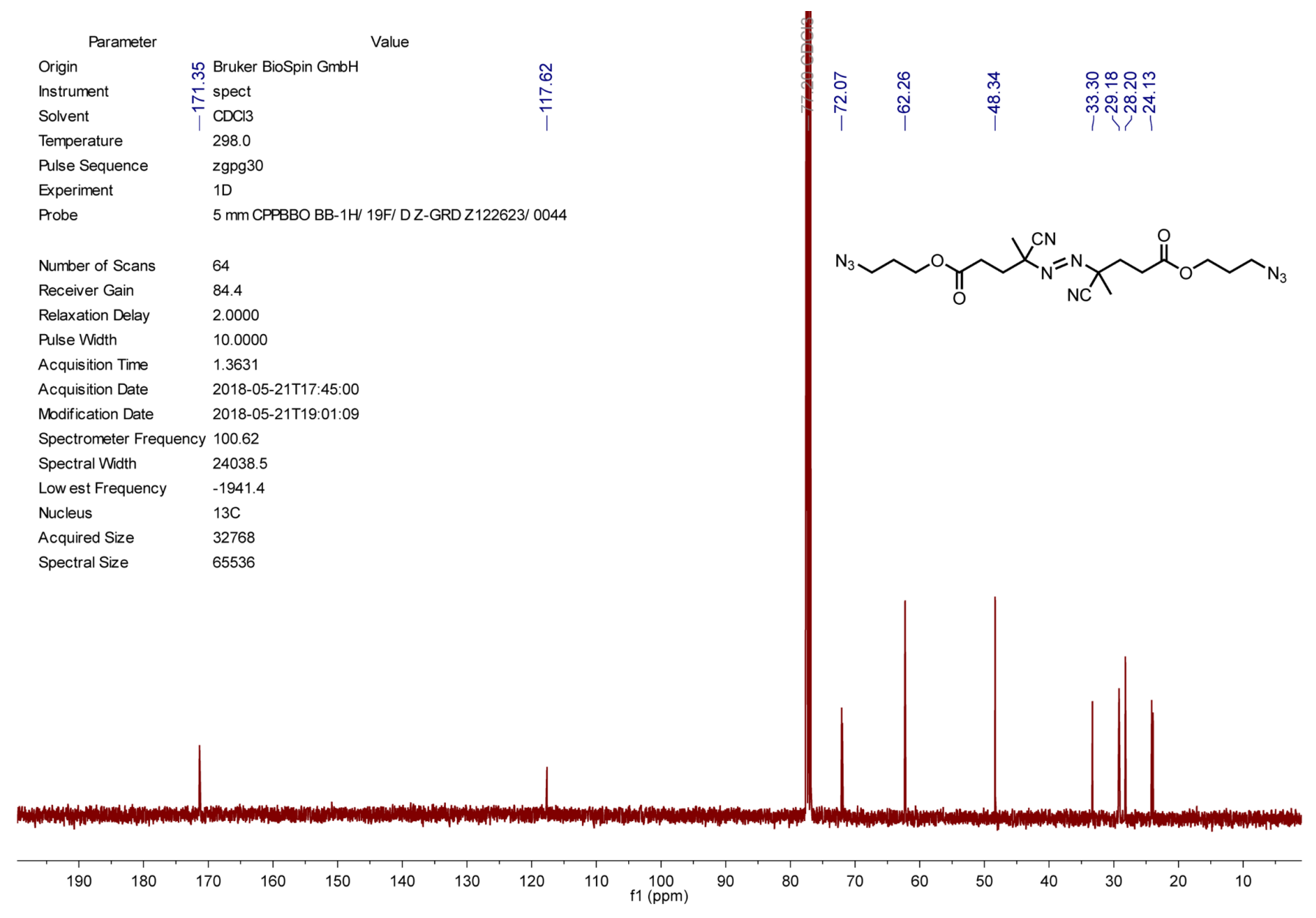

Figure SP5. ${ }^{13} \mathrm{C}$ NMR spectrum $(100 \mathrm{MHz})$ of Az-ACVA in $\mathrm{CDCl}_{3}$. 


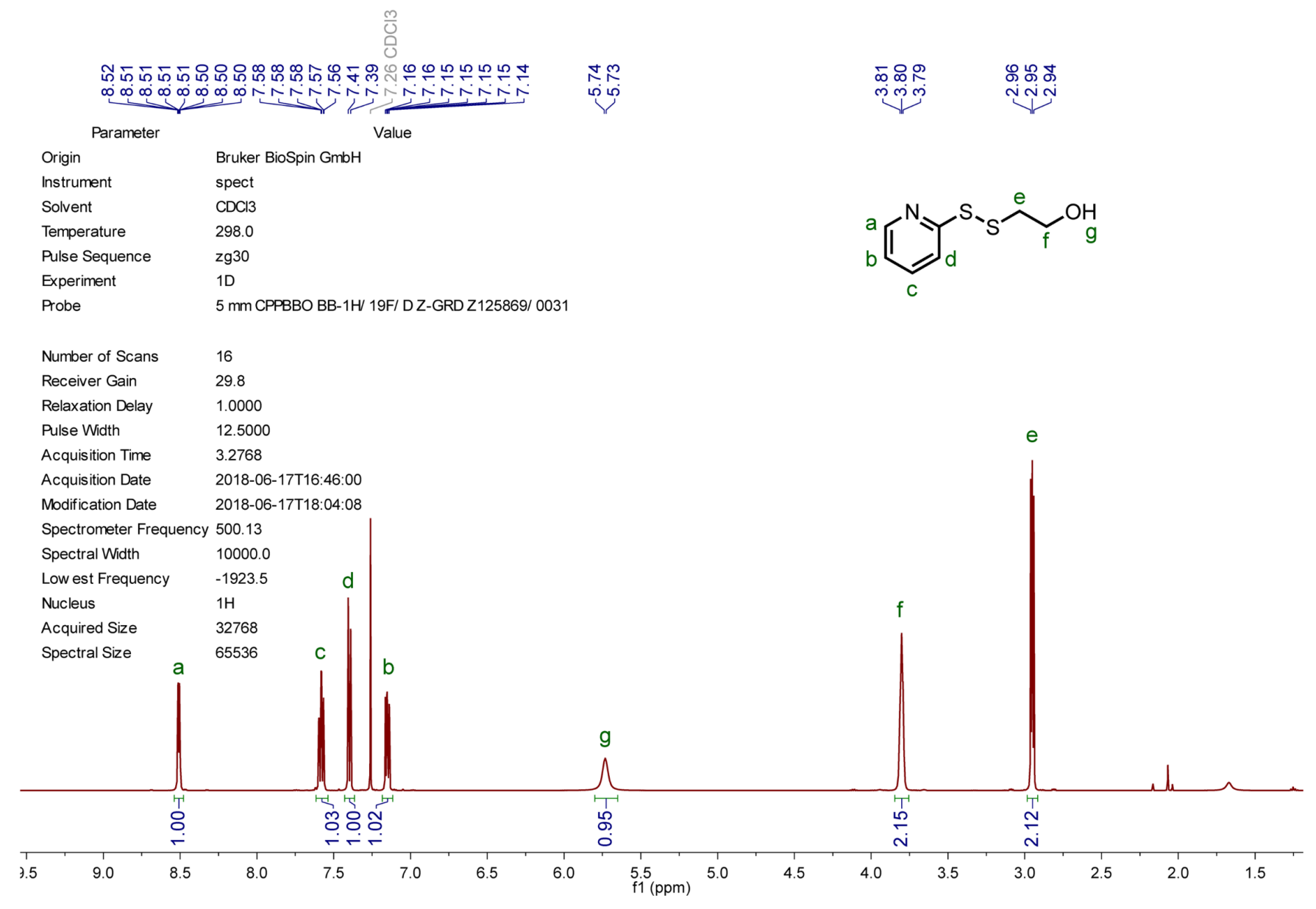

Figure SP6. ${ }^{1} \mathrm{H}$ NMR spectrum (400 MHz) of 2-(pyridin-2-yldisulfanyl)ethanol in $\mathrm{CDCl}_{3}$. 


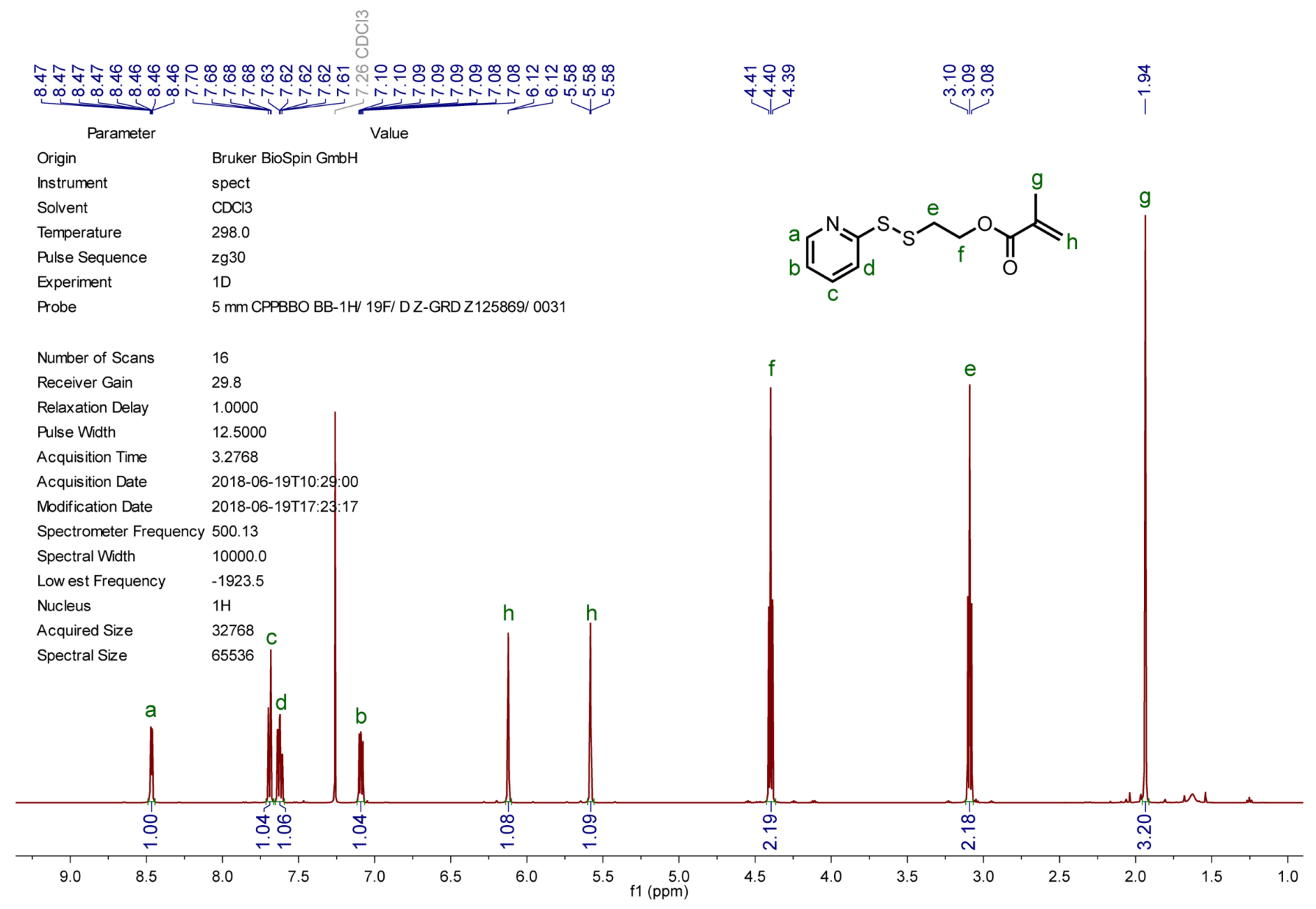

Figure SP7. ${ }^{1} \mathrm{H}$ NMR spectrum $(500 \mathrm{MHz})$ of pyridyl disulfide ethyl methacrylate in $\mathrm{CDCl}_{3}$. 


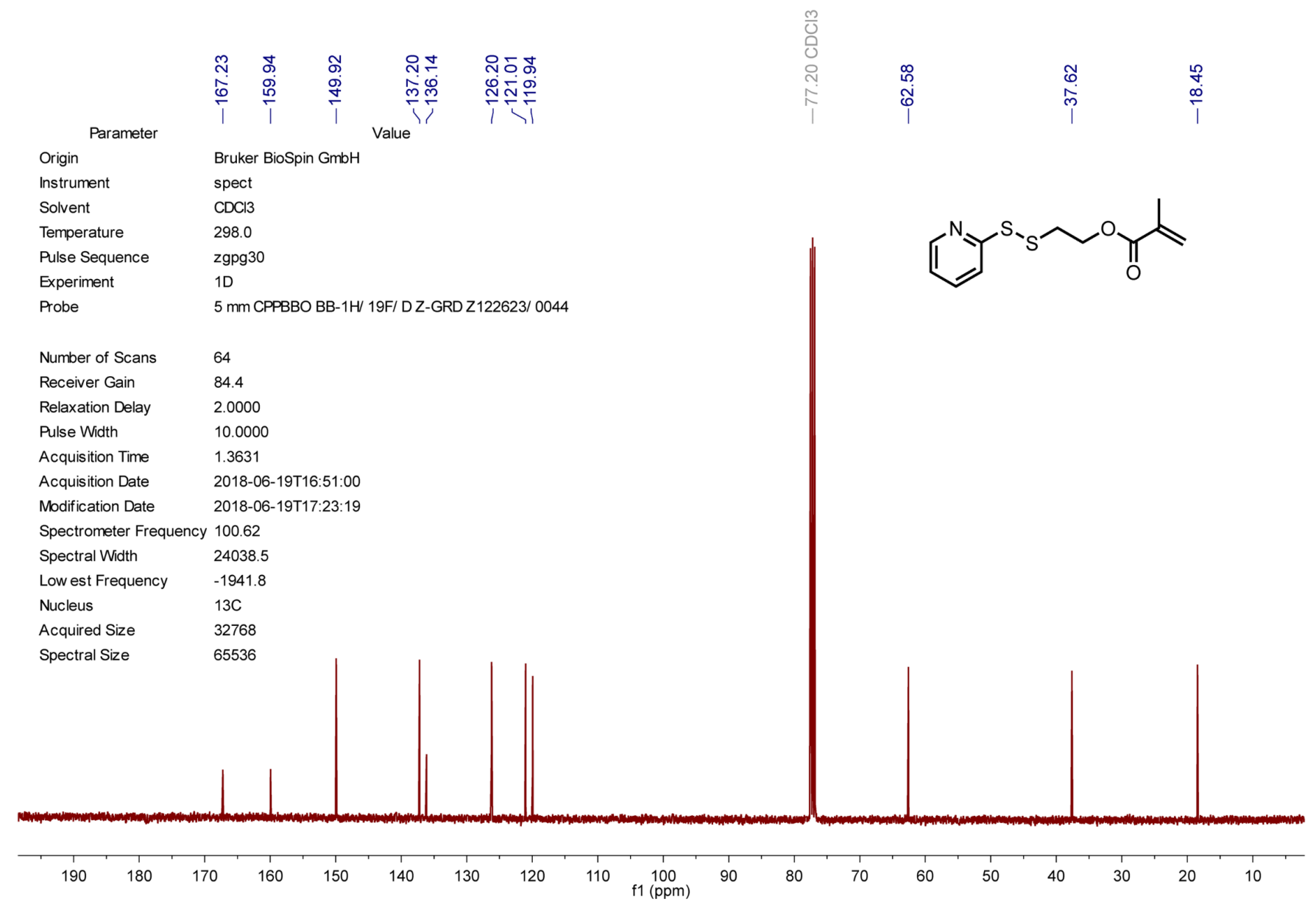

Figure SP8. ${ }^{13} \mathrm{C}$ NMR spectrum $\left(100 \mathrm{MHz}\right.$ ) of pyridyl disulfide ethyl methacrylate in $\mathrm{CDCl}_{3}$. 


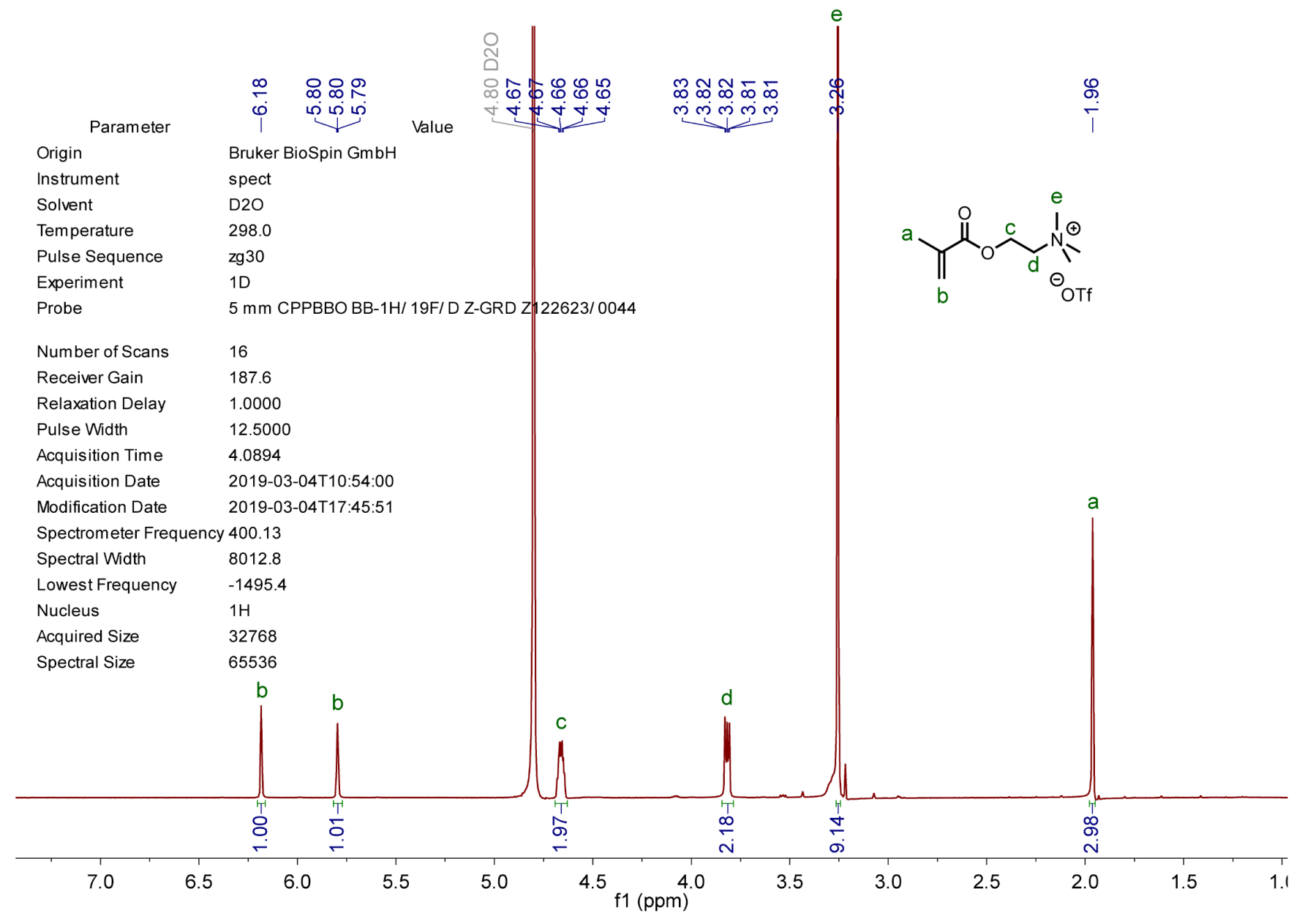

Figure SP9. ${ }^{1} \mathrm{H}$ NMR spectrum $(400 \mathrm{MHz})$ of 2-(methacryloyloxy)ethyltrimethylammonium triflate in $\mathrm{D}_{2} \mathrm{O}$. 


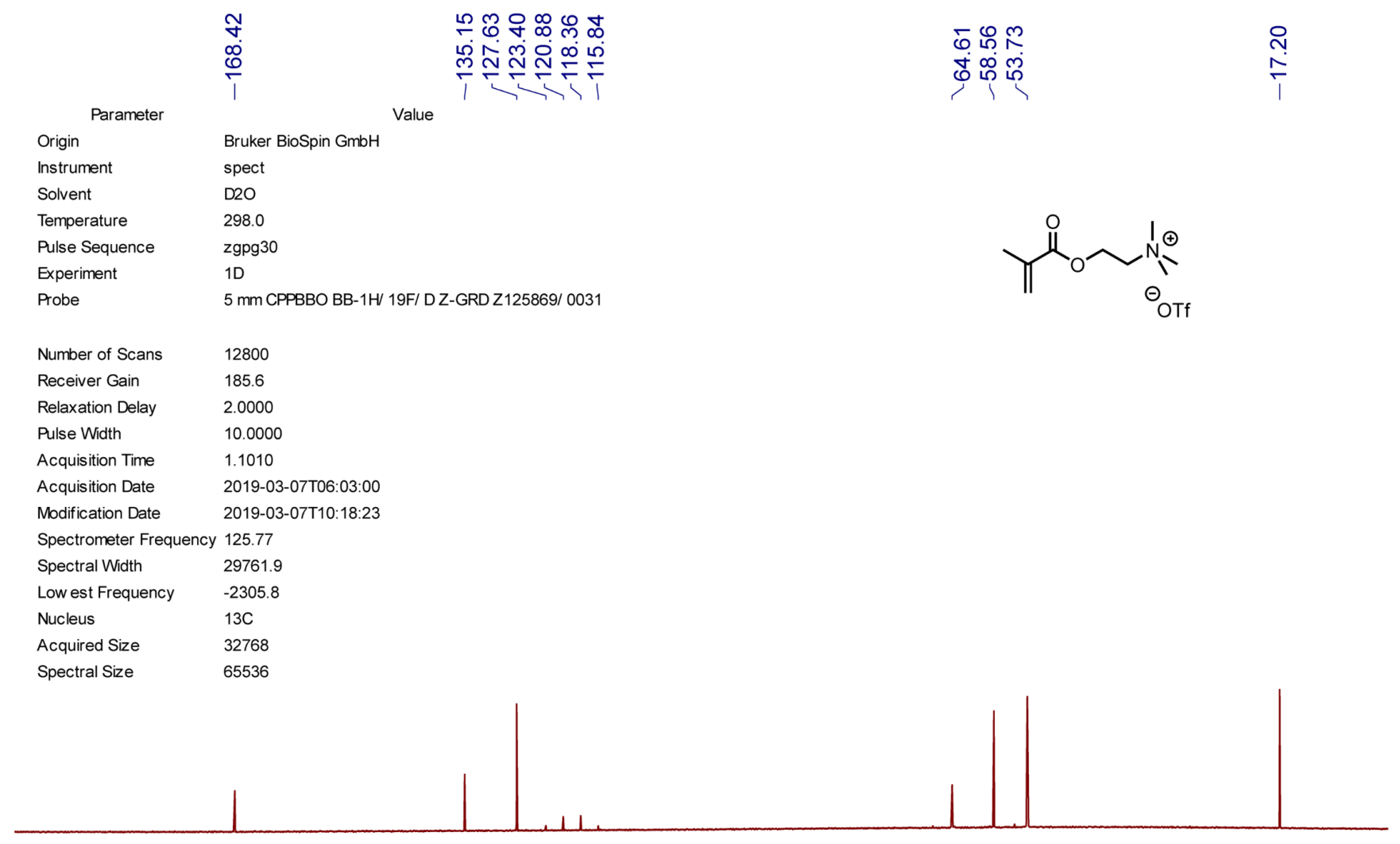

\begin{tabular}{|c|c|c|c|c|c|c|c|c|c|c|c|c|c|c|c|c|c|c|c|}
\hline 30 & 190 & 180 & 170 & 160 & 150 & 140 & 130 & 120 & $110_{f}$ & $\begin{array}{c}100 \\
(\mathrm{ppm})\end{array}$ & 90 & 80 & 70 & 60 & 50 & 40 & 30 & 20 & 10 \\
\hline
\end{tabular}

Figure SP10. ${ }^{13} \mathrm{C}$ NMR spectrum $(125 \mathrm{MHz})$ of 2-(methacryloyloxy)ethyltrimethylammonium triflate in $\mathrm{D}_{2} \mathrm{O}$. 


\begin{tabular}{ll}
\multicolumn{1}{c}{ Parameter } & \multicolumn{1}{c}{ Value } \\
Origin & Bruker BioSpin GmbH \\
Instrument & spect \\
Solvent & D2O \\
Temperature & 298.0 \\
Pulse Sequence & zgflqn \\
Experiment & $1 \mathrm{D}$ \\
Probe & 5 mm CPPBBO BB-1H/ 19F/ D Z-GRD Z122623/ 0044 \\
& \\
Number of Scans & 32 \\
Receiver Gain & 5.1 \\
Relaxation Delay & 2.0000 \\
Pulse Width & 15.0000 \\
Acquisition Time & 1.1010 \\
Acquisition Date & $2019-03-04 T 11: 18: 00$ \\
Modification Date & $2019-03-04 T 17: 45: 56$ \\
Spectrometer Frequency & 376.47 \\
Spectral Width & 59523.8 \\
Low est Frequency & -53869.9 \\
Nucleus & $19 \mathrm{~F}$ \\
Acquired Size & 65536 \\
Spectral Size & 131072 \\
& \\
&
\end{tabular}

$\begin{array}{llllllllllllllllllllllll} & 0 & -5 & -10 & -15 & -20 & -25 & -30 & -35 & -40 & -45 & \begin{array}{c}1 \\ (\mathrm{ppm})\end{array} & -55 & -60 & -65 & -70 & -75 & -80 & -85 & -90 & -95 & \end{array}$

Figure SP11. ${ }^{19} \mathrm{~F}$ NMR spectrum $(376 \mathrm{MHz})$ of 2-(methacryloyloxy)ethyltrimethylammonium triflate in $\mathrm{D}_{2} \mathrm{O}$. 


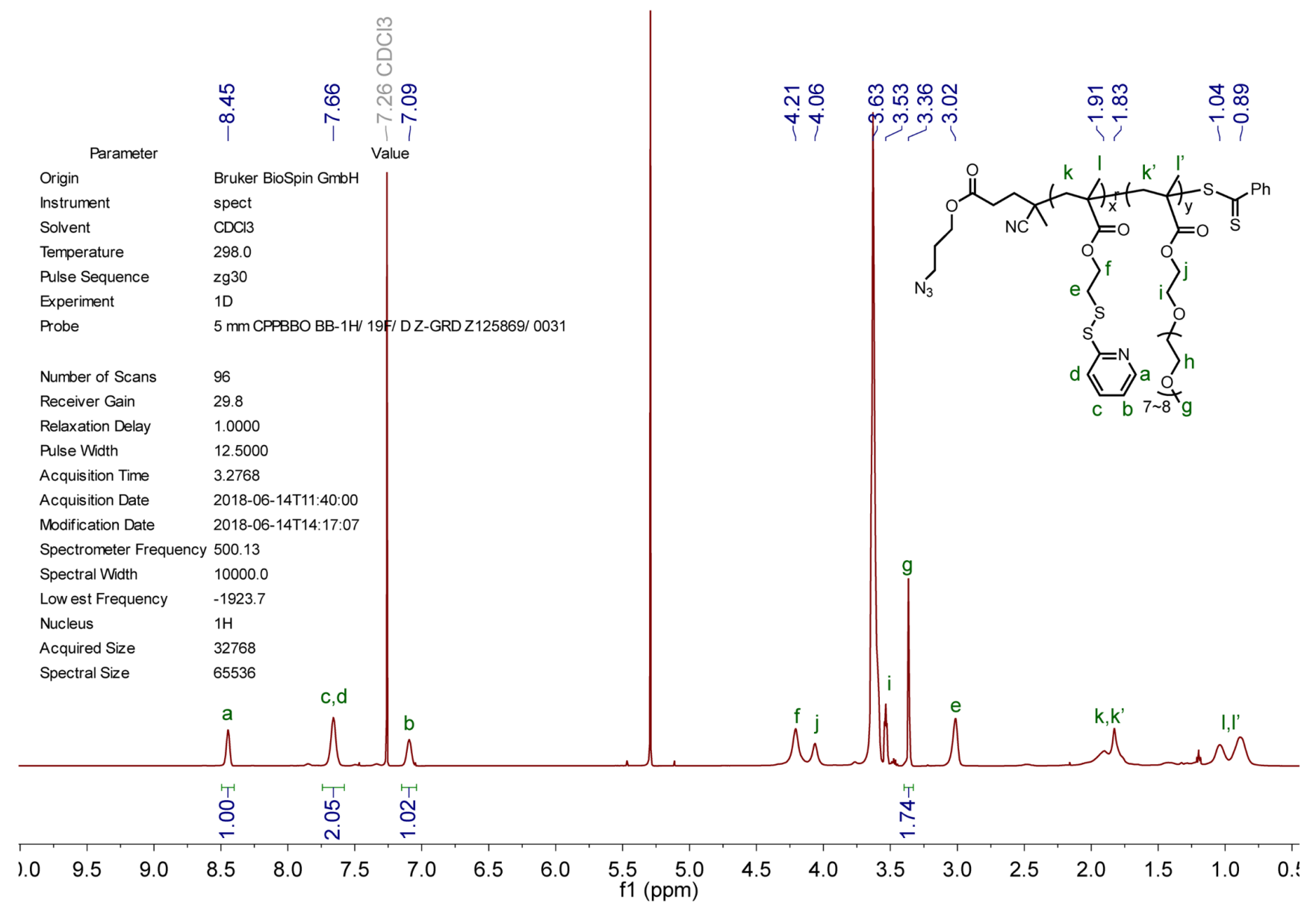

Figure SP12. ${ }^{1} \mathrm{H}$ NMR spectrum $(500 \mathrm{MHz})$ of PEG in $\mathrm{CDCl}_{3}$. 


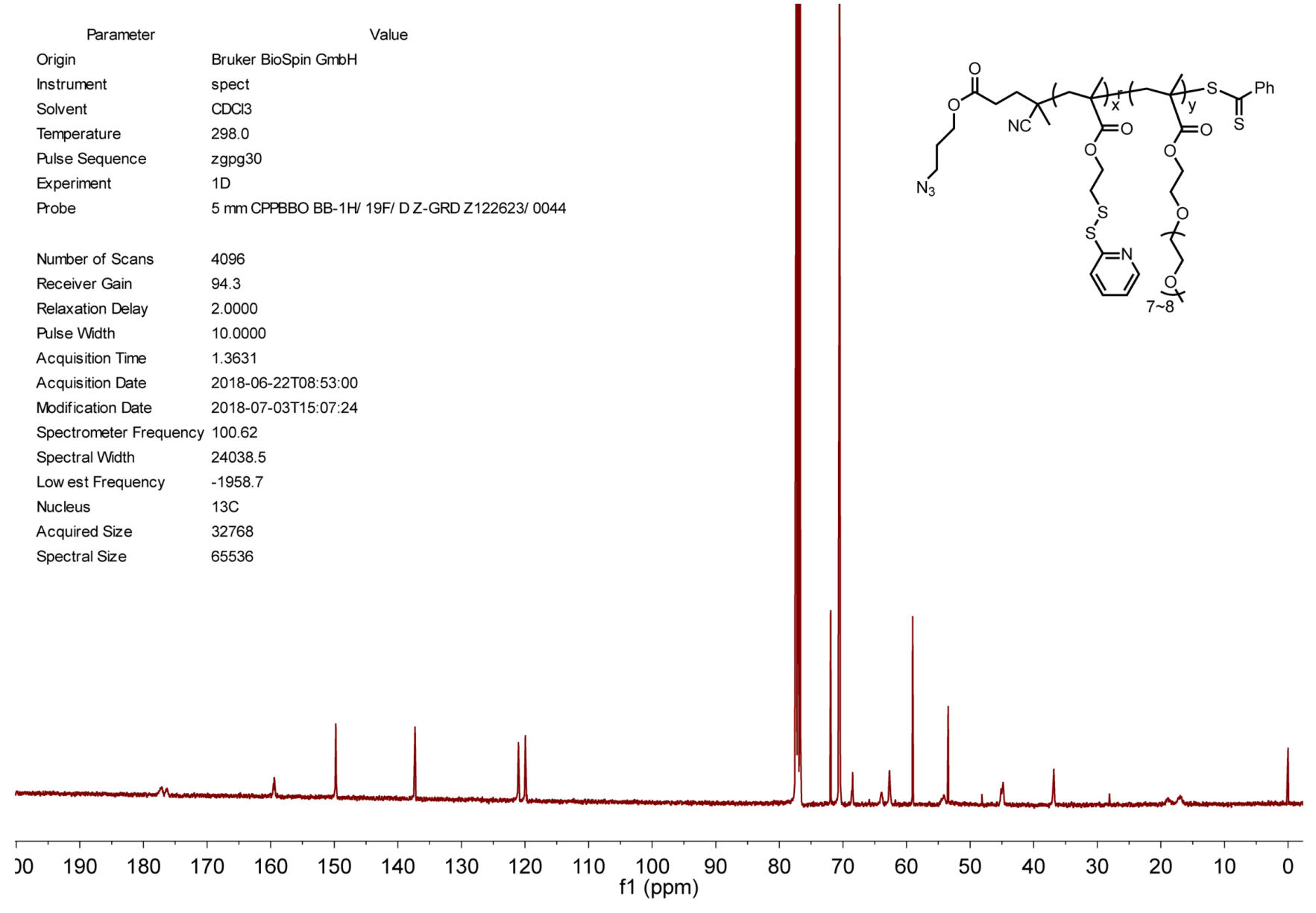

Figure SP13. ${ }^{13} \mathrm{C}$ NMR spectrum $(100 \mathrm{MHz})$ of PEG in $\mathrm{CDCl}_{3}$. 


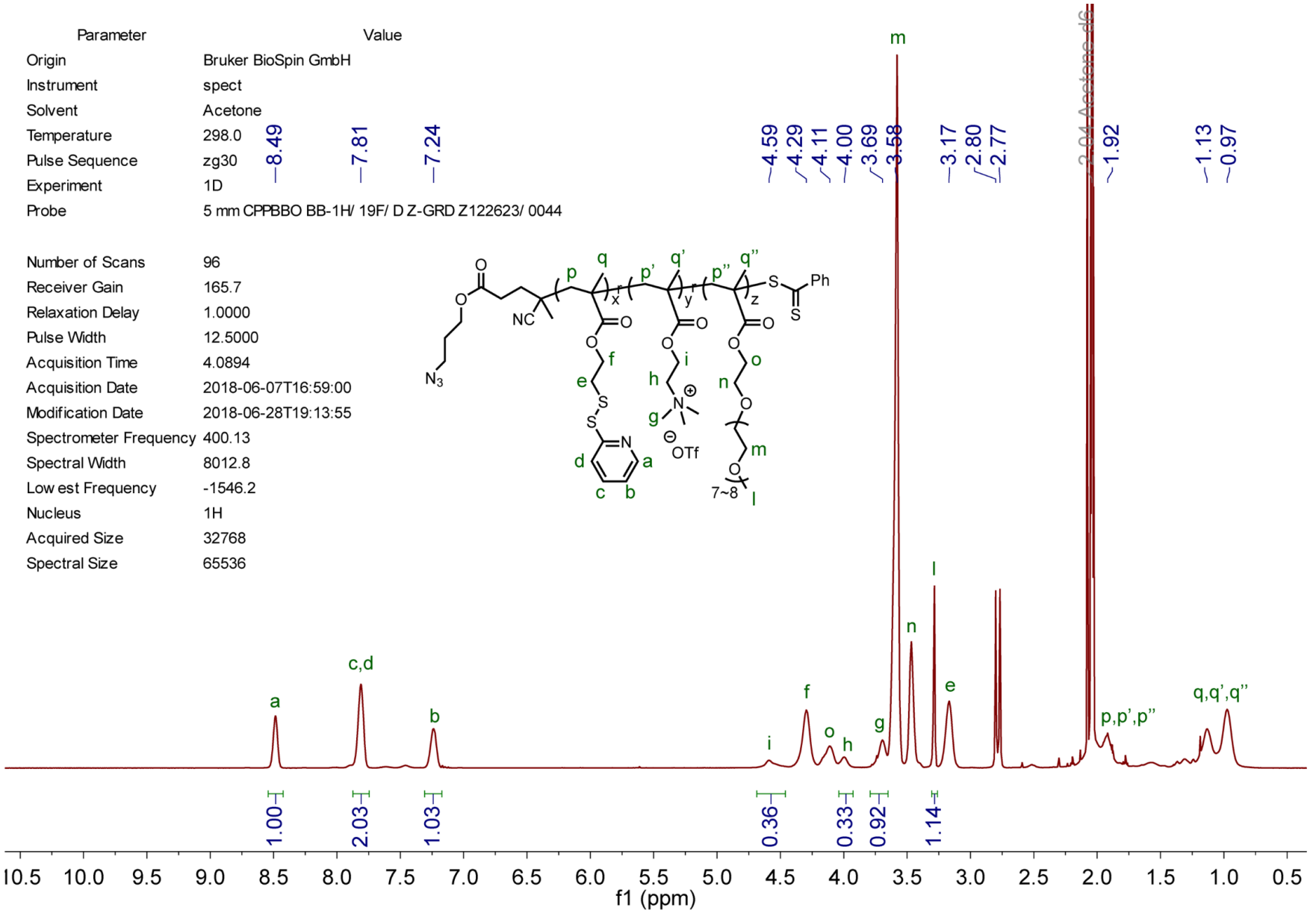

Figure SP14. ${ }^{1} \mathrm{H}$ NMR spectrum $(400 \mathrm{MHz})$ of POS in acetone- $d_{6}$. 


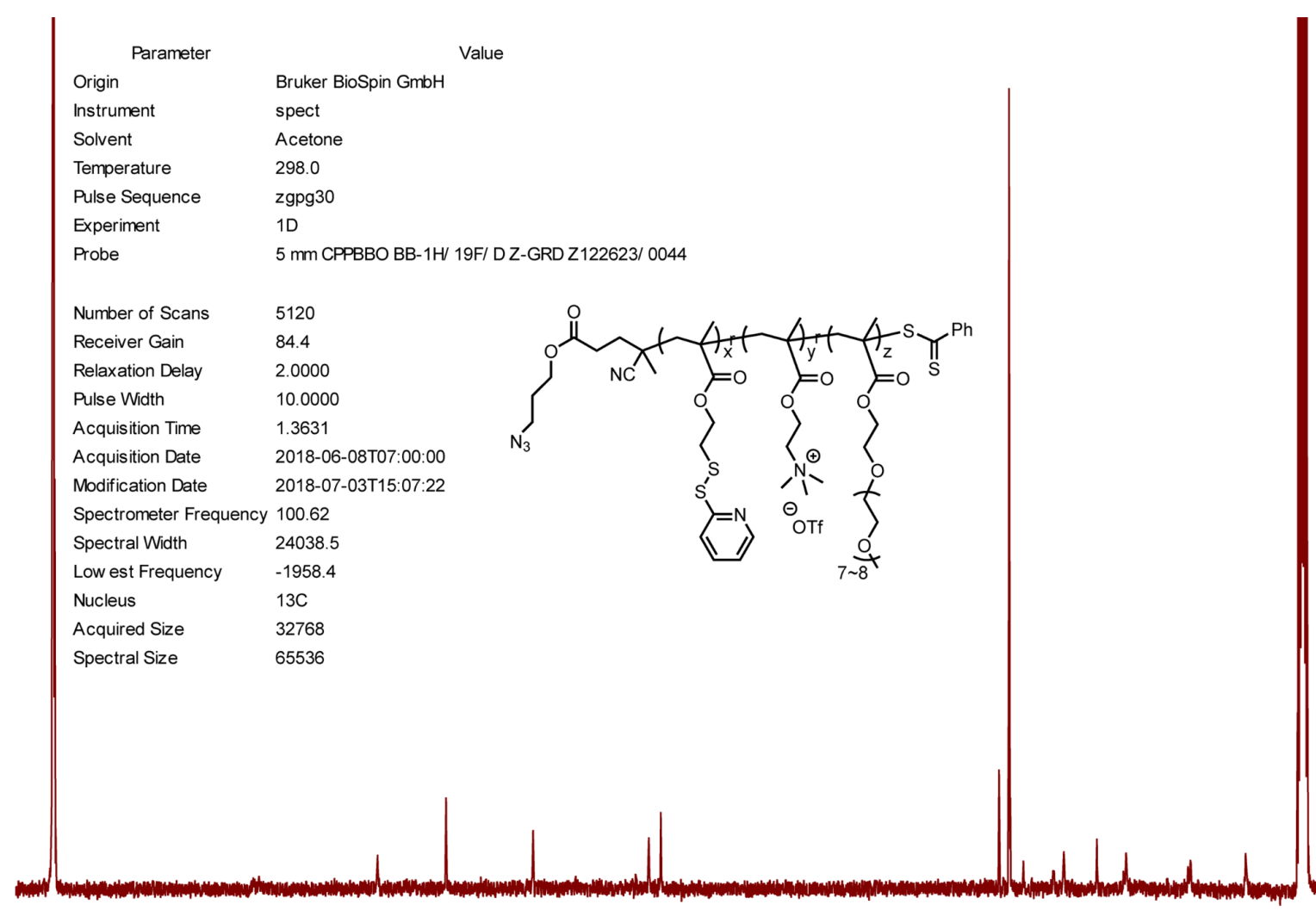

$\begin{array}{llllllllllllllllllllll}10 & 200 & 190 & 180 & 170 & 160 & 150 & 140 & 130 & 120 & \begin{array}{l}110 \\ \mathrm{f} 1(\mathrm{ppm})\end{array} & 100 & 90 & 70 & 60 & 50 & 40 & 30 & 20 & 10\end{array}$

Figure SP15. ${ }^{13} \mathrm{C}$ NMR spectrum $(100 \mathrm{MHz})$ of POS in acetone- $d_{6}$. 


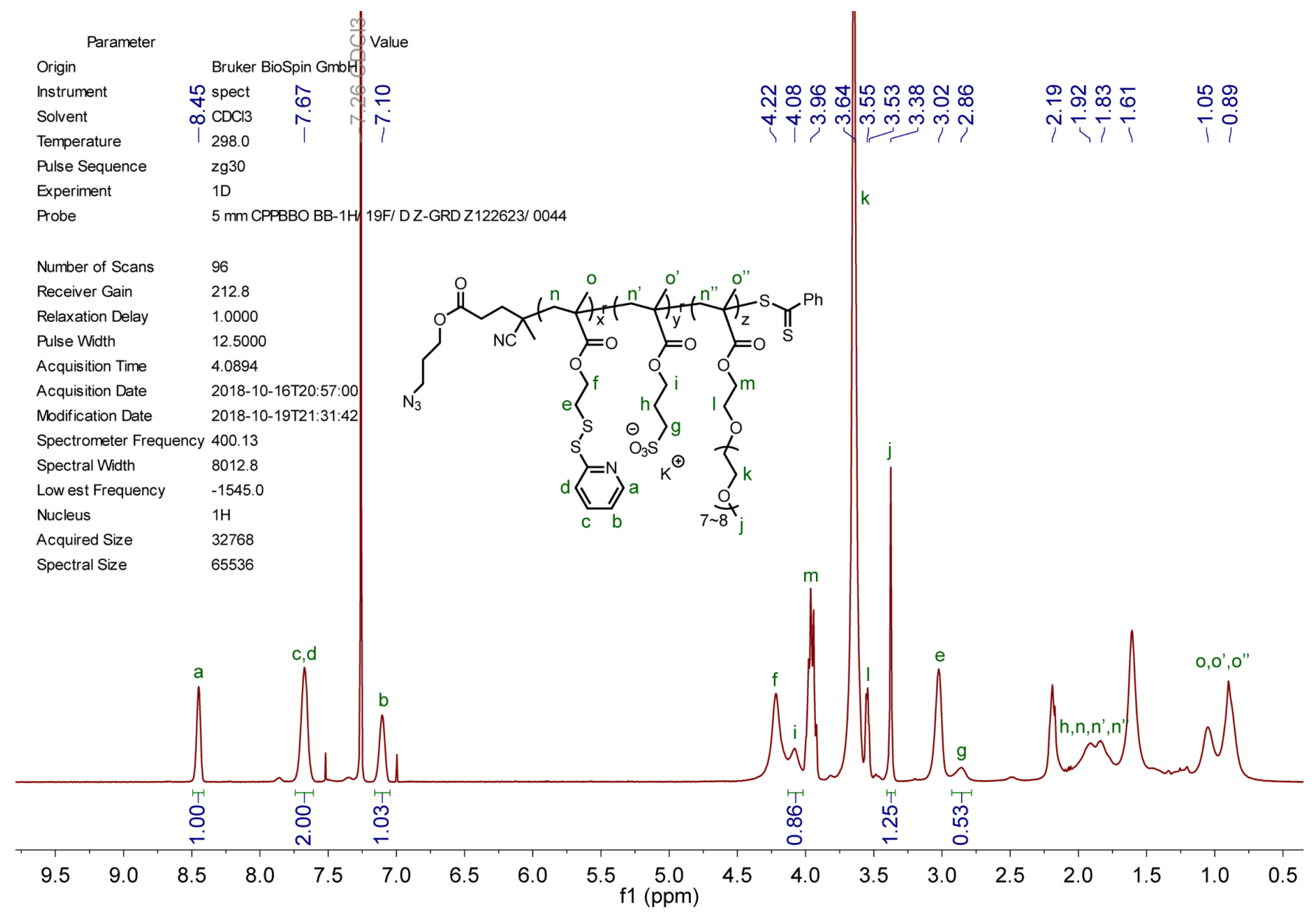

Figure SP16. ${ }^{1} \mathrm{H}$ NMR spectrum $(400 \mathrm{MHz})$ of $\mathrm{NEG}$ in $\mathrm{CDCl}_{3}$. 


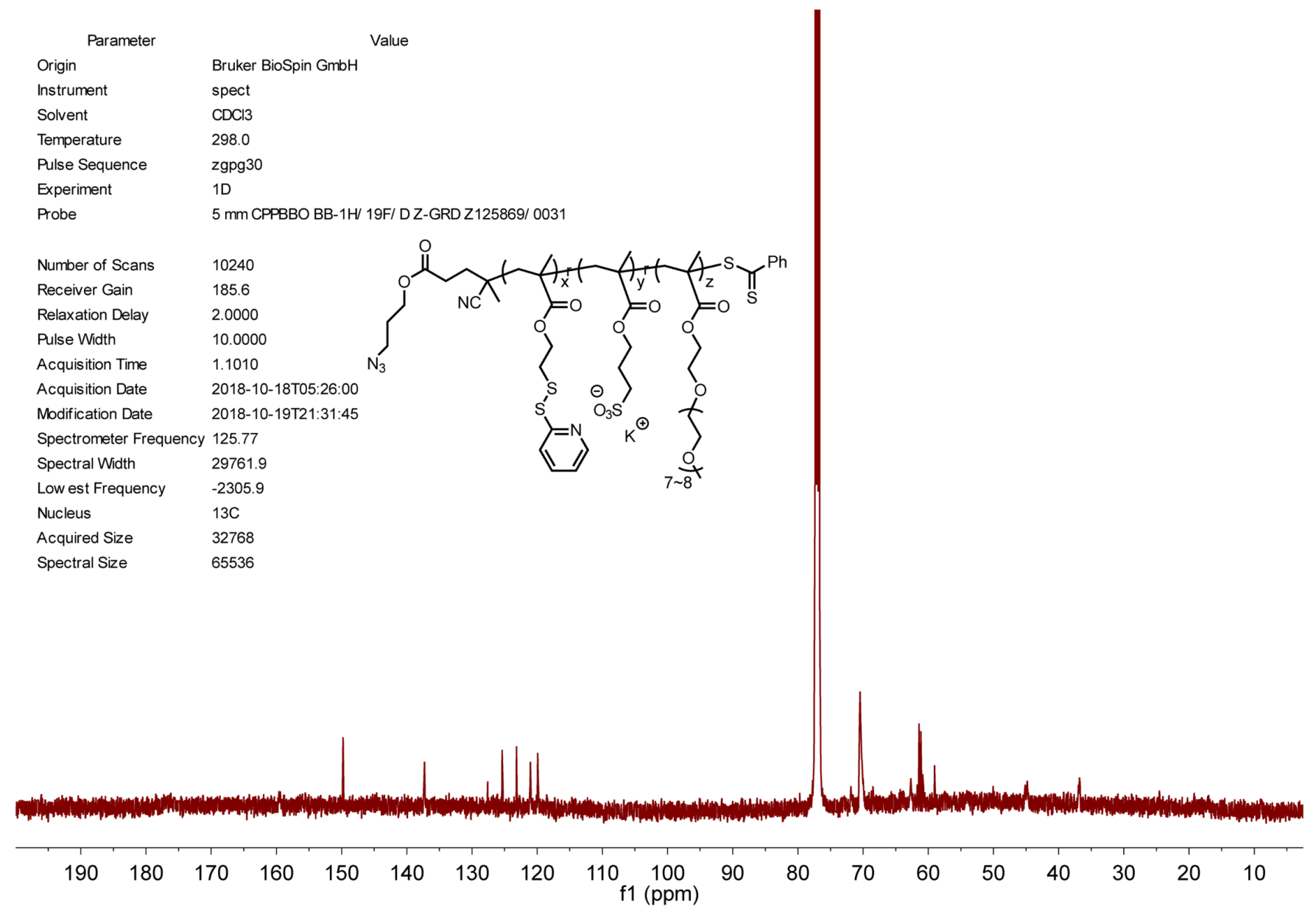

Figure SP17. ${ }^{13} \mathrm{C}$ NMR spectrum (125 MHz) of NEG in $\mathrm{CDCl}_{3}$. 


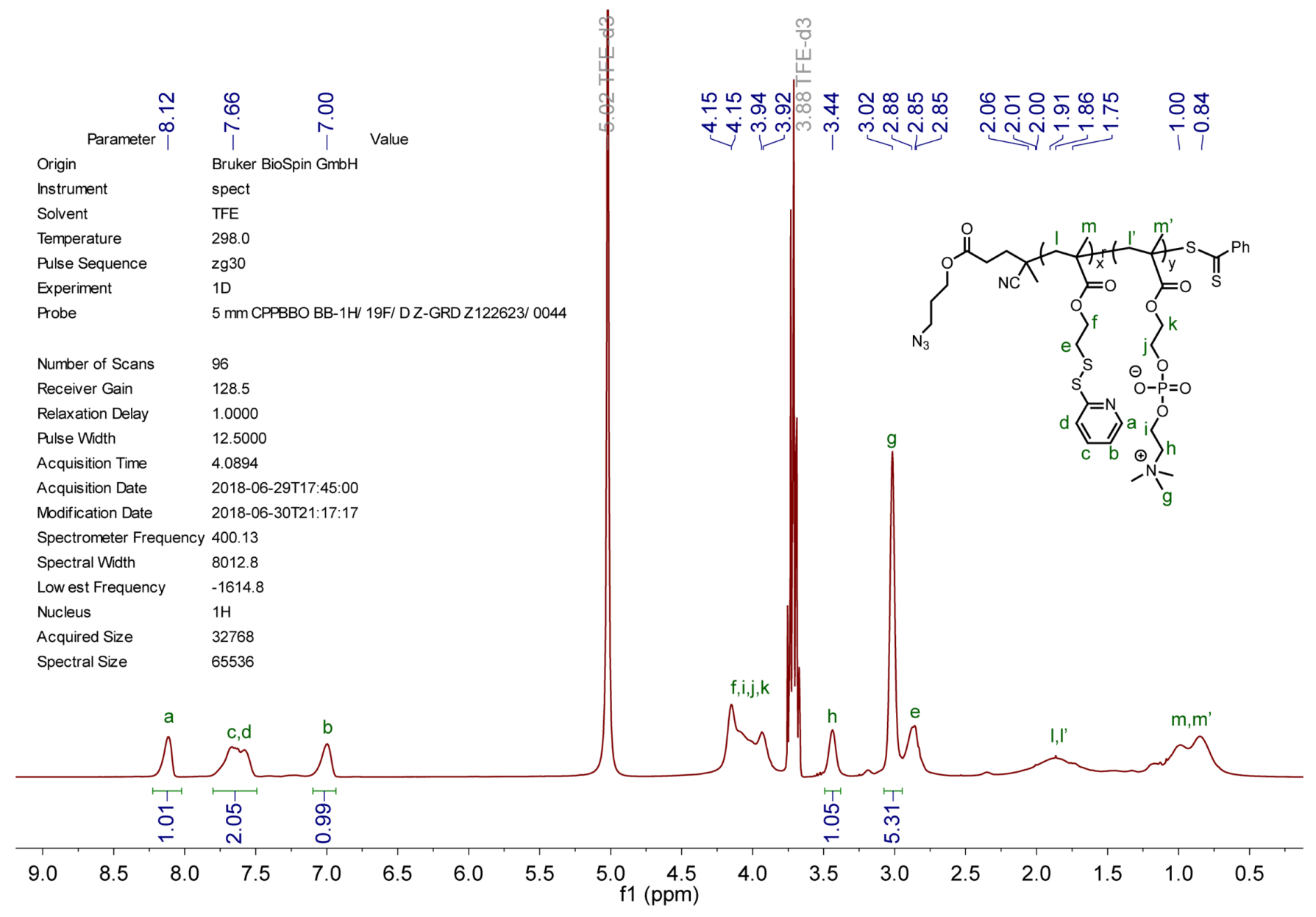

Figure SP18. ${ }^{1} \mathrm{H}$ NMR spectrum $(400 \mathrm{MHz})$ of MPC in trifluoroethanol- $d_{3}$. 


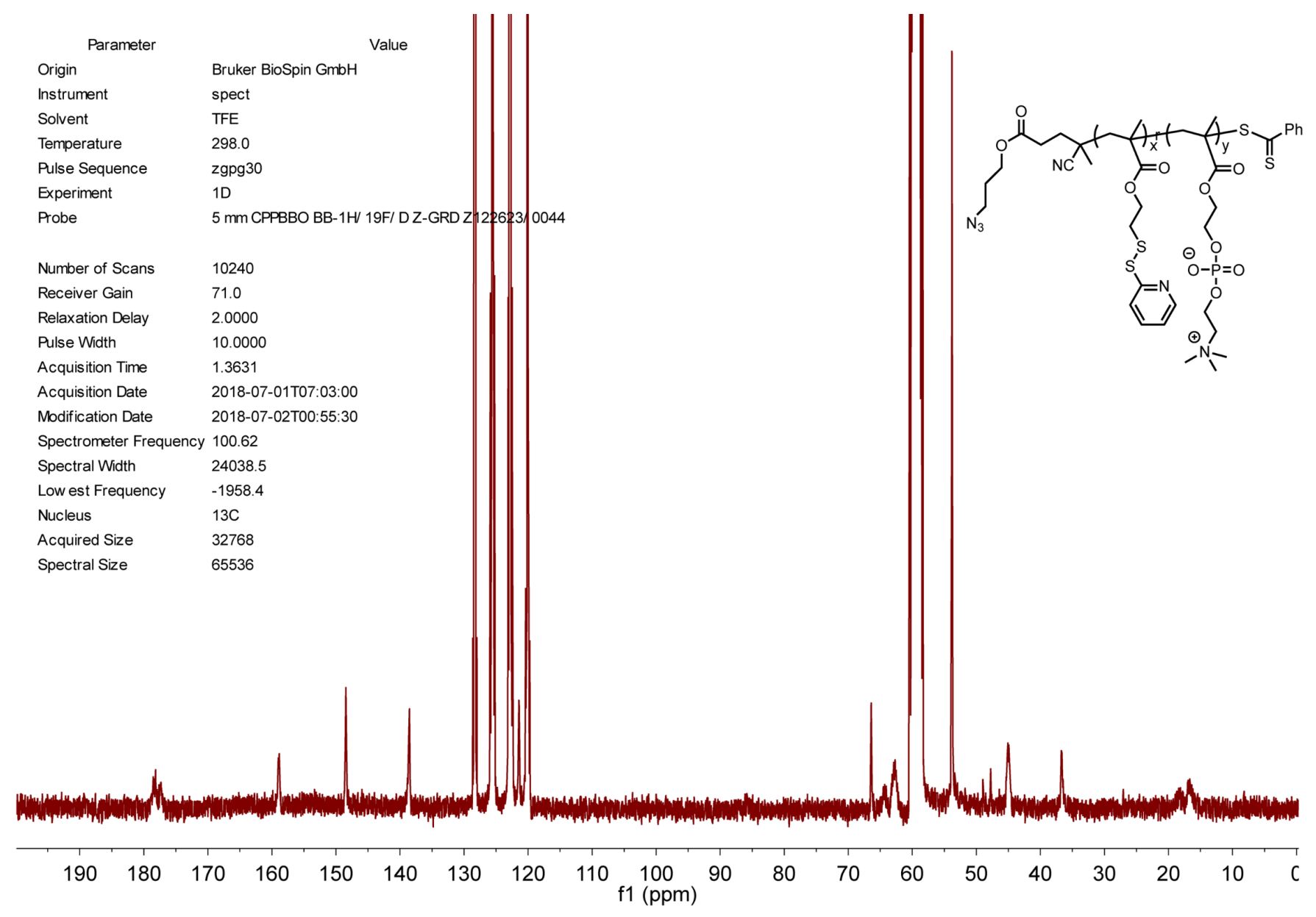

Figure SP19. ${ }^{13} \mathrm{C}$ NMR spectrum $(100 \mathrm{MHz})$ of MPC in trifluoroethanol- $d_{3}$. 


\begin{tabular}{|c|c|}
\hline Parameter & Value \\
\hline Origin & Bruker BioSpin GmbH \\
\hline Instrument & spect \\
\hline Solvent & TFE \\
\hline Temperature & 298.0 \\
\hline Pulse Sequence & zgpg30 \\
\hline Experiment & $1 \mathrm{D}$ \\
\hline Probe & 5 mm CPPBBO BB-1H/ 19F/ D Z-GRD Z122623/ 0044 \\
\hline Number of Scans & 5120 \\
\hline Receiver Gain & 103.2 \\
\hline Relaxation Delay & 2.0000 \\
\hline Pulse Width & 12.0000 \\
\hline Acquisition Time & 0.5112 \\
\hline Acquisition Date & 2018-06-30T17:16:00 \\
\hline Modification Date & 2018-06-30T21:17:23 \\
\hline Spectrometer Frequency & 161.97 \\
\hline Spectral Width & 64102.6 \\
\hline Low est Frequency & -40150.1 \\
\hline Nucleus & $31 \mathrm{P}$ \\
\hline Acquired Size & 32768 \\
\hline Spectral Size & 65536 \\
\hline
\end{tabular}

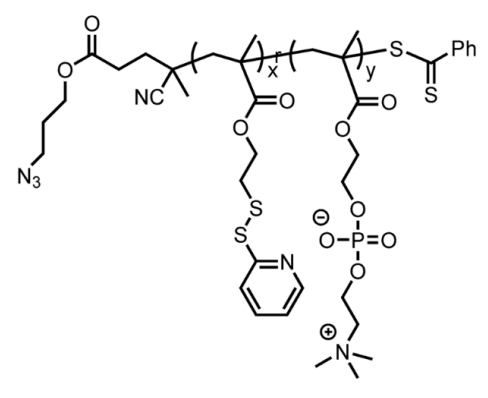

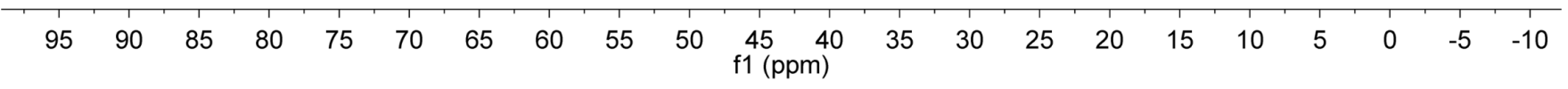

Figure SP20. ${ }^{31} \mathrm{P}$ NMR spectrum $(161 \mathrm{MHz})$ of MPC in trifluoroethanol- $d_{3}$. 

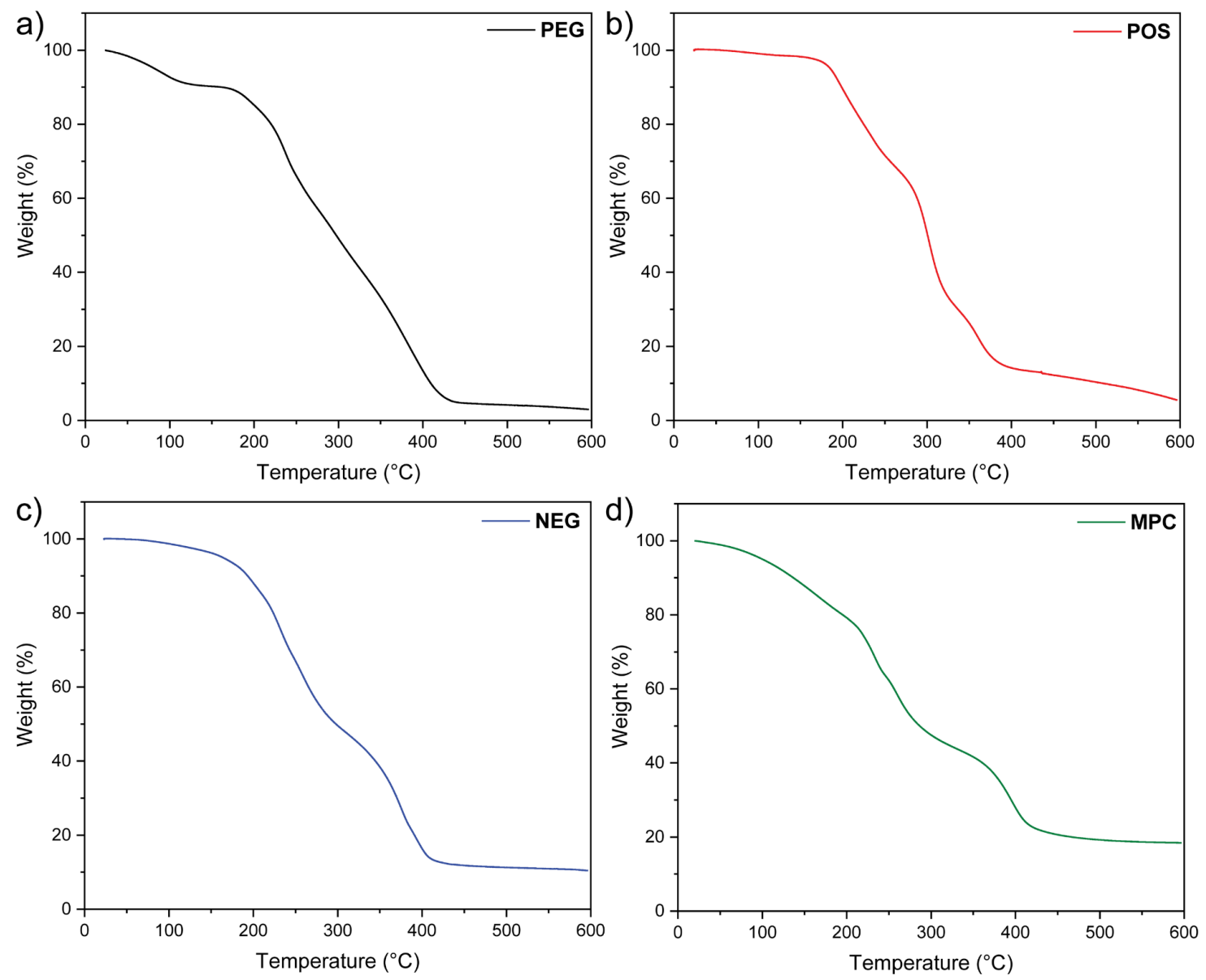

Figure SP21. TGA curves of (a) PEG, (b) POS, (c) NEG, and (d) MPC. 


\section{References}

1. Harvey, J.; Hardy, S. C.; Ashford, M. L. J., Dual actions of the metabolic inhibitor, sodium azide on KATP channel currents in the rat CRI-G1 insulinoma cell line. Br. J. Pharmacol. 1999, 126 (1), 51 60.

2. McComb, R. B.; Yushok, W. D., Metabolism of Ascites Tumor Cells. IV. Enzymatic Reactions Involved in Adenosinetriphosphate Degradation Induced by 2-Deoxyglucose 1964, 24 (2 Part 1), 198-205.

3. Koivusalo, M.; Welch, C.; Hayashi, H.; Scott, C. C.; Kim, M.; Alexander, T.; Touret, N.; Hahn, K. M.; Grinstein, S., Amiloride inhibits macropinocytosis by lowering submembranous $\mathrm{pH}$ and preventing Rac1 and Cdc42 signaling. J. Cell Biol. 2010, 188 (4), 547.

4. Jiang, Y.; Huo, S.; Mizuhara, T.; Das, R.; Lee, Y.-W.; Hou, S.; Moyano, D. F.; Duncan, B.; Liang, X.J.; Rotello, V. M., The Interplay of Size and Surface Functionality on the Cellular Uptake of Sub-10 nm Gold Nanoparticles. ACS Nano 2015, 9 (10), 9986-9993.

5. Kirchhausen, T.; Macia, E.; Pelish, H. E., Use of Dynasore, the Small Molecule Inhibitor of Dynamin, in the Regulation of Endocytosis. In Methods Enzymol., Academic Press: 2008; Vol. 438, pp 77-93.

6. McCluskey, A.; Daniel, J. A.; Hadzic, G.; Chau, N.; Clayton, E. L.; Mariana, A.; Whiting, A.; Gorgani, N. N.; Lloyd, J.; Quan, A.; Moshkanbaryans, L.; Krishnan, S.; Perera, S.; Chircop, M.; von Kleist, L.; McGeachie, A. B.; Howes, M. T.; Parton, R. G.; Campbell, M.; Sakoff, J. A.; Wang, X.; Sun, J.-Y.; Robertson, M. J.; Deane, F. M.; Nguyen, T. H.; Meunier, F. A.; Cousin, M. A.; Robinson, P. J., Building a Better Dynasore: The Dyngo Compounds Potently Inhibit Dynamin and Endocytosis. Traffic 2013, 14 (12), 1272-1289.

7. Patel, P. C.; Giljohann, D. A.; Daniel, W. L.; Zheng, D.; Prigodich, A. E.; Mirkin, C. A., Scavenger Receptors Mediate Cellular Uptake of Polyvalent Oligonucleotide-Functionalized Gold Nanoparticles. Bioconjugate Chem. 2010, 21 (12), 2250-2256. 
8. Saha, K.; Kim, S. T.; Yan, B.; Miranda, O. R.; Alfonso, F. S.; Shlosman, D.; Rotello, V. M., Surface Functionality of Nanoparticles Determines Cellular Uptake Mechanisms in Mammalian Cells. Small 2013, 9 (2), 300-305.

9. Brito, D. A.; Rieder, C. L., The ability to survive mitosis in the presence of microtubule poisons differs significantly between human nontransformed (RPE-1) and cancer (U2OS, HeLa) cells. Cell Motil. Cytoskeleton 2009, 66 (8), 437-447.

10. Rehman, Z. u.; Hoekstra, D.; Zuhorn, I. S., Protein kinase A inhibition modulates the intracellular routing of gene delivery vehicles in HeLa cells, leading to productive transfection. J. Controlled Release 2011, 156 (1), 76-84.

11. Harush-Frenkel, O.; Debotton, N.; Benita, S.; Altschuler, Y., Targeting of nanoparticles to the clathrinmediated endocytic pathway. Biochem. Biophys. Res. Commun. 2007, 353 (1), 26-32.

12. Harush-Frenkel, O.; Rozentur, E.; Benita, S.; Altschuler, Y., Surface Charge of Nanoparticles Determines Their Endocytic and Transcytotic Pathway in Polarized MDCK Cells. Biomacromolecules 2008, 9 (2), 435-443.

13. Xiao, K.; Li, Y.; Luo, J.; Lee, J. S.; Xiao, W.; Gonik, A. M.; Agarwal, R. G.; Lam, K. S., The effect of surface charge on in vivo biodistribution of PEG-oligocholic acid based micellar nanoparticles. Biomaterials 2011, 32 (13), 3435-3446.

14. Perumal, O. P.; Inapagolla, R.; Kannan, S.; Kannan, R. M., The effect of surface functionality on cellular trafficking of dendrimers. Biomaterials 2008, 29 (24), 3469-3476.

15. Dausend, J.; Musyanovych, A.; Dass, M.; Walther, P.; Schrezenmeier, H.; Landfester, K.; Mailänder, V., Uptake Mechanism of Oppositely Charged Fluorescent Nanoparticles in HeLa Cells. Macromol. Biosci. 2008, 8 (12), 1135-1143.

16. Jiang, X.; Dausend, J.; Hafner, M.; Musyanovych, A.; Röcker, C.; Landfester, K.; Mailänder, V.; Nienhaus, G. U., Specific Effects of Surface Amines on Polystyrene Nanoparticles in their Interactions with Mesenchymal Stem Cells. Biomacromolecules 2010, 11 (3), 748-753. 
17. Jiang, X.; Musyanovych, A.; Röcker, C.; Landfester, K.; Mailänder, V.; Nienhaus, G. U., Specific effects of surface carboxyl groups on anionic polystyrene particles in their interactions with mesenchymal stem cells. Nanoscale 2011, 3 (5), 2028-2035.

18. Schrade, A.; Mailänder, V.; Ritz, S.; Landfester, K.; Ziener, U., Surface Roughness and Charge Influence the Uptake of Nanoparticles: Fluorescently Labeled Pickering-Type Versus SurfactantStabilized Nanoparticles. Macromol. Biosci. 2012, 12 (11), 1459-1471.

19. Tian, H.; Guo, Z.; Lin, L.; Jiao, Z.; Chen, J.; Gao, S.; Zhu, X.; Chen, X., pH-responsive zwitterionic copolypeptides as charge conversional shielding system for gene carriers. J. Controlled Release 2014, 174, 117-125.

20. He, C.; Hu, Y.; Yin, L.; Tang, C.; Yin, C., Effects of particle size and surface charge on cellular uptake and biodistribution of polymeric nanoparticles. Biomaterials 2010, 31 (13), 3657-3666.

21. Zaki, N. M.; Nasti, A.; Tirelli, N., Nanocarriers for Cytoplasmic Delivery: Cellular Uptake and Intracellular Fate of Chitosan and Hyaluronic Acid-Coated Chitosan Nanoparticles in a Phagocytic Cell Model. Macromol. Biosci. 2011, 11 (12), 1747-1760.

22. Kang, J. H.; Jang, W. Y.; Ko, Y. T., The Effect of Surface Charges on the Cellular Uptake of Liposomes Investigated by Live Cell Imaging. Pharm. Res. 2017, 34 (4), 704-717.

23. Tu, Z.; Achazi, K.; Schulz, A.; Mülhaupt, R.; Thierbach, S.; Rühl, E.; Adeli, M.; Haag, R., Combination of Surface Charge and Size Controls the Cellular Uptake of Functionalized Graphene Sheets. Adv. Funct. Mater. 2017, 27 (33), 1701837.

24. Zhang, L. W.; Monteiro-Riviere, N. A., Mechanisms of Quantum Dot Nanoparticle Cellular Uptake. Toxicol. Sci. 2009, 110 (1), 138-155.

25. Jiang, X.; Röcker, C.; Hafner, M.; Brandholt, S.; Dörlich, R. M.; Nienhaus, G. U., Endo- and Exocytosis of Zwitterionic Quantum Dot Nanoparticles by Live HeLa Cells. ACS Nano 2010, 4 (11), 6787-6797. 
26. Tan, S. J.; Jana, N. R.; Gao, S.; Patra, P. K.; Ying, J. Y., Surface-Ligand-Dependent Cellular Interaction, Subcellular Localization, and Cytotoxicity of Polymer-Coated Quantum Dots. Chem. Mater. 2010, 22 (7), 2239-2247.

27. Ho, L. W. C.; Yung, W.-Y.; Sy, K. H. S.; Li, H. Y.; Choi, C. K. K.; Leung, K. C.-F.; Lee, T. W. Y.; Choi, C. H. J., Effect of Alkylation on the Cellular Uptake of Polyethylene Glycol-Coated Gold Nanoparticles. ACS Nano 2017, 11 (6), 6085-6101.

28. Zhang, D.; Wei, L.; Zhong, M.; Xiao, L.; Li, H.-W.; Wang, J., The morphology and surface chargedependent cellular uptake efficiency of upconversion nanostructures revealed by single-particle optical microscopy. Chem. Sci. 2018, 9 (23), 5260-5269.

29. Jin, J.; Gu, Y.-J.; Man, C. W.-Y.; Cheng, J.; Xu, Z.; Zhang, Y.; Wang, H.; Lee, V. H.-Y.; Cheng, S. H.; Wong, W.-T., Polymer-Coated NaYF4:Yb3+, Er3+ Upconversion Nanoparticles for ChargeDependent Cellular Imaging. ACS Nano 2011, 5 (10), 7838-7847.

30. Xie, J.; Pan, X.; Wang, M.; Ma, J.; Fei, Y.; Wang, P.-N.; Mi, L., The role of surface modification for TiO2 nanoparticles in cancer cells. Colloids Surf. B. Biointerfaces 2016, 143, 148-155.

31. Li, Z.; Qu, L.; Zhu, W.; Liu, J. a.; Chen, J.-Q.; Sun, P.; Wu, Y.; Liu, Z.; Zhang, K., Self-accelerating click reaction for preparing cyclic polymers from unconjugated vinyl monomers. Polymer 2018, 137, $54-62$.

32. Quémener, D.; Davis, T. P.; Barner-Kowollik, C.; Stenzel, M. H., RAFT and click chemistry: A versatile approach to well-defined block copolymers. Chem. Commun. 2006, 48, 5051-5053.

33. Ghosh, S.; Basu, S.; Thayumanavan, S., Simultaneous and Reversible Functionalization of Copolymers for Biological Applications. Macromolecules 2006, 39 (17), 5595-5597.

34. Ryu, J.-H.; Chacko, R. T.; Jiwpanich, S.; Bickerton, S.; Babu, R. P.; Thayumanavan, S., Self-CrossLinked Polymer Nanogels: A Versatile Nanoscopic Drug Delivery Platform. J. Am. Chem. Soc. 2010, $132(48), 17227-17235$. 
35. Grassart, A.; Cheng, A. T.; Hong, S. H.; Zhang, F.; Zenzer, N.; Feng, Y.; Briner, D. M.; Davis, G. D.; Malkov, D.; Drubin, D. G., Actin and dynamin2 dynamics and interplay during clathrin-mediated endocytosis. J. Cell Biol. 2014, 205 (5), 721-735.

36. Park, R. J.; Shen, H.; Liu, L.; Liu, X.; Ferguson, S. M.; De Camilli, P., Dynamin triple knockout cells reveal off target effects of commonly used dynamin inhibitors. J. Cell Sci. 2013, 126 (22), 5305-5312. 